Portland State University

PDXScholar

\title{
On Thin ICE? Domestic Violence Advocacy and Law Enforcement-Immigration Collaborations
}

\author{
Diana Rempe \\ Portland State University
}

Follow this and additional works at: https://pdxscholar.library.pdx.edu/open_access_etds

Part of the Counseling Commons, Domestic and Intimate Partner Violence Commons, Immigration Law Commons, and the Law Enforcement and Corrections Commons Let us know how access to this document benefits you.

\section{Recommended Citation}

Rempe, Diana, "On Thin ICE? Domestic Violence Advocacy and Law Enforcement-Immigration Collaborations" (2014). Dissertations and Theses. Paper 1638.

https://doi.org/10.15760/etd.1637

This Dissertation is brought to you for free and open access. It has been accepted for inclusion in Dissertations and Theses by an authorized administrator of PDXScholar. Please contact us if we can make this document more accessible: pdxscholar@pdx.edu. 
On Thin ICE? Domestic Violence Advocacy and

\title{
Law Enforcement-Immigration Collaborations
}

by

\section{Diana Rempe}

A dissertation submitted in partial fulfillment of the requirements for the degree of

\author{
Doctor of Philosophy \\ in \\ Applied Psychology
}

\author{
Dissertation Committee: \\ Janice Haaken, Chair \\ Yves Labissiere \\ Eric Mankowski \\ Rob Roeser
}

\section{Portland State University}




\begin{abstract}
The public focus on domestic violence has been one of the most successful campaigns of the modern women's movement. This success was achieved in part through the creation of strategic alliances among agencies and organizations responding to partner violence. One of the most contested of these alliances involved partnering with the criminal justice system. While representing an advance in holding police accountable in protecting all citizens (Coker, 2006), this alliance has had problematic consequences, particularly as it has extended state power into the lives of women of color (e.g. Richie, 2005). This problem is exacerbated by new collaborations between law enforcement and Immigration and Customs Enforcement (ICE). Federal mandates like the Secure Communities program bring together local law enforcement and ICE throughout the United States, to increase deportation rates (Immigration and Customs Enforcement, 2009). As a result, many recommendations by domestic violence advocates to survivors now potentially include the presence of ICE in that referral.

This dissertation explores how domestic violence advocates within the tri-county area of Portland, Oregon are responding to law enforcement-ICE partnerships. Advocates remain understudied in the domestic violence literature, in spite of the complexity of their roles. This dissertation fills this research gap in examining the processes advocates employ in responding to dilemmas faced by marginalized survivors. A total of twentyfive advocates from three separate agencies participated in the study, which centered on focus groups carried out in the agency settings.
\end{abstract}

The dissertation pursues three research questions: 1) How do advocates work 
through a key dilemma that has emerged in their practice? 2) What are the discursive strategies enlisted by advocates in addressing a dilemma at the border of domestic violence and immigration politics? 3) What is the relationship between each group's proximity to working with undocumented survivors and their decision-making process?

A case study methodology was used to evaluate proximity to work with undocumented survivors and the organizations' general orientation to domestic violence work. Transcripts of the focus groups were analyzed using a discursive method centered on identifying how the groups worked through a set of dilemmas presented in the focus groups, which involved a crisis call scenario involving an undocumented woman and an agency practice common to many domestic violence service providers.

In the analysis of discursive strategies of the groups, a key finding centered on the groups' use of a decision-tree heuristic to work through dilemmas of practice presented in the two scenarios. This discursive strategy facilitated the process of group decisionmaking at points where the actions required were clear and concrete. However, as more complexity, ambiguity or ambivalence were introduced, the limitations of the decisiontree strategy become more apparent.

Findings related to the agency's proximity to undocumented workers suggest that this affinity was less important than was the agency's working relationship to the Criminal Justice System (CJS). Closeness to the CJS was associated with reliance on a discourse that places the police at the center of services for all survivors of domestic violence, regardless of documentation status, and a heightened focus on the risk of lethality to rationalize the risks associated with referrals involving law enforcement-ICE 
collaborations. 


\section{Acknowledgements}

Throughout the last seven years I have received support and encouragement from a great number of people. My advisor, Dr. Jan Haaken, has been a mentor and friend. Her guidance has made this a thoughtful and rewarding experience. I thank my dissertation committee, Yves Labissiere, Eric Mankowski, and Rob Roeser for their work with me over the past two years as I moved from an idea to a completed study. Additionally, my gratitude goes out to the participants of this study who took time out of their already overloaded schedules to offer thoughtful insights to my questions.

This process would not have been possible without my graduate colleagues. Jimena Alvarado, Jennifer Wallin-Ruschman, Kealani Balfour and Karen Morgaine deserve particular thanks. You each gave me intellectual guidance, unwavering support, hours of listening and lots of laughter. I appreciate you all so much.

My amazing friends have been so patient and supportive. Marj Hogan, Kate Sokoloff, Nancy Hamilton, Beth Hoar, Matt Mavko, Kim Whitney, Amy Schuff, Diana Bianco, Anthony Effinger, Natalie Ramsland, Jude Gerace, May Wallace, and Laurie King are just a few of the many people who lifted me up throughout. I am so grateful for the listening, suggesting and commiserating you have given me.

Most importantly, I thank my family. Isabelle, Elijah, and Violet, you have grown up during this journey and I am indebted to you all for everything you have given me. You've been loving and forgiving when I wasn't as present a mother as you deserved. I have always learned the most from the three of you.

And finally, my partner, Pat. Throughout everything you remain the most solid, 
dependable, generous, kind, loving, hilarious, brilliant, quirky person I have ever known. Without you, this simply wouldn't have been manageable. I love you. Thanks so much. 
Table of Contents

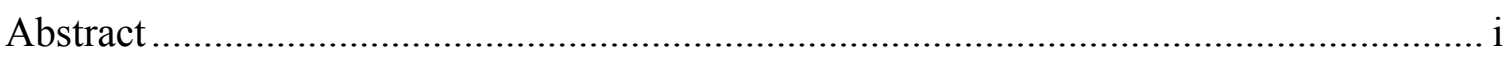

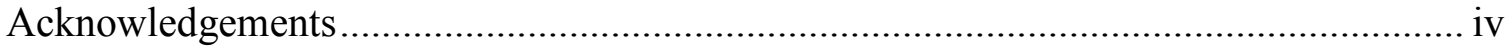

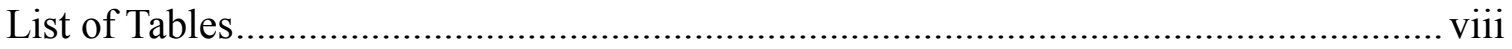

List of Figures .................................................................................................. ix

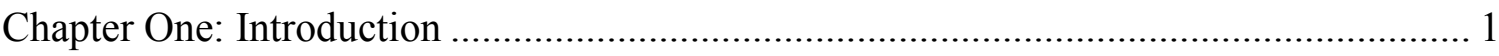

Border Tensions and Advocacy............................................................................ 1

Background to the Study.................................................................................. 4

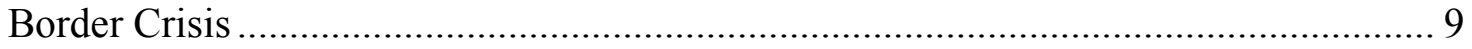

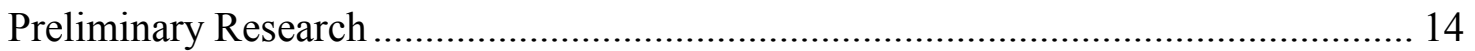

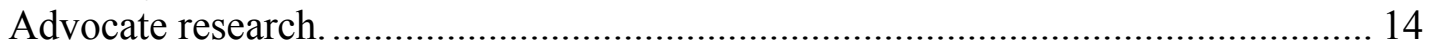

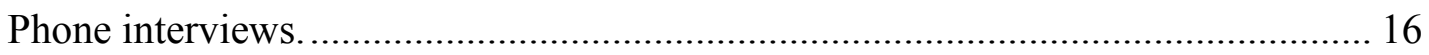

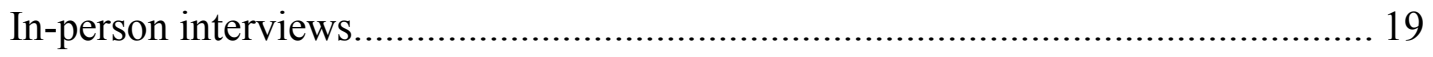

Chapter Two: Literature Review............................................................................... 22

Domestic Violence, the Criminal Justice System and Immigration.............................. 22

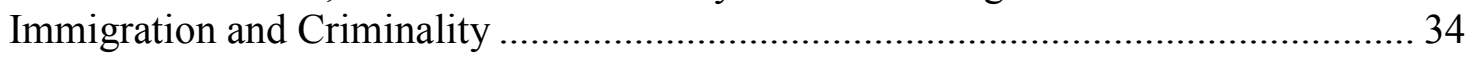

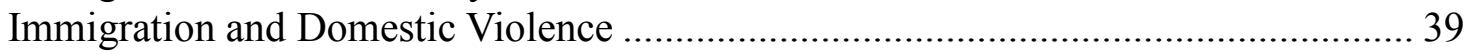

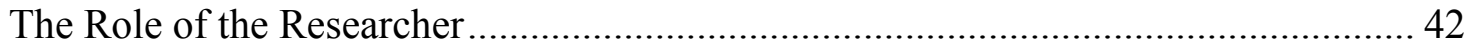

Action Research and the Lewinian Tradition............................................................ 45

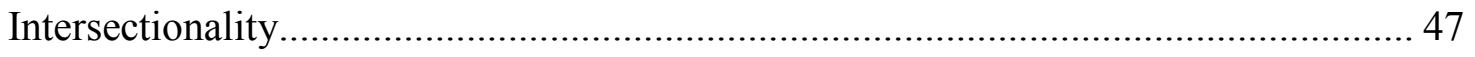

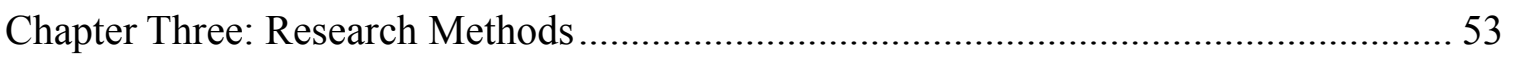

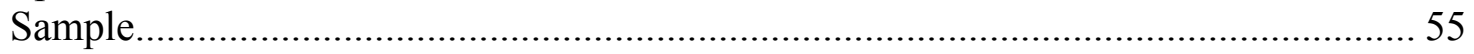

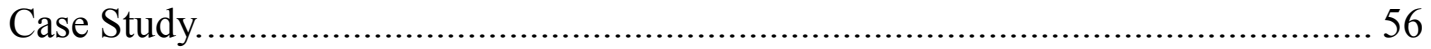

Focus group rationale

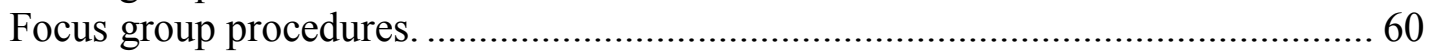

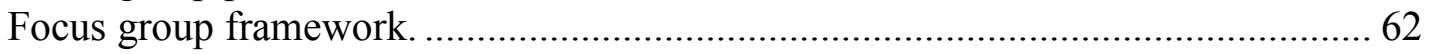

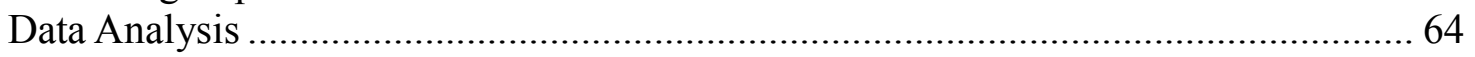

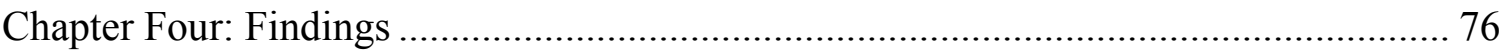

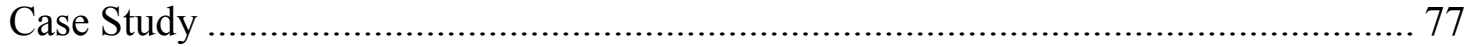

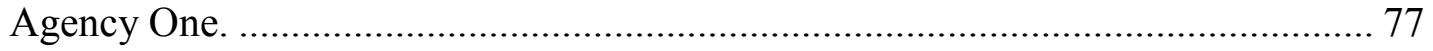

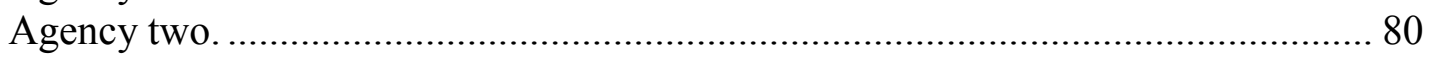

Agency three ................................................................................................ 83

Summary of the Agencies' orientations to DV work............................................ 85

Proximity to Work with Undocumented Survivors.................................................... 89

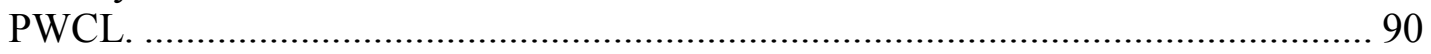

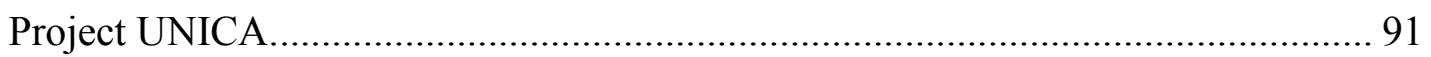

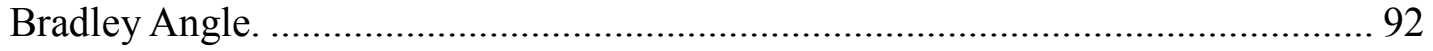

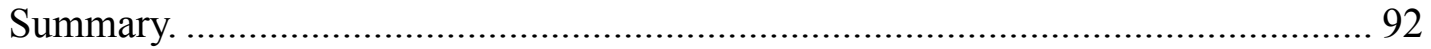

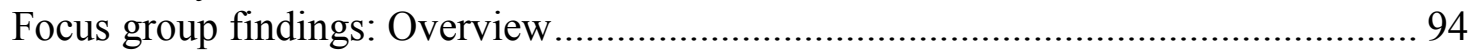

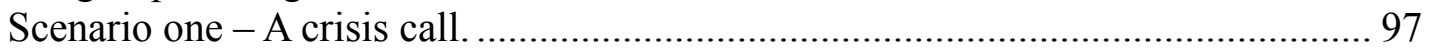

Scenario Two - Recommending 911. ...............................................................112 


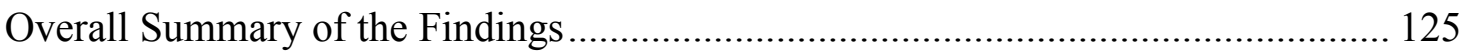

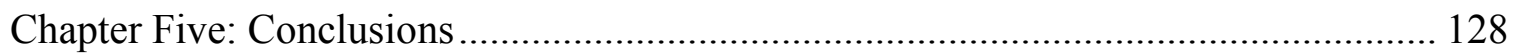

Limitations to the Study and Possibilities for Future Research ................................. 141

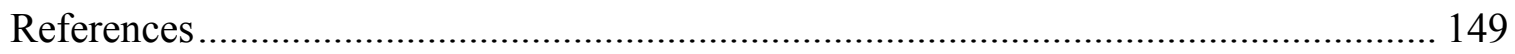

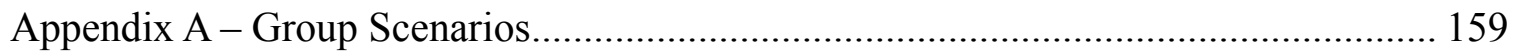

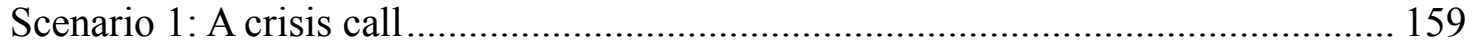

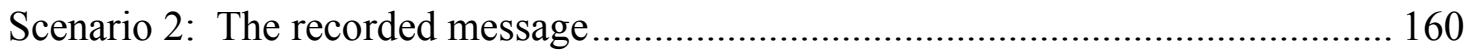

Appendix B - Focus Group Letter for Consent ............................................................ 161

Appendix C - Focus Group Script....................................................................... 162

Introduction and information about Secure Communities $(20 \mathrm{~m})$............................. 162

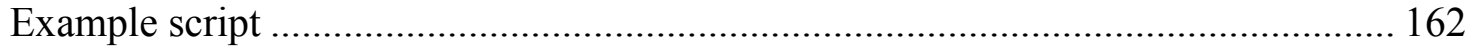

Focus group discussion begins: (50m)........................................................... 164

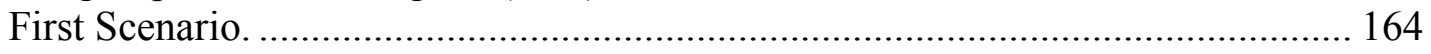

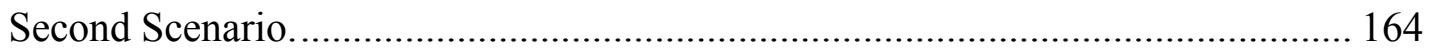

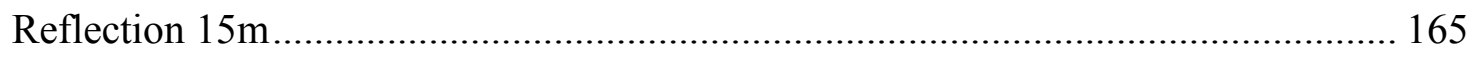

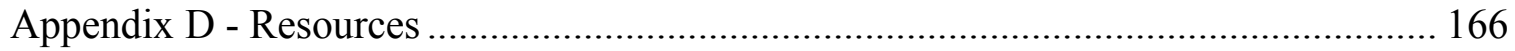

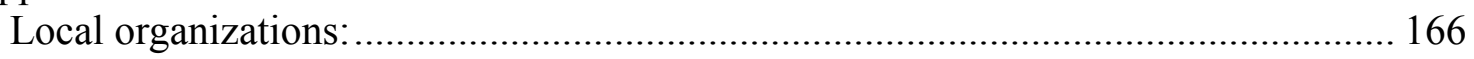

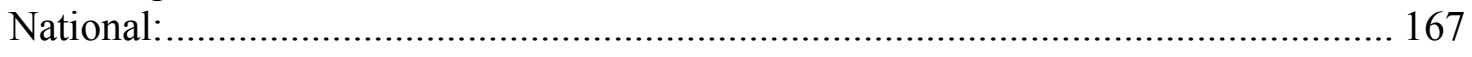

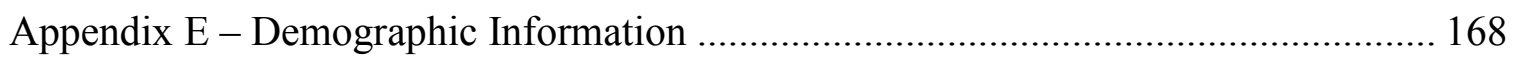

Appendix F - Transcript of a focus group ............................................................ 163 


\section{List of Tables}

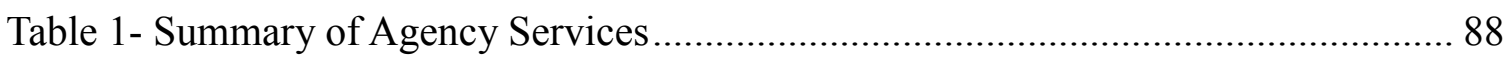

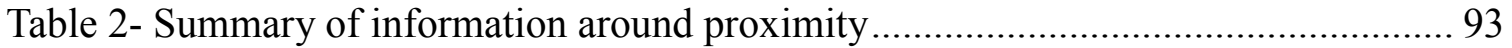




\section{List of Figures}

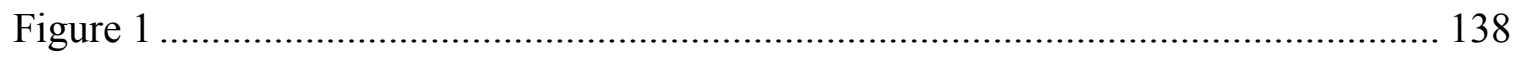




\section{Chapter One: Introduction}

"Boundary: In political geography, an imaginary line between two nations, separating the imaginary rights of one from the imaginary rights of the other" (Bierce 1911).

A border begins with a boundary - a line drawn to indicate difference. This

demarcation is always imaginary, even when it takes on the illusion of permanence, like a border fence carefully constructed of concrete, wire, and weapon. The imaginary is not without real consequences, however, and negotiating the border can be perilous, whether it is a border between countries, groups, or individuals.

Intimate partner violence is all about border crossings. Intimacy creates its own border, marking the space between two people and others in their surroundings. These boundaries can be ruptured by violence and their crossing made unavoidable in the search for safety and peace. Survivors become a kind of refugee - persons who leave the country of their home, seeking the promise of a better life. In doing so, they must reach out and seek assistance, as they maneuver the terrain of this new land. It is often the domestic violence advocate who guides women through this unknown territory. Offering aid to those leaving a violent situation requires border negotiations as well, as diverse service providers are brought together to work collaboratively. The advocate must act as translator, interpreting both the language and culture of different organizations and individual women, as she makes recommendations.

\section{Border Tensions and Advocacy}

When groups with cultural differences or conflicting philosophies negotiate a common space, the site of dissonance that arises has been called a place of border 
tensions (Haaken \& Yragui, 2003). This border tension can be a site of conflict, and it can also offer a space for resistance. It is often the domestic violence advocate who is charged with navigating these places, managing the relationships between their own agency and the partnering groups. Not unlike other areas of politics, advocates working in the domestic violence field confront multiple border tensions as they work at the crosscurrents of agency mandates and movement commitments (Haaken \& Yragui, 2003; Haaken, 2010). As multidisciplinary teams in the DV field continue to grow, advocates experience most acutely the stresses in navigating relationships between their agencies, the partnering groups, and one another.

This dissertation studies decision-making at the border, using an issue especially critical to the current DV movement. New collaborations between law enforcement and Immigration and Customs Enforcement (ICE) target immigrant people, who unwittingly engage ICE when they encounter law enforcement, either deliberately or unintentionally. Any recommendation an advocate might make that involves the use of the criminal justice system must include the potential for the presence of ICE in that referral.

This dissertation centers around three research questions:

1. How do advocates work through a key dilemma that has emerged in their practice?

2. What are the discursive strategies enlisted by advocates in addressing a dilemma at the border of domestic violence and immigration politics?

3. What is the relationship between each group's proximity to working with undocumented survivors and their decision-making process? 
The first question asks how advocates within the battered women's movement are responding to law enforcement-ICE partnerships within the tri-county area of Portland, Oregon. The second examines the discursive strategies advocates use during crisis calls and safety planning with women, when such decisions must be made quickly and decisively. The third question examines the relationship between how closely advocates work with undocumented survivors and the decisions the advocates make.

Undocumented women and their children are potentially being placed at more risk by the domestic violence movement's continuing reliance on the criminal justice system. This endangerment may well exceed that which women face from their intimate partners. At the same time, although advocates carry a complex understanding of the risks of enlisting the police and courts in advising women, there is great pressure, born out of history, habit, and individual fear of causing harm, to keep this practice in place.

Preliminary research indicated that Latina-focused organizations had more information about the effect of law enforcement collaborations with ICE as well as more experience working with survivors experiencing the adverse effects of these partnerships. Because of this affinity, it was my assumption that advocates working more closely to undocumented survivors would offer more complex responses. I also assumed that the advocates' use of an intersectional perspective - one that considered multiple social factors such as racism, sexism, classism, and immigration status - would emerge as an indicator of the group's use of a more complex way of thinking about the dilemma posed by law-enforcement collaborations with ICE.

For this project, focus groups were held during regular staff meetings with crisis 
advocates from three domestic violence service organizations, chosen for the work they do around domestic violence and with undocumented survivors. I introduced a dilemma of practice - a conflict point where responses cannot be effectively managed through established protocol. I asked advocates to address some of the dilemmas of working with undocumented women, which are exacerbated by new collaborations between law enforcement and ICE. I enlisted the group in working through the dynamics of the problem, offering two scenarios: one that mimicked a crisis call and one describing a common agency practice.

Because the research questions focus on how advocates respond to law enforcement/ICE collaborations in their discursive strategies, the data is analyzed using a discourse analysis approach. This methodology focuses on the ways that advocates use language in response to the scenarios and how the group attends to issues particular to undocumented survivors. The groups share a domestic violence discourse that centralizes the role of the criminal justice system in responding to survivors. The use of the discourse varies, depending on the agency's partnership with the criminal justice system. My assumption was that proximity to work with undocumented survivors would be related to more complex responses to law enforcement/ICE collaborations. Instead, findings of the study suggest that proximity to the criminal justice system is a more important relationship.

\section{Background to the Study}

I bring to this project a history of advocacy on the borders. Advocates are those who provide direct service to survivors experiencing violence from their intimate partner, 
implementing any policies created by their respective agencies. For ten years I worked as an advocate, first answering the crisis line in a shelter and finally as part of a coordinated community response team, riding along with sheriff's deputies as they responded to domestic violence calls. I also worked at a university center for survivors of sexual assault and relationship violence and facilitated trainings for police officers, attorneys and teachers. Throughout this work experience I became increasingly aware of the complexities underlying the prototypical simple story that circulates in the DV field stories that cast victims and perpetrators as one-dimensionally either good or bad. And I struggled to negotiate the irreducibly variable realities I encountered, and my own resistances to fitting each person and situation into a unified and uncomplicated narrative. Subsequently, it was difficult to offering formulaic advice to survivors, even in carrying out the basic work of information and recommendations.

Crisis calls are made up of a series of questions and answers. Advocates try to provide support for women as they make complex decisions based in part on the advocate's suggestions. These suggestions often come in the form of referrals for housing, food and other material concerns, but also include recommendations for how to stay safe from an abusive partner (Bennett et al., 2004). Guided by statistics indicating that domestic violence is the leading cause of injury for women (Goldsmith, 2006), providing safety has been at the heart of domestic violence advocacy. This principle has led to sweeping policy decisions around partnering with the criminal justice system (Schechter, 1982; Pence, 2000). However, as I describe in more detail within this document, the effect of these partnerships has been different for survivors, depending 
upon their social location. Women of color, in particular, have exhaustively critiqued the reliance among DV advocates on the criminal justice system (Incite, 2005; Richie, 2005; Smith, 2002).

This decision to advise women experiencing violence from their intimate partner to enlist law enforcement by calling 911 has even more onerous implications now that law enforcement has entered into alliances with the Department of Homeland Security's Immigration and Customs Enforcement (ICE). Since 2008, and across much of the United States, when a call reporting domestic violence is made to law enforcement and an arrest is made, the caller enlists ICE as well. Federal mandates, such as the Secure Communities program, bring ICE into local jails. When a person is booked for a crime, his or her fingerprints are entered into the immigration database, potentially generating a hold, regardless of whether or not the persons are charged with a crime.

I became aware of the partnerships between law enforcement and ICE through the work I have done with Jobs with Justice (JwJ), a coalition of labor and community organizations working for economic justice and worker rights. JWJ is closely aligned with immigrant rights groups and is part of the Safe Communities coalition (now the ACT for Justice and Dignity Network), formed to address these partnerships. I began attending the Safe Communities meetings in May 2010, just after the announcement that a local sheriff's office had entered into an agreement with ICE, implementing the Secure Communities program. Beginning immediately, anyone booked into the jail has his or her fingerprints sent to the ICE database. I was concerned about the effect this partnership would have on women reporting domestic violence and was surprised by the 
silence around the issue. There was never any mention of domestic violence in the accounts of those affected by Secure Communities. Immigrants were spoken of in general, with a particular focus on low-wage workers. Not surprisingly, then, there was no one from DV services present at the Safe Communities meetings. I do not believe that this was a deliberate omission, but one likely to have been borne out of the traditional divide between DV work and more male-dominated struggles such as the labor and immigrant rights movements.

I am interested in the ways new alliances among DV providers and other groups not traditionally part of DV services may be created in this climate of law enforcement/ICE partnerships. Although domestic violence service providers have collaborated with other groups throughout the history of the movement, they have traditionally remained separate from other social justice organizations, particularly those comprised primarily of men. This may be because alliance with these organizations might indicate complicity with those who might be abusers, themselves. In the early years, as activists described the ubiquity of intimate partner violence against women, they foreclosed the possibility for alliance with men, who all carry this potential for abusing. Outside the U.S., this division has diminished over time but in the U.S., particularly in DV service provision, the segregation still persists.

Ironically, however, one of the strongest collaborations created between the DV movement and an outside group has been with the criminal justice system, a highly male dominated world, particularly within law enforcement and corrections. This relationship remains indirect, however, through constructing the advocate as the intermediary that acts 
as the liaison between the criminal justice system and the DV movement. The partnership can remain removed from the day-to-day working of the movement that takes place primarily in shelters, which continue to be the private domain of the battered women's movement. The advocate becomes the gatekeeper - deciding when and how to engage or recommend enlisting law enforcement, as a system, despite recognition of the potential for individual law enforcement agents to be abusers (Stinson \& Liederbach, 2013).

Common to any proposed intervention, be it the on-going use of the criminal justice system or alternative practices, is the presence of the DV advocate. Generally women, and often survivors of violence, advocates work in shelters, community settings and within the criminal justice system. Regardless of their location, their roles are necessarily complex, as they intervene within the system on behalf of the women with whom they work (Haaken, 2010). Advocates are often thrust into multiple roles simultaneously, particularly as domestic violence work has continued to become the site of numerous partnerships.

There is little research literature on the role of the advocate, despite their central role in the DV field. There is a small body of literature focused on advocates as gatekeepers (Kendrick, 1998; Loseke, 1992), storytellers (Haaken, 2010; Rothenburg, 2002), and as more professionalized staff (Wies, 2008). In the psychology literature, some work has focused on the positive effect of working with advocates (Allen, Bybee \& Sullivan, 2004; Bybee \& Sullivan, 2005) but the emphasis is largely on accessing services. Advocates, for the most part, remain understudied, mentioned primarily in an 
undifferentiated way, which belies their complexity. This dissertation fills this research gap in examining the processes advocates employ in responding to dilemmas faced by marginalized survivors.

\section{Border Crisis}

Because the stakes are even higher when an advocate recommends that survivors call law enforcement in situations of partner abuse, it is important to understand how advocates are reconciling the need for immediate assistance with the risks in bringing in the criminal justice system. Much like the questions framing my earlier work on safety and shelters (Rempe, 2001), the idea that practices are immutable because of their perceived connection to safety frames the questions of this project. The ubiquitous use of 911 is one of these highly protected and unexamined practices.

It is common to be given the advice to call 911 when reaching the initial recorded answer at most human service providers, from therapists to primary care physicians to dentists. This advisory also holds true for domestic violence service providers. I called multiple service providers in my local area and, with very few exceptions, first reached a recording that almost immediately instructed, "If this is an emergency, hang up and dial 911". Though less common, this was also the advice given on several of the agency websites, particularly on their safety planning pages. Despite this practice, the policy of indiscriminately recommending 911 does not appear to be the procedure during an inperson crisis call. As I describe in more detail at the end of this section, I spoke with shelter directors and staff at several local organizations about their crisis line protocols. Each described a more nuanced practice for determining the advice to be given, though 
most were unable to cite specific procedures. It is apparent that the advocate answering each call must make the decision where to direct individual callers, via agency practices learned in staff and volunteer trainings. However, the automatic recommendation to call 911 persists. It remains up to the advocate on the crisis line to reconcile the potential contradiction presented by the recorded information and crisis line practice.

Responding to a crisis call defies simple formulation. The moment of crisis brings together multiple, potentially contradictory commitments: the advocate must juggle the needs of the individual woman, the agency for whom she works, other allied agencies, and her own beliefs and ethics. And the stakes can be extraordinarily high, particularly for undocumented women. If an undocumented woman in crisis describes herself as in immediate danger, for example, the advocate must decide between recommending the woman call 911 and risk deportation for herself and her family or advising her to manage the potential crisis herself, with its concurrent dangers. The advocate must potentially go against current practice and agency prescriptions in deciding how to act. And, she must live with the outcome of her decision-making process. The woman could die or be deported, the advocate could lose her job or get in trouble, or she simply might never know what happened to the woman, leaving her to wonder if her advice had the desired effect.

Pennell and Kim (2010) describe how advocates must assess each situation and measure the cost and the benefit to the individual survivor, depending upon her particular context and situation. Advocates must continually negotiate this complexity. The authors offer an example of an advocate's decision not to make a mandatory child abuse call 
because she recognized the potential harm this would do to all the members of the family. Yet the authors fail to explain how an advocate arrives at such a decision, or what effect this daily negotiation might have on the advocate.

This dissertation examines this site of negotiation via unpacking the decisionmaking process during crisis calls and safety planning when the decision to involve the criminal justice system becomes complicated by collaborations between law enforcement and ICE. This critical lens does not rule out the potential for alliances with law enforcement. Certainly, as Buzawa \& Buzawa (2003) note, reliance upon the criminal justice system (CJS) is an important response to domestic violence and continues to shape intervention strategies. Additionally, the collaboration with the CJS has been very effective in addressing intimate partner violence, particularly against middle class white women. However, throughout the history of the movement tension has been created around whether to continue to maintain practices that positively affect only one part of the population, while potentially causing more damage to those holding a more complex set of needs. Partnering with the criminal justice system remains one of the greatest sites of dispute (Incite!, 2005; Pence \& Paymar, 1993). This project enlists advocates to reflect on this controversy. By examining advocates' decision-making processes, the dissertation illuminates a dilemma at the borders of domestic violence advocacy and the criminal justice system.

The dissertation is grounded in the foundational works of the innovative, early social psychologist, Kurt Lewin, both epistemologically and methodologically. Lewin's insights around group dynamics and processes of change offer a means of excavating the 
social-psychological barriers or forces that may compel advocates as they negotiate crises with women experiencing violence from an intimate partner (Lewin, 1997). In analyzing interactions and generating a picture of how places of crisis or conflict are managed, it is possible to understand how decisions are made and how advocates may act in ways that may go against their best interests and/or the interests of those they represent.

These interactions take place against the backdrop of the political strategies negotiated throughout the history of the DV movement in relation to the criminal justice system. The grassroots domestic violence movement was shaped by a feminist orientation that reframed violence in the home as a structural rather than an individual issue, looking to societal relationships of power in locating primary causes of the problem (Dobash \& Dobash, 1992; Haaken, 2010; Schechter, 1982). A similar feminist epistemology grounds this dissertation, which has at its core a recognition that knowledge is necessarily shaped by culture, class, disability, ethnicity, race and gender, which are themselves affected by interactions of power (Collins, 1991; Crenshaw, 1991, Harding, 2004). Therefore, I will begin by briefly describing my position as researcher.

I am a middle-aged, upper middle class, white woman who worked as a DV advocate from 1995 until my return to graduate school in 2005. These demarcations of privilege give me an insider/outsider perspective that affects the research at all stages of the process. My relationship with the participants in the study is affected by our differing places of power but there remains an opportunity for connection along our shared emancipatory political values. Assiter (2000) describes what she calls "epistemic communities," places of commonality or unification, created out of shared political 
affiliations, bound together by context rather than a similar social identity. This recognizes the commonality present through engaging in domestic violence work, without smoothing out the differences inherent to the multiple ways in which we are situated.

This attentiveness to context arises in Lewin's (1997) description of the life space of the individual and the group. Behaviors are produced by their immediate context, continually emerging out of interaction between individual and the environment. This individual level description is extended to groups, which are also subject to the aggregate effect of multiple, continuous forces. Although Lewin does not overtly describe the effect of disparate power relations articulated by feminist theorists, his articulation of a dynamic process continually shaped by the interplay of person and environment leaves room for such an understanding.

Throughout this study, advocates describe their practice and consider the possibilities for negotiating the demands of multiple agencies in a way that is both creative and practical. They perform a delicate balancing act, managing their own needs with those of the client and the larger agencies. This research attends to the theoretical implications and the ideological aspirations along with the practical realities of undervalued social service work, particularly in this time of massive cuts to support of social programs. This work arose in response to a practical question that came from my fieldwork as an advocate and the preliminary research I conducted as I planned this dissertation. Because this project is focused on both the theoretical and the practical, Lewin's oft repeated quote 'There is nothing so practical as a good theory' (quoted in 
Marrow, 1977) provides the foundation for this inquiry.

In the following section I describe the preliminary research for this dissertation. In addition to my years of advocacy work, I consider the results of a focus group I had conducted with Dr. Haaken in 2005, in which advocates described their complicated role in negotiating the multiple partnerships between their agencies and other systems providers. I also assess the veracity of assumptions I held entering into this project. Because it has been several years since I have done crisis work, I felt I needed to determine if crisis calls and safety planning were still conducted in a manner similar to my experience as a DV advocate. In addition I was interested in determining if law enforcement/ICE collaborations presented an issue to advocates providing domestic violence services. I followed the phone interviews with in-person interviews speaking with women from two organizations that provide DV services in a rural county where the Secure Communities program had been entered into voluntarily.

\section{Preliminary Research}

Advocate research. In 2005 I conducted a focus group with Dr. Jan Haaken as part of her field research around domestic violence and storytelling, held in Portland, New York City, Germany, England, and the Pine Ridge reservation in South Dakota (Haaken, 2010). The focus group brought together advocates across a range of positions within the greater Portland metropolitan area. I was working as an advocate at the time and suggested possible participants based on the work I knew they were doing within the community. The rest of the group was gathered via a snowball technique, in which participants recommended others who might be interested in the subject. The group 
included advocates from child protective services, several domestic violence agencies that offered shelter, outreach and culturally specific programs, the county's domestic violence coordinator's office and an elder abuse agency. The focus group was facilitated by Dr. Haaken and held at Portland State University in the Psychology department. Rather than casting advocates as merely witnesses or translators of the experience of survivors, we began with the assumption that advocates face a range of dilemmas in how to frame the experiences of survivors.

Advocates in the focus group brought the conversation back to a recurrent and familiar theme - discussion of the complexity of their own role as advocates, who were cast into what they described as either "good" or "bad" advocates, a dichotomous division based on their willingness to fulfill agency expectations around their role, particularly with respect to their work with individual women. They described the same binary distinction in their work with women. Advocates described the pressure to fit each woman into the category of either "good" or "bad" victim. This simple categorization then delimited the services available to her: good/deserving women could access multiple services within the DV field, while bad/undeserving women were given the phone numbers of homeless shelters. In a shelter I worked at in Arizona, this practice was codified through the use of index cards - the caller's name was written down and on the back was inscribed "homeless". If she called again, or someone from another shelter called to check her name (a common practice for determining if a woman was eligible for shelter services) we would check the file cards. If she had previously been given that moniker, she was denied. Those deemed eligible for services still found their choices 
shaped by the partnerships of the movement that were, in turn, prescribed by other factors. Women with children were given priority and, in many cases, able to access services not available to single women. Undocumented women faced even more restricted options.

Advocates described this delineation of "deserving" and "underserving" victims as playing out even more markedly within the criminal justice system. They expressed ambivalence about working with the system, explaining the way in which they were expected to push women to file restraining orders and follow through with prosecution, even if this did not conform to the wishes of the women with whom they worked. They described frustration with the lack of choices available to women and the expectation that they would offer the same range of services to each, regardless of circumstance.

This preliminary research provided insight into the ways in which advocates felt bound by larger agency and movement commitments, which in turn shape their responses to survivors. In this dissertation, research questions one and two build on this, through assessing how advocates manage the demands placed on them by their agencies and partnering groups and the limitations created by law enforcement collaborations with ICE.

Phone interviews. From July 2010 through March 2011, I conducted phone interviews with crisis line advocates at eight, non-culturally-specific domestic violence shelters in the Portland metropolitan area. I chose to speak specifically with agencies on the mainstream because my previous work experience had been entirely within such agencies and I was interested in determining if the assumptions I had about shelter 
policies around answering crisis calls were still accurate.

I called each shelter and explained that I was a former advocate who was now in graduate school in psychology, conducting research around crisis line policies regarding law enforcement. I explained that it had been several years since I had done direct service and I was interested in ascertaining whether practices were still similar to those in place when I was doing the work. I added that this was research for my dissertation project, which I planned to carry out the following year. Each call lasted approximately ten minutes.

My experience as a crisis advocate was that each crisis call began with the advocate asking, "Is this a safe time to talk?" The caller's subsequent response shaped the direction of the call. If affirmative, the advocate went on to get some context for the call, made referrals and generally engaged in safety planning prior to hanging up. If negative, however, the tenor of the call changed dramatically and the advocate began intensive safety planning, determining if children were present and working out strategies for immediate responses, primarily around enlisting allies, which invariably included calling 911 or asking a neighbor to call 911, should the danger become emergent.

I began by asking if it was still the practice to begin a call by asking if the person was safe to talk. In each shelter setting this was the case. I followed this by inquiring about the response should the person answer in the negative, indicating s/he was in danger. The answers to this were also quite similar. Advocates described each call as unique, saying that they try and work with the individual explaining options, asking what has worked in the past, and determining the level of danger through questions about 
weapons and past violence. Each said there was no specific protocol for crisis calls, and described the training each advocate completed prior to answering the crisis line. I then asked if they would recommend a caller phone 911, if they were in immediate danger. Advocates answered equivocally. One said, “I don’t recommend she call 911, but I don’t not recommend calling the cops." Another said, "I would not necessarily recommend a woman call 911. Definitely the police are someone we view as allies.”

At the same time that advocates expressed their own ambivalence around enlisting law enforcement, they registered sensitivity to the different needs of survivors, depending upon the survivor's social location. Each described groups who might be reluctant to call police, citing prostitutes, lesbians or trafficked women and describing the groups' disparate experience with the criminal justice system. However, none referenced immigrant or undocumented survivors or referred to issues around documentation or deportation.

At the end of each interview I asked if it was common practice to inquire about a caller's documentation status. Each advocate said it was not, and one described that the caller might "feel fearful about revealing her immigration status." However three indicated documentation status figured into their choice of referrals, implying that they gathered that information in some way. Five advocates said that they generally referred all Spanish-speaking callers to the Spanish language crisis line.

In addition to confirming my assumption that responding to crisis calls remained similar to my experience as an advocate, the results of these phone interviews helped me generate the first two research questions: how could advocates reconcile their awareness 
that their agency policies potentially conflicted with the needs of the most marginalized survivors? Would employing an intersectional perspective help them work through this conundrum?

In-person interviews. I followed this series of phone interviews by assessing whether law enforcement/ICE collaborations were regarded as a problem by representatives of the DV movement. Staying close to the Lewinian insight that conflict opened a space for change (Lewin, 1997), I looked to a rural county where the sheriff of the local law enforcement division had just announced a voluntary Secure Communities partnership. I spent two hours, separately, with the shelter program director of an organization located on the mainstream of the DV movement and the director of a Latinaspecific DV program, in this county. I found that the awareness of the collaboration between law enforcement and ICE, and the analysis of it as a problem varied dramatically.

The non-culturally specific agency runs a crisis line, emergency shelter, transitional housing program and community advocacy, including legal and rural programs and support groups. This agency has a strong history of collaboration with police, including a former position on a CCR team. Their mission statement articulates an ideology based on women's self-empowerment and the reduction of domestic violence via service provision. The shelter director described serving a large Latina population both within the shelter and in the community. Despite this, she had never heard of the partnership and looked to me for information. She also reported talking with the Latinaspecific advocate at their shelter, who did not appear to be familiar with the partnership 
either. In addition, this advocate was described as working closely with ICE in the past on cases involving the Violence Against Women Act's (VAWA) provision for immigrant women, and reported these experiences as very positive.

The Latina-specific program also offers a crisis line, temporary emergency shelter, and community support groups. However the response from the director of the Latinaspecific shelter was very different. She was intimately familiar with law enforcement/ICE collaborations and the distinct programs within this partnership. She described the Latina community as "under siege" and gave numerous examples of deportations, detentions, and the fear that had arisen within the community as a result of these occurrences. Women were unwilling to call the police for any reason and many had begun keeping their children out of school for fear of being picked up by the police while they were in school. She described them as unwilling to access social services or use any of the public safety net for which they were eligible - eschewing public health offerings like dental work, immunizations and health clinics for themselves or their children, out of fear of deportation. In addition, she described the way she felt abandoned by the other, mainstream service providers in the county. Because of this practice, she had turned for assistance to non-DV providers, forging alliances with immigrant rights organizations and labor groups instead, working with them to change state policy around the collaborations. The two agency directors expressed radically different understandings of the complicated problems undocumented survivors faced because of law enforcement collaborations with ICE. This led to my articulation of the third research question, and the question of how closeness to work with this population might shape practice. 
The results of this preliminary research shaped the research questions that guide this dissertation. The division around awareness and response to law enforcement/ICE collaborations, together with the ambivalence advocates expressed around implementing policies generally when situations called for more nuanced decision-making, led to the following:

1. How do advocates work through a key dilemma that has emerged in their practice?

2. What are the discursive strategies enlisted by advocates in addressing a dilemma at the border of domestic violence and immigration politics?

3. What is the relationship between each group's proximity to working with undocumented survivors and their decision-making process?

The following section describes the relevant literature that provides a background to this dissertation. I begin with literature establishing context, followed by the project's broad conceptual orientation. Each of these sections is connected to the three research questions. 


\section{Chapter Two: Literature Review}

This chapter situates the research both contextually and conceptually. I begin with the context, describing the history of the DV movement's collaboration with the criminal justice system, including the ongoing critiques of such decisions. I then lay out a brief history of immigration and its connection to criminalization, returning to the way in which the DV movement has taken up the issue. I move on to the dissertation's theoretical orientation, beginning with the early articulation of Action Research as a methodology and moving into current descriptions of qualitative research practices. I then describe the way in which intersectionality provides a theoretical framework for the project and explain my conception of border tensions as a means of furthering this conceptual structure.

\section{Domestic Violence, the Criminal Justice System and Immigration}

The public focus on domestic violence has been one of the most successful campaigns of the modern women's movement (Haaken, 2010). In the late 1960s and

early 1970s, feminists challenged the notion that all actions within the home were private, bringing intimate partner abuse into the public sphere and reframing the problem as a public health issue (Dobash \& Dobash, 1979; Schecter, 1982). In doing so, feminists created the possibility for radical social change in multiple social domains.

This change was possible in part through the creation of strategic alliances and partnerships among agencies and organizations that respond to partner violence. One of the most effective and simultaneously most contested, was the decision among women's 
advocates to partner with the criminal justice system. While important for the way it held police accountable as the state agency mandated to protect all citizens (Coker, 2001), this alliance has had multiple problematic consequences as a result of the increased state power in the lives of those experiencing partner violence (Ferraro, 1987; Haaken, 2010; Richie, 2005).

This criminal justice collaboration has been particularly problematic for women of color, who often feel the presence of the state more acutely than do white women. Many women of color experience poverty, which causes them to rely more heavily upon social services and government programs. In addition, communities of color have a more contested relationship with the police and men of color are subject to far higher rates of incarceration than white $\operatorname{men}^{1}$ (Lindsey, 2006). The relationship between communities of color and law enforcement can be more antagonistic than that of white people, particularly white people of higher social economic status. People of color are killed more often by law enforcement and are the subject of closer police scrutiny (Richie, 2005; Ritchie \& Mogul, 2007) $)^{2}$

Because of these differences, women of color have questioned the strategy by the grassroots DV movement to erase all differences, in describing violence against women as something that happens to all women. This sole reliance upon a gender analysis, the

\footnotetext{
${ }^{1}$ This disparity can be broken down as follows: approximately 12 percent of black males between the ages of 20 and 39 are either in prison or jail, 4 percent of Hispanic males and 1.6 percent of white males. However, given the recent rise in immigrant detentions, the number of Hispanic males is likely to be higher now.

${ }^{2}$ A 2007 joint study by Colorlines and the Chicago Reporter found that in major urban areas, black people were killed at double their percentage of the population.
} 
idea that women as a category share a common oppression, was based on the aim of diminishing the emphasis on race and class. The history of race and class differences carried conservative political freight, including the argument that battering took place because of some defect in oppressed racial or ethnic groups. Instead, battering was reconceptualized as a social problem, affecting all women equally, regardless of race or class (Sokoloff \& Dupont, 2005).

Haaken (2010) and Richie (2005) describe the ways this strategy, though effective, has had unintended consequences that mask real differences in women's lives. These differences not only made them more vulnerable to battering, but also left them further victimized by the programs and policies set up to help survivors. Richie (2005) suggests that this aggregate approach allows white middle class women to become symbolic of the survivor, both as victim and movement leader. This has shaped the specific policies and constructed public sentiment as to who a "deserving" victim of intimate partner violence should be. It also moves the discussion around violence against women away from a structural one, rooted in a systemic imbalance in the larger societal system, to a more individual model, in which each woman possessed the ability, and the responsibility, to shape her own future. This individual empowerment model reflects a larger, conservative telling of the role of the state in the lives of women. Public assistance is replaced by a focus on crime control, and as welfare, housing, food stamps and employment programs are cut, prison, military and law enforcement spending is increased.

This conservative political focus on crime control has been mirrored within the 
DV movement since the beginning. The early emphasis on changing law enforcement's response to violence against women came out of an historic disregard by police to assaults on women by an intimate partner. From the beginning of the movement, activists demanded that domestic violence be treated as a crime, calling for reform within law enforcement policies that ignored violence against women and legal practices that failed to hold men accountable for violence against their partners (Schecter, 1982). Early advocates criticized mediation, the common police practice that positioned the officer as a peacekeeper and rarely resulted in anyone being arrested at domestic violence calls. Using research showing that mediation did not lower rates of abuse, they called for law enforcement to provide meaningful safety measures for women experiencing violence from their partners (Steinman, 1991). At the same time, there was a focus on legislation and by 1980 most states had created laws specifically addressing domestic violence (Koss, et al., 1994).

Concurrently, three successful lawsuits pushed police departments to make significant policy changes (Daniels \& Brooks, 1997). Two were filed against police departments in Oakland and New York City, citing failure to respond to women, particularly women of color, who were victims of DV. These changed police policy locally. Finally, Tracy Thurman's successful $1984 \$ 2.3$ million civil suit against a Connecticut police department for failure to protect her from her abusive partner resulted in significant changes, nationally, in law enforcement response to domestic violence calls. Additionally, beginning in 1980, the Reagan administration began dismantling social programs and instilling crime control models in their place. This resulted in an 
increased focus on criminal justice responses in general and a concurrent shift in the power of the state over individuals and communities (Ferraro, 1996). Such practices as pro and mandatory arrest policies became normative, and no-drop prosecution was introduced, a strategy that removed the desire of the abused woman in determining if a case went forward for prosecution (Davis, et al., 2002). Many of these policies emerged out of an experiment in rural Minnesota called the Duluth Domestic Abuse Intervention Project (DAIP) and a study examining the efficacy of couple separation or arrest called the Minneapolis Domestic Violence Experiment (MDVE).

DAIP began as a community experiment, overhauling the criminal justice response to violence against women by an intimate partner in Duluth, Minnesota in the early 1980s (Pence \& Paymar, 1993). The DAIP, or as it came to be known, the Duluth Model, drove a range of changes that were adopted in addressing domestic violence throughout the US and in countries around the world. The Duluth batterers' intervention program, Coordinated Community Response teams (CCR) and the Power and Control Wheel are among the now ubiquitous programs that emerged from the DAIP.

The Duluth approach was positioned outside the mental health system, within the criminal justice system. Haaken (2010) describes the way that feminist activists became increasingly vocal in their critique of therapeutic approaches to batterers. As a corrective to therapeutic models that interpreted battering as a form of individual pathology, Duluth framed male battering as a symptom of the larger system, as a component of patriarchy, which creates the entitlement men use to control and dominate their female partners, both physically and emotionally. This allowed the reframing of the power motive as a choice, 
rather than a result of a temporary loss of control, effectively moving it away from the realm of therapeutic treatment.

The Duluth model focused, instead, on the coordination of all services that would potentially intervene in domestic violence cases. In this way, the framers sought to hold the community responsible for controlling violent men, shifting responsibility away from survivors. Despite the emphasis on social change, rather than simply social management of violent men, the result of the DAIP has been to build multidisciplinary teams focused almost exclusively around the criminal justice system (Pence \& McDonnell, 1999; Thelen, 2000). The Duluth model basically codified the alliance between the mainstream DV movement and the criminal justice system, while creating specific roles for each: the criminal justice system has the responsibility for managing the perpetrator, mandating educational and support systems for offenders and victims; the social service agencies, in turn, are responsible for maintaining these mandates, even if their structure comes in conflict with agency philosophies. And, because the Duluth model is posited on consistent and forceful consequences for the batterer, policies like mandatory arrest and no-drop prosecution were quickly taken up across the country after the findings of the MDVE (Sherman \& Berk, 1984).

Mandatory arrest policies began in Oregon in 1977 when a bill was passed requiring that police make an arrest if an assault had taken place during at domestic violence call (Daniels, 1997). This policy of preferred, or mandatory, arrest did not get taken up nationally, however, until the MDVE study conducted in Minneapolis in 1984. This measured the efficacy of three different responses to misdemeanor domestic 
violence cases. Significantly less recidivism was found among men who were arrested and temporarily incarcerated, as compared to those who received mediation or couples who were simply separated by the police. This experiment received wide attention and was quickly adopted by police departments across the country. The laws gained purchase among DV advocates for the way they removed the decision to arrest away from individual police officers once probable cause was determined (Buzawa \& Buzawa, 2003). Within two years, $46 \%$ of cities with populations in excess of 100,000 had implemented this policy (Steinman, 1991). Currently, all states in the U.S. have a preferred arrest policy and twenty states plus the District of Columbia have a mandatory arrest policy (Goodmark, 2004).

These policies remain controversial, particularly because replication has remained equivocal, proving impossible to get the same results for all segments of the population. Follow-up studies have resulted in outcomes showing that arrest deterred recidivism in only a small fraction of the population - married men who are middle or upper class (Salter, 2012). More troubling, arrest has been seen to increase violence in unmarried men of lower social and economic standing, who make up a majority of those coming into contact with police (Buzawa \& Buzawa, 2001; Iyengar, 2009; Sherman, Schmidt \& Rogan, 1992). An additional problem is the inconsistency shown by police departments faced with implementing legislated mandatory and pro-arrest policies. Divergent frameworks remain for deciding when arrest is mandatory. These differences have been exacerbated by failure to train police officers how to respond to these cases, despite their potential role as arbitrator. In cases in which it is not overtly obvious who the perpetrator 
is (for instance, where both parties are injured, or neither are), the officer is forced into the role of judge and often simply arrests the couple. This practice is particularly onerous in light of law enforcement/ICE partnerships in which an ICE hold may be generated even if the charges are subsequently dropped against one or both of those arrested.

Additionally, the emphasis on arrest fails to account for the ambivalence many women articulate about enlisting law enforcement. Ford (1991) describes the way that mandatory arrest laws may come in conflict with the strategies of women trying to keep themselves and their families safe. Further, the complexity of an intimate relationship makes the application of the law uniformly particularly difficult. An abusive partner is often much more than an abuser: s/he is possibly parent, economic provider, and lover. These multiple identities preclude easy categorization into criminal or innocent. Entrance into the criminal justice system, with its accompanying no-contact orders, fines and, for undocumented people, potential detention and deportation, may be much more onerous a response than many women desire.

Despite ongoing questions about the efficacy of mandatory arrest and no-drop prosecution programs, the Duluth model and multidisciplinary teams quickly took hold and remain persistent. Throughout the 1990s and 2000s use of the model continued to spread, especially in the form of coordinated community response teams (CCRs) and one-stop family violence centers, which were held up as a model by the Bush Administration and given prioritized funding (OVW, 2007), particularly through provisions of the Violence Against Women Act.

CCRs have spread across the country and are the norm in many urban areas. A 
common model, particularly in Oregon, is the Domestic Violence Enhanced Response Team (DVERT). DVERT is billed as a partnership between multiple service organizations, with an emphasis on the providing advocacy services. Though described as egalitarian, with power distributed equally among participating organizations, it was my experience as an advocate on a DVERT team that the criminal justice arm quickly became the leader of the group, with arrest and prosecution as the primary objective.

In 2002 I was hired by a non-profit domestic violence service organization to be the women's advocate of a nascent DVERT team in a rural county contiguous with a major urban area in northwest Oregon. The team was collaboration between the nonprofit, the sheriff's department, and the District Attorney's office. Though the model called for the non-profit to be the central organizing body, with women's safety as the guiding principle, from the beginning it was clear that the sheriff's and District Attorney's offices were in control. The sheriff's department managed the office and we were called the DVERT unit, with a detective in the role of overseer. There was an additional detective assigned full-time, along with a deputy, and a clerk from the records department also had an office on-site. There were two full-time district attorneys (DA) and their two advocates, who worked with women going through with prosecution. I was the sole representative of the non-profit agency.

The division of labor further highlighted this focus on arrest and adjudication. In my experience as a DVERT advocate, we met daily as a team to review police reports generated the night before. Any arrests were assigned to the DA advocates, whose focus on ensuring participation included beginning by informing women of our "victim-less 
prosecution" policy, despite repeated assurances from the DA's office that they would never proceed without the woman's agreement. My role involved working with all women not formally in the system, meaning a 911 call had been generated but that no arrest had been made. At morning meetings there was pressure on me to contact women and encourage them to recount an arrest-able assault, so that the system could kick in.

In Oregon confidential communication between an advocate and survivor is not legally protected as it is with a therapist or attorney. However, in this CCR team, it was the practice that the district attorney would never subpoena me for information a survivor might have shared. Because of this, I was allowed to provide the assurance of confidentiality to the women with whom I worked. However, many on the team expected me to provide her information to them, particularly if the woman did become part of the criminal justice system at any point. And, the assumption was that she would be convinced to become part of the system and cooperate in any investigation and subsequent legal process.

These examples highlight the ways the immersion in the criminal justice system can subsume the advocacy process. It was nearly impossible to escape the presence of the system in my work. In order to come to my office, women had to walk by multiple sheriff's cars, pass a deputy at reception and make their way through uniformed officers enroute to my tiny office. To alleviate this police presence, I took to meeting women all over the county - at fast food restaurants and coffee shops and in myriad parks and playgrounds. For I was the sole community based advocate for the entire county. If women were not in a temporary emergency shelter and wanted to access domestic 
violence advocacy services, they had to work through me. And, for many women particularly women of color - my connection to the criminal justice system potentially deterred them from making contact. As I describe below, the reluctance of women of color to access traditional domestic violence services has been well articulated. And, in the two years I was an advocate in the program, I saw very few minority women, despite ongoing outreach by my agency. The few women I did work with chose not to participate in the criminal justice system process and used advocacy services only from me in locations other than my office. Despite this, advocacy services continue to be located within CCRs and one-stop centers, with an emphasis on the criminal justice system.

One-stop service centers follow the practice of the CCR in bringing together multiple organizations addressing intimate partner violence against women. In a one-stop center, all services are located in a single place, with the intention of making access easier for women experiencing violence from an intimate partner. As with the CCR, however, this practice requires a woman to come to a place overtly connected to law enforcement. In 2009, a one-stop center opened in Multnomah County, Oregon, offering women the option of obtaining a restraining order, legal aid, housing assistance and counseling in a single place. When I visited the site indicators of the criminal justice system were pervasive, including armed, uniformed officers.

At the same time, partnering with the state has brought greater visibility to the issue of violence against women by an intimate partner. The DV movement has been quite efficacious in demanding changes in laws and law enforcement responses, which have had positive effects on women's lives. For example, programs that offer restraining 
orders remotely via videoconference alleviate the need for women to appear in court, which can reduce both emotional stress as well as exposure to violence.

From the beginning, however, this focus on the criminal justice system has been critiqued by many activists within the DV movement, especially women of color. Concerns were raised about the disproportionate way that the emphasis on treating violence against women as a "crime problem" diminished its social and political significance (Ferraro, 1996). As I described earlier, women of color, in particular, challenged the emphasis on partnering with the criminal justice system, citing the way in which it ignored women on the margins - at the intersection of race, class and sexual orientation (Crenshaw, 1991; hooks, 1984). They questioned the expectation that women of color call on the criminal justice system for help, when it had such a long history of oppression within these communities (Incite, 2006; Richie, 2005; Sudbury, 2003). African American women point to disproportionate rates of incarceration of African American men and the wider expansion of state power into the everyday lives of women (Richie, 2005). And increasingly, Latina women continue to describe the way in which fears of deportation compromise their willingness to access the state for assistance (Orloff \& Little, 1999; Vidales, 2010).

In the following section I describe growing concerns about the increased risk of deportation and detention for immigrant women experiencing violence. I begin by laying out a brief history of the connection between immigration and criminality, describing the way Latino immigrants, in particular, have been cast as criminals and subjected to antiimmigrant sentiments in the U.S. I also review recent changes in the relationship 
between the federal immigration agency and local law enforcement, especially in the context of current state legislation targeting immigrants and specifically those who are undocumented.

\section{Immigration and Criminality}

The link between immigration and criminality in public discourse has a long history within the U.S. (Hagen, Levy \& Dinovitzer, 2008). The Naturalization Act of 1790 limited naturalization to "free white persons" of "good moral character," describing not only those who were welcome in the U.S., but those were not and must be kept from remaining (Library of Congress website, 2013). In the mid-1800s, Chinese immigrants came to the United States during the western gold rush. The Chinese were allowed to remain for a prolonged amount of time, as their labor was used for the mass railroad construction that enabled the western expansion of the United States. However, after the work was completed, the Chinese were no longer welcome and the first law was created, excluding a specific race from entering, or remaining in, the U.S. The Chinese Exclusion Act of 1882 was accompanied by local laws against property ownership by all Asians in California, which later became the Asian Exclusion Act of 1924.

In the later nineteenth and early twentieth centuries, Congress enacted strong antiimmigrant laws in response to the large groups of mainly European immigrants who had arrived in the U.S. and found work in emerging industrial settings like factories and mills. In the 1920s, strict laws were passed, limiting immigration. These restrictions had the effect of maintaining fairly consistent levels of immigration and keeping public fears about immigrants relatively subdued. Beginning in the 1960s, however, immigration 
began to increase and by the 1970 s, the numbers had doubled. This was a new group of immigrants, arriving primarily from Mexico, Central and South America. Concurrently, the crime rate began rising in the US and anti-immigrant rhetoric began to focus on these growing numbers, linking them to the new tide of immigrants entering the country. Despite the impressive decline in crime that began and continued throughout the $1990 \mathrm{~s}$, this connection persisted, manifesting itself in intensified anti-immigrant sentiment and conservative legislative changes.

In the late 1990s, following the implementation of the North American Free Trade Act (NAFTA), movement across the southern border of the US shifted dramatically. This border had historically been relatively porous. People migrated north seasonally, working in the fields during harvest and planting, and returning to the south to their home communities in the interim (Bacon, 2008). NAFTA's provisions lifting the restrictions on US exports of corn into Mexico, for example, resulted in a flood of cheap corn into the Mexican market, wiping out small Mexican subsistence farmers who could not compete with the heavily subsidized US growers. These farmers and their workers headed north in search of work. The US responded to this large number of immigrants by militarizing the border, so that the workers, who had traditionally flowed back and forth as the seasons demanded, were forced to stay in the U.S. (Portes \& Rumbaut, 2006). This led to a 300\% increase from 1993-2000 in the number of undocumented Mexicans living in the US (International Labor Rights Forum, 2011).

This influx of people was greeted with the same animosity faced historically by all large immigrant groups over the course of U.S. history. Latino immigrants have been 
blamed for larger social problems including the economic recession, the collapse of the housing market, and voter fraud, among other issues. The response to this has been the creation of punitive laws targeting immigrants, such as Arizona's HB1070 which comprehensively targeted Latino immigrants in the state, requiring immigrants carry documentation with them at all time, followed by Georgia's HB 78, and Alabama's HB 56, both of which extend the Arizona law adding stricter sentencing to those using fraudulent identification to obtain work and increased restrictions on access to social services (Rieser-Murphy \& DeMarco, 2012). Currently there is anti-immigrant legislation proposed in multiple states, including legislation directed at denying children born in the U.S. of undocumented parents access to education and other rights of citizens, despite their constitutional protection via the $14^{\text {th }}$ amendment.

The increase in anti-immigrant laws is exemplified by the changes in the relationship between what is now called Immigration and Customs Enforcement (ICE) and local law enforcement. Historically, these have been relatively disparate domains. ICE has operated as a federal body, which since its formation in 2002, via the merging of customs enforcement and immigration and nationalization services (INS) has been charged with policing the border, enforcing customs and tariff violations and detaining and managing immigrants. Prior to this merger, INS operated relatively autonomously, partnering only peripherally with local police (Romero \& Serag, 2005).

As public sentiment against immigrants increased, this distance between the policing institutions of the state began to shrink. ICE and local law enforcement began working together on sweeps targeting immigrants, particularly on the southern border of 
the US (ibid, 2005). Following the 2001 bombings in New York, these partnerships became codified through a small provision of the Illegal Immigration Reform and Immigrant Responsibility Act of 1996 . The federal 287(g) program allowed for certain state and local law enforcement agencies to engage in federal immigration enforcement activities. Originally intended for trafficking cases and violent crimes, by 2006 the Department of Homeland Security (DHS) began to use this program more widely, deputizing local law enforcement officers to perform immigration officer duties.

In 2008 DHS introduced a new collaboration between law enforcement and ICE called Secure Communities. The program was described as a technological tool for law enforcement that gave law enforcement the ability to check an arrestee's fingerprints against a DHS database and automatically notify ICE if fingerprints match those in the database (ICE website). The program was used in conjunction with the $287(\mathrm{~g})$ agreement, but also served as a means of circumventing state laws like Oregon's statute 181.850, which prohibits law enforcement from acting as immigration agents (ORS. 181.850). Secure Communities requires law enforcement to contact ICE when an arrestee has questionable immigration status, which has been interpreted as a great enough separation to be immune from the statute (Rural Organizing Project website, 2011).

All descriptions by DHS of the Secure Communities program emphasize the focus on people who have already been convicted of level 1 crimes, such as homicide, rape, kidnapping or robbery (DHS website). However, DHS' own numbers show that the program is being applied indiscriminately to both criminals and non-criminals. In the 
first year of the program, 100,000 of the 110,000 identified were people booked for minor offenses such as traffic violations or property crimes (ROP, 2009). Numbers of deportees remain high, with many being deported pre-conviction or after facing charges on minor crimes. In addition, despite calls for regulation to avoid issues of racial profiling, protect civil rights, account for the negative effects on community policing and general oversight, DHS pushed ahead with unregulated implementation nationally in 2013 (DHS website, 2013).

Secure Communities and $287(\mathrm{~g})$ are part of a comprehensive shift in the way law enforcement and ICE work collaboratively. In addition, there are many similar law enforcement-ICE programs, operating under the umbrella of the Criminal Alien Programs (CAP). All of these programs have been widely criticized, by both immigrant rights groups and Sheriff's organizations, on multiple levels, including their opacity and lack of accountability, the way they codify racial profiling, the potential failure to offer due process through enhanced detainment and deportation prior to conviction, as well as the way they make communities more unsafe through limiting an individual's ability to report crimes and work with local law enforcement. This is particularly true for immigrant women experiencing battering.

In the next section, I describe how the grassroots DV movement has addressed problems particular to immigrant women experiencing violence from an intimate partner. This highlights the important legislative changes written into the Violence Against Women Act (VAWA). I also discuss how undocumented women came to be excluded from these benefits. This has also led to confusion among advocates about who is 
eligible for the VAWA provisions.

\section{Immigration and Domestic Violence}

In 1990, DV advocates began addressing legislatively the issue of the interplay between battering and immigration (Bhuyan, 2008). This came partially in response to the 1986 Immigration and Marriage Fraud Amendment (IMFA) which required that any foreign nationals who joined their U.S. Citizen or legal resident spouse in the United States remain with conditional resident status for two years, if they had been married less than two years prior to emigrating. Advocates argued that this did not allow women experiencing battering any recourse, forcing them to remain within the relationship or face deportation. This had the effect of giving the abuser a powerful means of further controlling his partner.

In what Bhuyan (2008) describes as an "unprecedented collaboration" (p. 158) DV advocates began partnering with immigrant rights groups to respond to the IMFA. This resulted in both the battered spouse waiver for the IMFA and the subsequent provision within the Violence Against Women Act (VAWA) of 1994, which offered women a means of responding to a deportation notice and self-petitioning for enhanced citizenship. While this legislation fundamentally altered existing immigration law, which, prior to this, had entirely ignored battering, it is important to consider who remains excluded from accessing these provisions.

These exceptions to immigration law recognize only those legally bound within a marriage of "good faith" as so defined under the 1996 Defense of Marriage Act (DOMA). In addition to requiring that the partnership be codified in this particular, state sanctioned 
manner, any same sex marriage is ineligible, regardless if it is recognized under international or US domestic laws, such as those in Canada, Massachusetts or Hawaii. In addition, the marriage must be to a U.S. Citizen or legal permanent resident, thus excluding the estimated 12 million undocumented people living in the U.S. access to this legislative recourse. This delineation of who is a "deserving victim" is crucial, for confusion remains around eligibility for the VAWA provisions. Advocates in several of my preliminary conversations expressed uncertainty about whether there was language in the VAWA addressing undocumented women. One advocate said that to alleviate confusion she recommended all women with questions about documentation try and use the VAWA provision. While not directly harmful, this practice has the effect of raising women's expectations about the relief possible through this legislation. Additionally, this can also lead to a more widely held belief that the issue of battering and immigration has been comprehensively addressed by the VAWA and is no longer a pressing matter for the movement.

Outside the mainstream movement, however, activists have called for alternatives to reliance upon the criminal justice system and particularly law enforcement, in responding to violence against women. Promising alternative interventions have been described, focused especially on restorative justice programs where the perpetrator of violence is held responsible both to the woman who has been injured and the greater community (Ptacek, 2010). Other ideas focus upon tapping the resources of family and community, eschewing legal remedies in general (Pennell \& Kim, 2010). Some Native American communities incorporate traditional practices, making use of storytelling as 
part of both intervention and reparation (Haaken, 2008). Despite these alternatives, however, partnerships between much of the domestic violence movement and the criminal justice system remain normative.

Even as partnerships with the state have had negative effects for many marginalized survivors, especially undocumented immigrants, little is known about how advocate practices operate within those partnerships. This unmapped terrain provides the basis for my first two research questions. The dissertation examines the strategies by which advocates make decisions by proposing a dilemma of practice at these border regions. This information is critical in filling the gap in the literature.

Next I focus on the epistemological stance guiding the research choices I made during this project. Research begins with multiple decisions, predicated on beliefs about the production of knowledge and the role of power within such practice (Rabinowitz \& Weseen, 1997). The choice to conduct qualitative or quantitative research is not neutral, but is loaded with the researcher's beliefs about issues around bias, subjectivity and reflexivity. Informed by this tradition of inquiry, my discussion of epistemological premises begins with a description of role of the researcher, followed by a description of Action Research, the larger philosophical framework guiding this project. The discussion of the methodological paradigm is laid out historically, from its beginning in the U.S. in the 1930 s, with special attention given to its collaborative practice and focus on group processes. I then describe the way conceptions of intersectionality and border tensions enhance Lewinian concepts of group processes. 


\section{The Role of the Researcher}

This dissertation asserts a critical feminist position predicated on the understanding that knowledge production is value-laden and research is necessarily the site of ongoing power differences (Denzin \& Lincoln, 2003). I use the word critical in relation to the production of knowledge, both generally and in regard to psychology specifically (Fox, Prilleltensky \& Austin, 2009; Nelson and Prilleltensky, 2005; Teo, 2005). A critical epistemology considers the ways multiple axes of a social system intersect to create subjectivity, and pays close attention to how power flows throughout in unequal distribution. Critical psychology, in turn, reflects on the ideological limits of our own practice, as psychologists, producing psychological knowledge and the potential to (re)produce systems of oppression. As a feminist research project, the study is also oriented toward emancipatory social change (Fine, 1992; Maguire, 2001; Piran, 2001).

Social scientists often deny or mask the political nature of their research practices. Fine (1992) challenges this stance, describing the way that all social scientists necessarily come out of a specific epistemological position that carries with it political premises. These often go unarticulated, registered in what is omitted as well as embedded in the questions or modes of analyses. Yet the researcher inevitably constructs a world through the collection and analysis of data. Feminist and action researchers attempt to make such processes explicit.

Research is a dynamic process that carries all of the participants' histories and identities into the process. As a researcher, I am always-already determining the trajectory and affecting the findings. Therefore my ongoing reflection on the process is 
crucial. I can look at the dynamic interventions and make interpretations based on my epistemological understandings of the phenomenon.

As one key premise, this dissertation takes an activist stance - one that is explicit as a lens through which questions are raised, interpretations are made, and stories are told. My aim is to attend to "local meanings, changes over time, dominant and suppressed frames, and contextual contradictions" (Fine 1992, p.220), and also to identify emergent possibilities. Through envisioning potential for new practices, there can be a disruption of commonsense assumptions, making space for a radical change in expectations and possibilities.

This space cannot be created, however, without considering the way in which discussion has been limited in order to build a coherent movement. Haaken (2010) describes the necessity of creating solidarity around specific foundational premises when building a social movement. While coherence is important, particularly in a nascent movement that is highly politically charged, the practice has other potentially damaging consequences. This apparent unanimity can have the effect of producing scripted and potentially simplistic responses, which serve to mask complexity through creating a kind of gag order around what can be said.

Lifting these prohibitions can be difficult, however. DV advocacy is, for many, a political act that carries with it a loyalty to the movement that may preclude overtly questioning some of the foundational principles bound by silence. In addition, the DV movement has been critiqued for being a movement led by white, middle class women that is too often silent around structural issues that affect oppressed and marginalized 
groups differently (Richie, 2005). Discussion of these intersectional places and their connection to power and privilege may create anxiety that results in self-censorship and repression of others. As a researcher I pay attention to this history of verbal suppression, at both the individual and group levels.

Compounding this, the grassroots DV movement has a long and uneasy relationship with academic researchers, including psychologists (Hamberger \& Ambuel, 2000). Although there are many examples of collaborative endeavors between psychologists and the grassroots DV movement (Fine \& Gordon, 1989; Gondolf, 1997; Haaken, 2010; Mankowski, Haaken \& Silvergleid, 2002) there is also evidence, particularly from the early years of the movement, of psychologists pathologizing women experiencing violence from their intimate partners (cited in Hamberger \& Ambuel, 2000). Because of this, it has been necessary to engage in a project that is collaborative, enlisting the experts working in the field, at all stages of the project. Additionally, the focus of the project is on analyses at the group, rather than the individual level, which also addresses the association of psychology with clinical and pathologizing stances.

As an activist-informed project, this dissertation is grounded in the action research tradition. Action research offers a means for attending to the collaborative process through employing a dialectical approach that engages the community and the researcher in creating and sustaining emancipatory change, as it is attentive to discursive practices that may impede or limit such change (Boog, 2003; Goodley \& Parker, 2000). In the following section, I describe a history of action research in the Lewinian sense, outlining its particular praxis - an orientation grounded both in the theoretical and practical. 


\section{Action Research and the Lewinian Tradition}

Action research emerged simultaneously out of the work of John Collier and Kurt Lewin, as they worked separately in the 1930s and 1940s (Pasmore, 2001). Collier's work centered on race relations, particularly between whites and Native Americans. He believed that research must be participative, involving both researchers and laypersons. It was not enough to simply engage the participants in dialogue, however, as differences in opinion would inevitably emerge, stifling the potential for change. Only by involving participants would it be possible to see how to create the actual conditions for making change.

Around the same time, Lewin emigrated to the U.S. from Germany. Much of his work revolved around his struggle to make sense of fascism, through understanding the way in which people behave within groups (Lewin, 1997). Working from a Gestalt tradition, with its emphasis on the totality of an individual's situation as a means of understanding behavior, Lewin described a more democratic research process that recast the participant in a more egalitarian, active role within it. Like Collier, he described the necessity for including the voices of participants in articulating their own struggle, denying the artificial separation of the researcher from the researched and refiguring social science research as inherently political and fundamental to the process of maintaining democracy.

Lewin described both social fields and phase spaces as a tangible way of mapping the diverse forces present within group interactions. Rather than focusing solely on the inner workings of an individual, he emphasized what he calls the total situation: a focus 
on the person within the entire, immediate, context. Although Lewin was responding directly to the Freudian practices of his time, this focus on context is consistent with currents in social psychology - with its emphasis on roles and situational dynamics - but enlists the inclusion of power and larger contexts described by community psychologists (Trickett, 1994) and feminist critical theorists who describe the idea of intersectionality as a means of reconciling the disparate factors affecting women's subjectivity (Collins, 1991; Crenshaw, 1991). Lewin's description of field theory appears at first to be fairly static and mechanistic, through his use of a physical model that assumes equilibrium in the system both preceding and following the change. However, he describes the way the addition of forces compelling change will add an increase in tension that the system then struggles to bring to equilibrium (Lewin, 1997). The forces shaping the person, or group, are not additive, however, but are described by Lewin using the language of calculus, as happening over time, dynamic and continuous. This is analogous to the biological concept of homeostasis, which is best understood as a range that fluctuates, depending upon the conditions at the moment. In Lewin's "life space," the total factors influencing a group are fluid, adjusting according to the context.

The fluidity of Lewin's life space works well with the concept of intersectionality as a lens for understanding the dynamic forces present within decision-making. Intersectionality highlights interaction, transforming the notion of a single cause into multiple, shifting determinants. The affinity between the Lewinian model and the construct of intersectionality offers a critical theoretical space for pursing the questions guiding this study. 


\section{Intersectionality}

Intersectionality was described by feminist legal theorist, Kimberle Crenshaw (1991), as a means of reconciling the way that black women's experience could not be fit neatly into either the feminist or anti-racist movements (Davis, 2008). Rather than articulating identity based on binary or dichotomous categories of difference, intersectionality attends to the multiple, contradictory structural and individual aspects of experience that people continually negotiate via interactions and differing positions of power (Collins, 1992; Crenshaw, 1991). This dynamic approach offers a more critical lens and deeper understandings of "the complexity of social inequalities and identities" (Bilge 2010, p.12).

The multiple axes of difference cannot be understood separately - each category, alone, is unrepresentative of the whole. Instead, they are interwoven, multiple axes operating simultaneously as oppression or privilege, depending on ones social location. For example, a white woman's experience of patriarchy, though oppressive, may not have equal resonance to that of a woman of color, who does not experience race as a privilege like a white woman.

Work on intersectionality often takes up race, class and gender as particularly defining, but this dissertation offers a reminder of the shifting salience of particular lines of oppression. In this case, legal status marks the bearer with a distinct weight that may shift her experience of violence from her intimate partner. Any intersectional analysis must consider multiple factors as "social processes that inform each other but operate in distinct and particular ways" (Nash, 2008). Only in doing so is it possible to suggest a 
point of intervention.

This dynamic approach offers a more critical lens and deeper understandings of "the complexity of social inequalities and identities" (Bilge, 2010, p.12). In the study of psychological phenomena, a focus on intersectionality involves attending to both the person and her/his context along multiple dimensions. These axes cannot be understood separately but rather as part of a whole. They are interwoven, multiple axes operating simultaneously as oppression or privilege, depending on one's social location.

Intersectionality holds important implications for domestic violence work because it calls into question the assumption that domestic violence is the primary danger faced by the survivor seeking services (Bograd, 1999; Crenshaw, 1991; Davis, 2000; Haaken, 2010; Smith, 2005).

Mainstream DV discourse has traditionally considered patriarchy as the primary source of violence against survivors, reducing other indicators of social location, such as ethnicity, race, sexual orientation, to subordinate issues or stressors (Arnold \& Ake, 2013; Bogard, 2005). By not privileging gender as the sole explanatory framework, a focus on intersectionality recognizes the interplay between differing social dimensions and how they shape the experience of domestic violence for all affected by domestic violence: survivors, perpetrators, families, friends and the larger community. This can result in recognition of the need for a range of disparate responses to the survivor's hierarchy of needs.

More recently community-focused organizations, primarily made up of marginalized women, have inserted an intersectionality-oriented perspective into DV 
work. Organizations like INCITE, Sista II Sista, and CARA, for example, have critiqued the mainstream focus on responding rather than preventing or ending DV(Arnold \& Ake, 2013; Smith, 2006). These groups have worked within communities, organizing against broader issues of police brutality and targeting of communities of color, often through organizing other related groups with those focused on DV issues, alone. While the groups frame domestic violence in the same way as mainstream organizations - as a problem that emerges from believes around privilege and power that are rooted in institutional practices - their focus extends from a gender analysis to an emphasis on multiple, intersecting structures of domination (Collins, 1991; Crenshaw, 1991).

I enlist the construct of intersectionality as a lens for examining the single-issue politics of DV work as well as an indicator of the group's use of a more complex way of thinking about the dilemma posed by law-enforcement collaborations with ICE. As advocates consider ways of making decisions at a time of crisis, it is helpful to understand their use of intersectional thinking that considers violence against women, both broadly and in relation to individual women, as it is constituted by multiple social factors like, racism, sexism, classism, and immigration status.

The concept of intersectionality provides a framework for analyzing interactions present within the focus groups. Lewin (1997) suggests attending to the contextual processes dynamically shaping group and individual interactions. Intersectionality offers a lens for revealing power dynamics as they flow throughout the decision-making process, both in the group and within the larger ideological frames, which shape the kinds of discussions that take place and are silenced. 
Even as scholarship has developed on intersectionality, the concept also has been critiqued for being too broad and undefined, potentially resulting in a laundry list of broad social factors that lack specificity (Davis, 2008). To mitigate this, I bring in the concept of border tensions, as a means of narrowing the broad ideological sweep potentially present in an intersectional analysis. Rather than an intersection, with its implication of movement through, border tensions highlights the collisions, drawing attention to the point of impact and the injury that is possible at this concussive encounter. These intersections at the border need not be neutral nor negative, but can be sites of productive, generative, creative conflict offering the impetus for positive change.

Border tension (Haaken \& Yragui, 2003; Haaken, 2008; Haaken, 2010) is a concept that describes the conflicting ideologies and practices that people, individually and as representatives of institutions, bring to doing work around social problems. Haaken and Yragui (2003) introduce the concept of border tensions as a way of describing the conflict that that arises when feminist ideology around domestic violence work encounters policy practices. In interrogating the boundary drawn between hidden domestic violence shelters and the wider community, the authors describe an ideological divide that encompasses far more than the practical consideration of whether a shelter should be hidden or not.

The authors describe shelter locations as an area of border tensions in which the shelter operates both practically and symbolically. On the one hand, the division over whether or not to hide a shelter includes the practical argument as to whether shelters are viable responses to violence against women and should continue to be funded. On the 
other hand, the discussion of shelter location contains more symbolic loading, including notions of safety, care and refuge, as well as larger understandings of women as a category.

By looking at the way in which women of color bring a multidimensional analysis to the question of shelter location policies, the authors emphasize the variability present within a practice often presented as accepted and unchallenged. Additionally, by examining the multiple symbolic meanings inherent to the practice, the authors reveal the way that the focus on safety through drawing boundaries around it based entirely on "good women" and "bad men" ignores other important divisions that may have more salience, and provide increased safety, for survivors in varying social locations.

This encapsulation of both material and symbolic concerns is integral to the concept of border tensions. Because it refers to the collisions that occur when multiple, often conflicting, interests negotiate things like policy, services, and ideology, understanding border tensions means unpacking the dimensions, both practical and symbolic, present at these encounters.

We all carry with us multiple, sometimes contrary, beliefs about the work we do. These beliefs have the potential to come into conflict with other's beliefs in any collaborative practice. The importance of this concept for this project lies in the focus on what Haaken (2010) describes as acute border tensions, places in which conflicts become rigid and conversation around alternatives are difficult, if not impossible. These can bring about a kind of battle fatigue (Haaken 2010), a weariness that precludes examination. Additionally, these places can be marked by commonsensical assumptions 
that come without interrogation, as the bearer simply assumes them to be true.

Until now, work on border tensions has been primarily theoretical, focused on unpacking the concept and delineating its social psychological component, its construction at the group level and the historical forces occurring at moments of border tension (Haaken \& Yragui, 2002; Haaken 2008; Haaken et al. 2008; Haaken 2010). Making use of this heuristic, this project applies the concept of border tension to a current social problem affecting the domestic violence movement. Through introducing scenarios that bring forth acute border tensions, the dissertation examines the way in which advocates reconcile multiple competing claims, paying close attention to their discursive practices.

Border tension is felt more keenly the closer one is to the border. As one becomes more engulfed in the dominant system it can become harder to recognize the pressures affecting discrete groups. In this study, the proximity the group has to the border affects both the decisions made around how to respond to a problem as well as the way in which the issue, itself, can be discussed. As I describe in the following sections, this project will examines the proximal and distal effects - the varying border tensions - on advocates' decision-making processes. In addition to asking how advocates respond to the dilemma presented by collaborations between law enforcement and ICE and examining the discursive strategies used to manage this dilemma, the project focuses on whether a group's location related to the way in which the problem is articulated and addressed. 


\section{Chapter Three: Research Methods}

This section describes the project's methodology. The research questions are as follows:

1. How do advocates work through a dilemma that has emerged in their practice?

2. What are the discursive strategies enlisted by advocates in addressing a dilemma at the border of domestic violence and immigration politics?

3. What is the relationship between each group's proximity to working with undocumented survivors and their decision-making process?

Research questions one and two examine the ways in which advocates respond to the dilemma presented by law enforcement collaborations with ICE. I begin by discussing how advocates manage the problem and then explore their responses in greater depth, to understand the dynamics, through determining if they enlist strategies that keep the needs of the undocumented survivor in the forefront. In order to do this I conducted focus groups in which dilemmas of practice at the border of DV and immigration were presented. These were in the form of two scenarios: one that mimicked a crisis call and one that presented a policy common to all the groups.

Research question three asks what relationship each group's proximity to work with undocumented survivors has to the complexity of their decision making process. My preliminary phone interviews with advocates indicated that they employ an intersectional orientation to work with survivors that considers survivor needs across a range of dimensions. However, preliminary research with directors of two DV agencies indicated that staff at a Latina-focused agency had a greater understanding of the 
increased risk of deportation and the effect on undocumented survivors than staff at a more mainstream agency. I hypothesized that the closer the advocates' work was to undocumented survivors, the more salient the survivors' particular needs would be to the group. I assumed that advocates whose work was more proximal to undocumented survivors would articulate more complex suggestions for how to respond to the effects of collaborations between law enforcement and ICE.

I used a case study methodology as a means of both evaluating proximity and examining the organizations' orientation to domestic violence work, in general. Determining if the agencies had a similar general orientation to doing DV work was important for understanding if agencies were employing a similar theoretical framework for approaching DV work. It has been my experience, both in my work as an advocate and my preliminary research that advocates, in general, approach DV work with a similar political orientation that is rooted in a feminist conception of the dynamics of DV. I assumed the advocates involved in this study would assume a similar orientation, which would be reflected in their agency policies. This determination of shared orientation was important for responding to all of the research questions.

Additionally, this case study method was used to determine proximity to work with undocumented survivors. This was important for understanding if the organizations were, in fact, differently related in their closeness to work with undocumented survivors. This allowed me to respond to research question three and the issue of proximity.

The results of the focus groups were analyzed using a discourse analysis. In the analysis I examine the findings for evidence of intersectionality and determine if it is 
maintained within examples of practice and policy. In the following I begin by describing the sample, the case study and focus groups. This is followed by the analytic strategy.

\section{Sample}

The sample was drawn from the domestic violence service agencies in the tricounty Portland, Oregon area. Each organization has provided domestic violence and sexual assault services in Portland for at least twenty years. Two of the organizations are the oldest providers in the area. The organizations were chosen purposively, both for their multi-dimensional set of practices around DV service provision, including 24-hour crisis lines, and their work with undocumented survivors. As I describe in more detail in the case study, each of the participating organizations offers a wide range of domestic violence services. Collectively these include crisis lines, emergency shelter, transitional housing, outreach, and education services. Additionally each agency offers specific services, not provided by the other organizations: Portland Women's Crisis Line provides the primary crisis line for the Tri-county Portland area; Project UNICA is Latina-focused and offers a 24-hour Spanish language crisis line; and Bradley-Angle has a stated commitment to doing work with survivors of color and offers services specifically for African refugees.

The focus groups were comprised of twenty-five advocates from three organizations in the metropolitan area of Portland, Oregon. Each group consisted of between six and thirteen people, depending upon the size of the larger organization. For example, PWCL is a small organization with only ten staff members. There were six 
participants at that meeting.

Within each organization, participants work in multiple, varied roles, however all have answered the crisis line and done safety planning with survivors as part of their work. Among the advocates there was a range of experience doing domestic violence work, from housing to court advocacy to direct case management.

Case Study. This dissertation includes a case study methodology in order to determine the proximity of each organization to doing work with undocumented survivors. The case study also provides evidence of the shared orientation groups bring to doing DV work, which make possible similar approaches to survivors, including an intersectional perspective. Case study designs are suitable for studies that center on multiple perspectives within a shared context (Lewis, 2003). The descriptions of the organizational contexts provide important frameworks for analysis of the responses and data for answering the research questions. Yin (2003) suggests that the case study methodology is well suited for capturing context and its effect upon participants. In this dissertation a case study of the three participating organizations serves to situate each group in relation to each other as well as to their work around the issue of law enforcement/ICE collaborations' effect on undocumented survivors of domestic violence.

The organizations were chosen purposively, both for their similar set of practices around DV service provision and their differing proximity to the phenomenon. Proximity is indicated by their varying emphases on work with immigrant survivors. The three case studies are based on a range of available sources, including published materials, volunteer and staff training manuals, websites, informal interviews with staff, former staff and 
volunteers and other ethnographic methods. This material is used to situate the groups and connect the organizational claims and practices to the findings from the focus groups.

On the basis of this systematic treatment of the materials it is possible to identify the extent to which each agency focuses specifically on work with immigrant survivors. By gathering data on each of the organizations - their histories, current practices and how they describe themselves on websites and in print - the dimension of proximity, or closeness to the phenomenon, emerges. The case studies of the agencies include descriptions of trainings and materials offered in languages other than English, as well as whether specific trainings are offered around immigrant issues, and delineation of staff time around immigrant issues. The case study includes determining overall training and the amount of staff time given to issues pertinent to immigrant populations.

The case study is guided by the concept of intersectionality in examining how much the organizations serve or interact with minority populations, particularly immigrant, as well as their alliances with other organizations that work on issues relating to these groups. Additionally, I examine whether the agency connects domestic violence with other social problems and if that manifests itself in work with other organizations and agencies not traditionally aligned with domestic violence service providers. Finally, if agencies have existing policies specific to undocumented survivors, I assess these policies to determine if they reflect awareness of ICE/law enforcement collaborations.

All of the research questions are focused on the ways that groups manage the dilemma presented by collaborations between law enforcement /ICE. Research questions one and two ask specifically about process, while research question three examines 
whether that process is related to the advocates' work with undocumented survivors. In the following section I describe my choice of a focus group methodology as a means of responding to the research questions. I then describe the dilemmas of practice I introduced within each focus group. I follow this with a description of the procedure I adhered to in the three focus groups and the conceptual and subsequent methodological choices I made in structuring them.

Focus group rationale. Focus groups offer a means to observe the intersection of individual and group processes that can reveal the dynamic interactions between group members (Morgan, 2010). In addition, working with groups, as opposed to individuals, offers a means of seeing more synergistic interactions. The interaction of group members can support access to information and insights that may not arise in an interview setting, while allowing observation of social interactions within the group.

These group collaborations also serve to diminish the potential emphasis on the researcher's role in data collection. Group meetings can allow for a more egalitarian relationship between researchers and participants, as power is potentially more equally distributed throughout the group and the facilitators, as opposed to individual interviews in which the interviewer may be perceived as having a privileged position of power (citation). In addition, groups generally have a greater number of participants than facilitators, which can also support this power shift.

Focus group research has been critiqued for typically removing the participants from the settings where interactions commonly take place, bringing them into an unfamiliar space and asking them to interact with people they have never met (Madriz 
2001). To address this problem, I conducted the three focus group meetings during regular staff meetings, which allowed me to stay as close as possible to the organic phenomenon, by meeting with advocates where they work, among those with whom dayto-day decisions are made.

This project took place in the familiarity of the workspace, among co-workers engaged in similar practice. In addition, domestic violence work carries with it shared goals, which suggest a similar political orientation towards violence against women. This orientation can reflect that of the larger agency and diminish the possibility for disagreement along fundamental issues, which could prove insurmountable to other focus groups. In addition, the familiarity of the group may help to diminish power imbalances that might emerge in groups along the lines of race and ethnicity (Madriz, 2001).

Simultaneously, it was important to consider the role the workplace may play in creating power hierarchies that can stifle participation. The staff meetings include people in varying power roles - supervisors and staff. Work roles may have affected the degree to which a staff member felt comfortable suggesting departures from agency policy and may have precluded unfettered critiques of existent policies and practices. The presence of other staff members may have kept advocates from revealing any actions they may have taken that conflicted with agency policy and practice.

The power dynamic present in staff meetings may have been mitigated in the focus group meetings through staying focused on the dilemma presented by law enforcement/ ICE collaborations and the subsequent effect on advocate's work. At the beginning of each meeting, I provided a description of the subject we would be 
discussing, including a brief history of the collaborations between the DV movement and the criminal justice system, as well as the recent partnerships between law enforcement and ICE. This helped broaden the contextual frame of the meeting, taking the focus off of individual responses and placing it upon larger structural issues. Then, as the scenarios describing a dilemma of practice were introduced, and throughout the focus groups, the moderator prompted the group to consider the issues collectively and work through them as a group. The scenarios are described in more detail within the following section.

Focus group procedures. I called the executive directors of each organization, explained my project and requested that a single focus group be held during the time of their regular staff meeting. They were given an offer to learn more about the project in an in-person meeting with the principal investigator. None of the directors requested an inperson meeting.

In the initial phone call to the executive directors of the potential participating agencies, I briefly discussed the purpose of the study. I explained that I was interested in conducting the study with staff members only, and described the way that staff members might feel more comfortable speaking openly about difficult dilemmas among their colleagues. Each director expressed interest in having staff members participate. I described the study in greater length, explaining the audiotaping, types of scenarios, transcript review, confidentiality, and the use of quotes. I offered to answer any questions the directors had and discussed the proposed length of time for the focus group. I sent each director a letter of consent (appendix B) that they could give to each staff member 
prior to the meeting. Along with my letter I offered my contact information, should they have additional questions. I was not contacted again by any of the directors.

When staff members arrived for the focus group, they were offered an additional copy of the letter of consent. At the beginning of the meeting, we discussed confidentiality. I suggested that individual confidentiality was the goal, and outlined practices such as expunging all names and identifying information from the transcript. I cautioned, however, that I could not insure that others would not discuss the meeting after leaving. I also talked about the way that confidentiality is difficult to achieve in a small community like the domestic violence service provision community of the Tri-county area. The staff members were offered an opportunity to refrain from participating if they did not desire to be part of the focus group. Of the three groups, one person opted not to participate. She explained that she was the agency's bookkeeper and rarely answered crisis calls. Those who participated were audio taped and a co-facilitator was present who moderated as advocates worked through scenarios.

In the groups, I introduced dilemmas of practice (Haaken 2010) - conflict points where responses could not be effectively managed through established protocol, in the form of scenarios describing a crisis call and a current agency practice. I described the larger problem of how advocates are addressing some of the dilemmas of working with undocumented women and enlisted the group in working through the dynamics of the dilemmas.

The first scenario focuses on a caller who describes emotional and physical violence to herself and her children by her partner/their father. He is the family's primary 
economic provider and deportation would result in extreme hardship for the family. Additionally, she, her partner, and their oldest child are undocumented.

The second scenario describes the recorded message one receives at many agencies, if the line is busy. The recording instructs the caller, "If this is an emergency, hang up and dial 911.” I asked the group to consider this advice, given what I had presented about the Secure Communities program. I also described organizations outside Oregon that have made the decision not to refer undocumented survivors to law enforcement. Please see appendix A for copies of the scenarios.

Focus group framework. I enlisted a Lewinian framework to guide my construction of the focus group format. In his articulation of action research Lewin describes working with individuals from organizations and institutions committed to addressing "minority problems" - the inequity and segregation present in the U.S. in the 1940s. He argues that although many organizations are well-meaning and determined to face the issues directly, they share an uncertainty that renders them unable to act. As he notes,

...these eager people feel themselves to be in a fog. They feel in a fog on three counts: 1. What is the present situation? 2. What are the dangers? 3. And most importantly of all, what shall we do? (Lewin 1997, p. 143)

It has been my experience both an advocate and researcher that DV advocates often share the questions Lewin describes. Problems can appear so vast and ubiquitous, that determining how to begin to intervene can feel insurmountable. It is possible that through understanding the way advocates process crisis calls and the manner in which decisions are made around seemingly unanswerable questions some clarity can emerge 
around how to respond.

Lewin poses the three questions as a framework for his delineation of the process necessary for researching social practices, with a focus on repeated planning, action and fact-finding (ibid, p. 146). He suggests that after articulating the research problem, a kind of reconnaissance is required, which allows the researcher an understanding of what is at stake and how to potentially address it. Following Lewin, I introduce these questions as a guide for framing the focus group meetings, using the first two to structure my contribution to the meeting and asking advocates to work through two scenarios in response to the third.

Lewin's first two questions help in describing the total situation, what he refers to as the entire, immediate, context (Lewin, 1997). Lewin's first question asks, "What is the present situation?” (p.143). In introducing this question, I described current law enforcement/ICE partnerships with a focus on the Secure Communities program and its effects both nationally and in Oregon.

Lewin's (1997) second question, "What are the dangers?" (p. 143) further draws out the total situation, via asking for articulation of what is at stake as a result of law enforcement/ICE collaborations. I explained the way in which throughout the DV movement, danger has been located primarily in the batterer, with services focused on getting women away from their abusive partners. I described how critiques by women of color, especially, have broadened the narrow focus on batterers, describing the various structural conditions that affect people unequally, based on social location.

I explained that law enforcement/ICE partnerships extend this complexity further 
in complicating the role the state takes in providing safety or creating additional danger for already marginalized populations. This contextualized the problem for the advocates and prepared the group to begin to respond to the scenarios. Prior to asking each group to begin responding, I brought in Lewin's third question saying, "In light of these collaborations between law enforcement and ICE, what shall we do?"

The following section describes my analytic strategy for the focus group data. I begin by describing discourse analysis, my analytic orientation. I follow this with a delineation of the analytic process, including the data organization.

\section{Data Analysis}

Because my research questions focus on discursive practices and the location of DV workers to work with undocumented survivors, I combine a case study method with a discourse analysis approach. Discourse analysis lends itself to the analysis of focus group data because these data stem from discursive interactions that occur among focus group participants (Cowan \& McLeod, 2004).

Willig (2003) describes the way in which discourse analysis has become more common in psychological research. As psychologists moved away from cognitivism and its focus on the internal states of individuals, the study of language shifted. Rather than viewing language as simply the manifestation of inner states, it was reconceptualized as productive - something people do rather than have.

Discourse refers to the use of language that carries assumptions shared by others in a specific communicative context. It acts as a framework for making sense of the world and the way in which a particular group talks and thinks about itself and its 
experiences. A discursive approach recognizes that language assists in constructing objects and phenomenon in our social world through socially, culturally and historically specific discourses (Weedon, 1987).

Discourse analysis (DA) offers a lens for understanding the processes at work that both encourage and limit action. Goodley \& Parker (2000) explain that "There are structural limits to change (which) are reflected in and reinforced by patterns of discourse" (p.12). This means that when a particular way of talking about something is used, it can have the effect of limiting other ways of thinking about (and talking about) that thing. This can seem fairly innocuous on the face of it, but it can be extremely powerful.

For example, the use of the term "illegal alien," while seemingly just crass or politically incorrect, serves a powerful purpose. It begins by separating the person away from the populous - "othering" them - through designating them as different, not human, alien. At the same time the term affixes criminality to their status, removing it from the action of border crossing, which might allow some room for discussion of causality or sympathy toward outsiders. In constructing the discursive object (the person one is talking about), the discursive practice (the choice of words) can uphold existing power structures. This conception of the relationship between discourse and power is important for my study as this dissertation is focused on understanding the way advocates manage dilemmas of practice which are themselves shaped by particular ways of understanding DV.

Discourse analysis offers a means of understanding the ways that language is used 
to construct meaning - socially, politically, and ideologically. Parker (1992) describes how discourse analysis can be used effectively to explore how language is employed to re-frame accounts, opening a space for understanding subjectivity - or, the way in which people experience the world and understand their place within it. He outlines a way of understanding language as a dynamic process that is both constitutive and reflexive meaning that it both creates and reflects reality.

This focus on language is appropriate for studying domestic violence issues, for in many ways the struggles within the domestic violence movement have been battles over words. Throughout the movement, activists have worked to bring domestic violence into mainstream political discourse. By shifting language describing domestic violence from the confines of the heteronormative patriarchal home (wife beating) to the realm of the general public (domestic or interpersonal violence) activists changed the domestic violence discourse, altering public perception of the problem from a private, interindividual, intra-familial issue to a criminal act warranting public attention and public sanction. However, this discursive shift from domestic strife to criminality carried with it unintended consequences, particularly around the increased presence of the state in the lives of survivors, that served to shape the movement as well.

It is necessary to understand more than just language in considering how advocates manage emerging dilemmas in their work. In research exploring evangelical Christian communities and domestic violence discourse, Haaken, Fussell \& Mankowski (2007) describe discourse analysis as a way of understanding dynamic fluctuations and shifts in meaning, particularly around sites of social conflict. By recognizing that terms 
used to describe and understand DV are embedded in larger social processes, it is possible to move away from fixed categories to reveal a more dynamic set of possibilities for change. The authors caution, however, against a tendency within discourse analysis to stay too fixated on language. They describe a dialectical approach that brings together an analysis of language and the larger material conditions affecting the women of their study.

This emphasis on both discourse and the accompanying context is crucial for my analytic strategy. I use the contextual findings from the case study and employ a discourse analysis approach that is focused on examining the narratives of the group to see if they use intersectional thinking. I am interested in understanding the discursive frames that delimit or expand the ways advocates are able to speak about potential responses to law enforcement/ICE partnerships. I examine both the language of the focus groups and the particular context within which these discussions take place. This context is rooted in a particular history - at the level of both the agency and the larger DV movement in which strategic choices have been made around partnering with the criminal justice system.

Discourse analysts stress that the approach is not simply a method, but also an approach or orientation (Antaki et al, 2002; Billig, 2001; Cheek, 2004; Parker, 1992; Willig, 2003). This method of analysis encompasses a wide range of practices centered on the way meaning is constructed through language (Parker, 1992). Walton (2007) suggests that "doing discourse analysis" (p.118) is less about a pedantic adherence to particular steps and more about employing the analytic categories and reporting the 
analysis in a way that maintains its theoretical foundations. Discourse analysis (DA) is described as flexible, working well with multiple organizing tools for coding and managing the data (Braun \& Clarke, 2006). However, the appeal of the DA method brings its own problems as well in deciding what exactly to do.

My strategy was to combine steps from Braun and Clarke's (2006) description of thematic content analysis with elements of Willig's (2003) description of Foucauldian Discourse Analysis (FDA). This approach seemed most helpful for the way it brought together pragmatic organizational tools while maintaining a focus on discourse through the use of FDA. Braun and Clarke describe a means of managing the data via looking at it broadly to determine patterns. This project is not about pulling out themes, however qualitative data can be unwieldy and the sheer volume of the data overwhelming, so I found it helpful as an early organizing tool.

FDA has a strong foundation in Foucault's theoretical positions, including the idea that discourses are historically situated and dictate the social construction of "reality". Discourses operate in both institutional and individual practices (Weedon, 1987). DV work, like all work, is shaped by the discourses that frame it, which themselves are products of a larger history. For example, the notion that DV is a crime, involving a victim and a perpetrator who are discrete individuals, is a commonly accepted discourse with a history in the larger DV movement; and, the belief that enlisting the criminal justice system as an ally to the larger DV movement is a commonly accepted practice tied to understandings of how to achieve control over the problem.

In this project I wanted to understand how DV advocates respond to a dilemma 
that calls into question movement practices around collaborating with the criminal justice system. If recommending a survivor enlist the police might result in more harm than the survivor is experiencing from her abusive partner, what can an advocate do? In order to understand this question it would not be enough for me to pull out the themes that emerged in the focus group, I needed to understand how the discourse worked.

I began by working systematically through the material and immersing myself in the content. This purpose of this was to produce an overall picture of the data. After transcribing the focus group discussions, I followed Willig's (2003) description of a discursive analytic approach, beginning by listening to the transcripts rather than reading them. She recommends this for the way it requires present and active participation with the text. This allowed me to experience the texts as a conversation and capture the nuances of the interactions, that weren't easily described in a transcript. Hearing the actual length of the pause, or the rush to respond, allowed me to (re)experience the focus group event. Willig (2001) describes the way in which this can allow the researcher to "feel" the text and potentially glean understandings that might not emerge in the printed word.

Because research questions one and two focus on understanding the discursive strategies advocates use when working through a complex social problem, I examined the structure of the discussion, looking for places where the discussion changed or came to a stop. As I listened I took notes about what I heard, marking places in which the discussion halted or made a sudden shift. I then read the transcripts multiple times in working toward what Patton (1990) describes as a rich description of data. These initial 
steps allowed me to begin to make sense of the data's broader meanings and implications (Braun \& Clarke, 2006).

Braun \& Clarke (2006) also describe the way a tangible, hands-on approach, though laborious, can be useful when combined with computer organizing programs. I combined a manual coding system that used practices like highlighters and post-it notes and actual cutting and pasting, with an Excel spreadsheet (Krueger, n.d.). I again read each focus group transcript several times while listening to the audiotape. I marked places that I recognized as similar across the three focus group transcripts and looked closely at how the places were organized in each group. I then made a copy of the transcripts with each place highlighted and cut them into sections, affixing them to a board in order to gain a wide overview of the data.

During this stage I identified patterns in the data suggesting that advocates in all three groups were using a common means of structuring their responses at similar points in the group discussions. At various points in each focus group, advocates enlisted an implicit decision tree mode of reasoning as a heuristic in organizing their responses. This way of proceeding allowed them to break their responses down into a series of yes/no contingencies, with each decision producing a sub-set of yes/no options with corresponding courses of actions.

Willig (2003) describes discourse analysis as proceeding as a result of the researcher's interaction with the text. Much like grounded theory, in which the merger between the method and the findings determines the course of action, my first finding structured the next set of methodological choices. I then created an Excel spreadsheet to 
organize the data according to the points in which I recognized the decision-tree heuristic. This allowed me to focus on specific moments in each focus group and to compare them across groups.

Following this initial organization of the data and findings, I made use of steps from Willig's (2001) delineation of FDA. I began with her concept of the discursive object and looked at the way it was referenced in the text, both implicitly and explicitly. Willig describes the discursive object as emerging out of the research questions. In the dissertation, the undocumented survivor occupies the position of discursive object, because my research questions focus on how it is that advocates work at the intersection of DV work and US immigration policies in advocating for undocumented survivors.

I began by marking all the places where the group used the words "undocumented", "Latina", "survivor" and "woman" or "women". In the next iteration I looked for the implicit references, searching for instances of the word "her", then reading the context to determine the subject. Was it the survivor they were referencing or another advocate? Finally I looked for ways in which consideration of the discursive object was absent. Were there moments in the text when policies and practices were discussed without reference to the undocumented survivor? Willig (2001) describes the way that a text ignores or does not reference the discursive object can offer an indication of the way the object is understood by the group.

I then followed Willig's articulation of discourses, which focuses on difference. I examined the way the discursive object was constructed and looked at the varying ways in which participants talked about undocumented survivors. Was this an intersectional or 
more homogenous way of understanding the undocumented survivor and her particular needs?

Research questions one and two ask about what advocates do when confronted with a dilemma of practice. How do advocates work through a key dilemma that has emerged in their practice? What are the discursive strategies enlisted by advocates in addressing a dilemma at the border of domestic violence and immigration politics? In designing this dissertation I held the assumption that advocates who make use of an intersectional analysis when considering the needs of an undocumented survivor hold a more complex articulation of possible responses in light of law enforcement/ICE collaborations. Guided by this theoretical assumption, the analytic process involved attending closely to the groups' use of intersectional ways of considering the survivor and her needs.

An intersectional perspective involves consideration of multiple axes which might include (but are not be limited to) immigration and documentation status, being a survivor of domestic violence, gender, having brown skin in the Pacific Northwestern area of the United States, lower socio-economic status, sexual orientation, and being a parent of children with differing documentation status. These axes are not discrete, but inform one another, operating dynamically in different contexts. Considering these varying social dimensions at particular moments in time and in relation to different parts of the larger social system could result in radically diverging responses by advocates.

Throughout the analysis of the data I made use of what Willig terms "positionings"- a way of understanding how the person doing the talking is also 
constructed by the discourse through which she speaks (Willig, 2001 p. 174). In other words, it is not just the discursive object that is affected by the discourse, but the speaker as well, who remains bound by the parameters through which she speaks. For this dissertation, the concept offered a means of thinking about how advocates' responses are constructed within a larger DV discursive community. For example, as I describe in the findings, all groups made use of common ways of understanding domestic violence that have their foundation in the Duluth Model and the Power and Control Wheel. This implies that advocates in all three groups bring certain similar assumptions to their work regarding the criminality of DV.

This concept of positioning helped illuminate how group responses may be shaped and constrained by the context. I used the idea of border tension to describe how advocates potentially carried with them multiple, often conflicting roles. As described earlier, border tension (Haaken \& Yragui, 2003; Haaken, 2008; Haaken, 2010) offers a means of describing the conflicting ideologies and practices people - individually and as representatives of groups or institutions - bring to their work. This concept emerged in the context of research at the intersection of communities with conflicting aims or interests. Advocates take on many roles in their work, depending upon their identity, politics, and organizational position at the time. For example, in working with survivors, they can simultaneously represent their agency, their community partner, the survivor and themselves. Negotiating these identities can bring them into conflict and require decisions around prioritizing these multiple roles, which can manifest border tension.

Throughout the analysis I paid close attention to places in the data in which 
participants would offer responses contingent upon their particular role within the agency. I also marked sites in the transcripts where group members identified an impasse moments when there was no negotiation around a response because it was a matter of agency policy. As I worked through each transcript and across groups, advocates were experiencing border tension at similar places. For example, in two of the focus groups advocates described feeling forced to respond in similar ways because of their agency policies, despite their discomfort with the potential outcome.

I combined my key theoretical constructs to try and understand what the discourse was doing. How were these moments of impasse - the places of border tension resolved? Did advocates use an intersectional way of proceeding to work through them or did they fall back on a more simplistic telling? What effect did that have upon the discursive object - the undocumented survivor? Did she disappear from the account or did the advocates maintain her presence as they worked through the scenarios?

Bringing together a method that combined elements of thematic analysis for determining patterns in the data, with concepts from FDA around discourse and discursive constructions proved fruitful in addressing the research questions. The three research questions are:

1. How do advocates work through a key dilemma that has emerged in their practice?

2. What are the discursive strategies enlisted by advocates in addressing a dilemma at the border of domestic violence and immigration politics? 
3. What is the relationship between each group's proximity to working with undocumented survivors and their decision-making process?

In the following section I describe the findings of the focus group in relation to these questions. I begin with the case study, which I used as a means describing context and determining each agency's proximity to work with undocumented survivors. I follow this by describing an overview of the focus groups. I explain the strategies advocates across all groups employ when considering both a crisis call and agency policies in light of the dilemma created by law enforcement/ICE collaborations. I follow this discussion with a description of the findings for each group in relation to the focus group scenarios. 


\section{Chapter Four: Findings}

In presenting the findings, I begin with the case study, describing the three participating organizations. The findings in the case study serve dual purposes. They describe the contexts of the participating organizations, situating them in relation to one another and the broader domestic violence movement. This is necessary for contextualizing the agencies and better understanding the participants' responses during the focus groups in relation to research questions one and two. Additionally, the case study describes the proximity construct, explaining each of the group's closeness to work with undocumented survivors. This is necessary for responding to research question three.

Using public information, including agency websites and printed materials, conversations I had with staff at each organization, and volunteer/staff training manuals, I summarize key aspects of the history of each organization in the tri-county area. I look at the agencies' mission statements or statements of values to better understand their orientation to domestic violence work. This is important for understanding the way in which the agency, and its representatives, approach domestic violence intervention. I then describe the current services each agency offers and the collaborative work they do in the larger community. Following this narrative description, I include a table outlining agency services related to the dimensions of my study.

After the descriptions of the agencies, I explain the proximity each agency has to immigrant and undocumented survivors. This description provides context for understanding the collective orientation of each group, as representatives of their 
respective agencies. This context includes information members of the focus groups bring to the discussions concerning undocumented survivors and the particular risks they face because of law enforcement/ICE collaborations. After describing each group's orientation to domestic violence services and its proximity to undocumented survivors, I present the findings from the three focus groups, followed by discussion of how findings inform the three research questions.

\section{Case Study}

Agency One. Portland Women's Crisis Line (PWCL) is the oldest organization in Oregon focused on violence against women. It began in 1972 as a rape crisis line and has operated continuously for forty years. It was one of the first sexual violence crisis lines in the United States to offer a crisis line as its primary program. Over time the agency expanded to offer other services, but the emphasis has remained on the crisis line as their main focus.

PWCL is an overtly feminist organization with an emphasis on social change. On the history page of their website they offer their definition of feminism, quoting the scholar bell hooks (hooks, 1984). They say, “At (PWCL), we define feminism as a movement to end sexism, sexist exploitation and oppression” (PWCL website).

This organizational commitment to feminism serves to place them within a particular way of understanding violence against women that is situated outside any notions of individual pathology. Instead, PWCL places itself within a larger history of the women's movement - with its recognition that structured gender inequality is the root cause of domestic violence and sexual assault (Sokoloff \& Dupont, 2005). In taking on 
the feminist label, PWCL defines its work as inherently political. At the same time, by choosing to use bell hooks' (1984) definition of feminism, the agency is aligning itself with women of color who have critiqued the mainstream battered women's movement's myopic focus on gender, calling for a more intersectional perspective that recognizes the shifting effect of multiple systems of power and oppression (Bograd, 1999).

Throughout their website and printed materials, PWCL emphasizes support and empowerment for survivors; however, this commitment to the individual is constantly accompanied by support for larger, structural change and a focus on social justice. In the "core values" section of their website they state, "PWCL was also founded as a social change organization. We believe that domestic and sexual violence are widespread in our society. Our purpose is to not only empower those who experience violence, but also to end the oppressions and violence which causes them to seek out our services" (PWCL website).

In the mission statement, the agency describes more clearly how they envision creating social change, and by extension, ending violence against women. The agency describes itself as committed to "ending domestic and sexual violence by providing confidential support services and education to empower our community" (PWCL website). The choice to include empowerment for the community, rather than focusing solely on the survivor level, provides insight into the agency's political orientation, which understands DV as a social rather than a psychological issue. This carries with it the radical feminist assumption that addressing DV requires social and institutional change (Schechter, 1982). 
They continue in this articulation of their inclusion of the larger community in addressing DV via their pledge to do outreach and form collaborative partnerships outside the agency. This is manifest in their list of partnering agencies, which is extensive and not limited only to DV service providers. In my conversation with the executive director, she described ongoing partnerships with locally-owned businesses within the community, who have made a commitment to the struggle against domestic and sexual violence, in the way articulated via her agency.

This radical orientation is also evident in their volunteer training manual. Prior to giving any information about domestic violence, the training concentrates on broader issues of systemic inequity and the role of advocacy in making structural change. Only after sections on racism and sexism is the topic of domestic violence introduced. The remainder of the training follows in a similar way, with specific education about domestic and sexual assault interspersed with elements focused on social class, anti-oppression work, and other social change projects.

PWCL offers a comprehensive 24-hour crisis line and referral center for both domestic violence and sexual assault services, including shelter services. The agency maintains an up-to-date list of available shelter beds and can directly connect callers to shelters with space. This alleviates the need for people in crisis to make multiple calls to DV agencies. Because of this, the organization is closely connected to DV and sexual assault service providers in five counties, allowing the agency special insight into current, available DV programming in the area. This allows them potentially to be a liaison for communication between representatives of agencies as well as survivors. 
In addition to the crisis line, PWCL has other services. Regular support groups for survivors of sexual assault and support services for families and friends of survivors are offered. The organization has an extensive volunteer and outreach and education program. They do not have a housing program, but work closely with multiple other agencies in town offering transitional and emergency housing.

In an interview with the director, she described the agency's work with marginalized groups as one of the important features of the agency and part of shaping the political identity of many of its staff. One example is their work directly targeting sex workers and developmentally disabled survivors. She also highlighted the outreach they do with homeless and LGBTQ advocacy groups providing services to youth experiencing domestic violence.

Despite the broad scope of their work, PWCL is a small organization with only nine staff members, four of whom are full time. In the focus group, participants discuss the way their size often limits their ability to do outreach to organizations not traditionally allied with DV organizations, like immigrant rights groups. Participants also described limitations in their training around these issues, due, in part, to recent, ongoing budget cuts.

Agency two. Un Nuevo Inicio para Concluir el Abuso/A New Beginning to End Abuse, or Project UNICA, is part of a larger program that provides a broad range of services, including immigration legal services, focused upon the low-income Latina/o community. This program is within Catholic Charities, an established non-secular organization that works on issues affecting marginalized populations. Catholic Charities 
began seventy-five years ago, advocating for children in foster care. Over the years, the scope of the organization has broadened immensely and there are programs across Oregon. In Portland, the organization offers assistance with housing, refugee resettlement, disaster relief, economic counseling, as well as adoption and post-abortion therapeutic programs. They also provide comprehensive services for Latino people, including legal assistance for immigration issues, emergency services, children's educational support and DV crisis services, in which participants in the focus group all work.

Since 1992, Project UNICA has provided the primary 24-hour Spanish language domestic violence and sexual assault crisis line in the county. While other organizations offering crisis lines can respond to mono-lingual Spanish speakers, via using outside translation services or any bilingual staff, all of Project UNICA's staff are bilingual Spanish speakers and most are bi-cultural (Latina).

UNICA offers support groups, as well as outreach and education services, parenting support and assistance with restraining and stalking orders. Although they do not have a specific domestic violence housing program, they are able to access the housing resources of their larger agency and provide ongoing case management and advocacy for survivors as they use the programs. Additionally, they can refer survivors to the immigration legal services provided by their parent organization.

The agency also has an advocate as part of a Domestic Violence Response Team (DVERT). As described earlier in this document, DVERT is a coordinated community response team, made up of members of the criminal justice system, state agencies and 
community groups. This DVERT team follows that model and includes members of two local police agencies, the district attorney's office, the Department of Human Services, Child Welfare, Legal Aid and three community organizations, including Project UNICA. The DVERT team responds to high lethality DV cases, as determined via a review and assessment tool.

On their website and in printed information, Project UNICA focuses on the problem of partner violence at the individual and family levels, highlighting empowerment and their commitment to Latina/o individuals and families. They state, "Our mission is to provide support, advocacy and opportunity for self-empowerment, assisting survivors to exercise free and informed life choices free of violence and oppression. We work to ensure that Latino individuals and families have equal access to community resources" (Project UNICA website). This focus is more limited than that articulated by PWCL, in which empowerment is described at the survivor level, but always in conjunction with community-level change.

The website describes working to changes behaviors, with an emphasis on alleviating individual abuses of power and control, which are described as resulting “when people unjustly exercise power over others.”(Project UNICA website). Rather than attending to larger structural issues related to violence, on their website, Project UNICA maintains an analysis at the individual and family levels. In contrast to the other participating agencies, no mention of social change appears on the website or any of the printed material I was able to procure. However, Catholic Charities, in which this agency is embedded, describes a commitment to creating a society "in which all people: thrive 
economically, socially and spiritually; cultivate diverse, respectful and just communities; recognize the inherent dignity and sanctity of human life" (Catholic Charities website). Though more subtle than the other agencies, this turn to social justice is indicated in the agency's description around justice and ensuring equal access to community resources for Latinas.

Agency three. Bradley Angle started the first domestic violence shelter on the west coast and has operated continuously for thirty-seven years. It was founded in 1975 as a homeless women's shelter specifically for women experiencing violence from an intimate partner. It began as a peer-to-peer help organization - all staff had past histories of abuse - and the expectation was that women using the services would have a role in determining the shape of the agency (Sanders, 2004). Bradley Angle continues that practice by emphasizing the experience of survivors on their website.

The website is full of the stories of survivors, both written and in video format. Each page has a sidebar with a "story spotlight." These stories are primarily by adult women survivors, but also feature children and siblings of those affected by violence. Although Bradley Angle does not evoke an overt feminist label in the same way as PWCL, the use of storytelling is part of a long feminist tradition of consciousness-raising present since the beginning of the modern battered women's movement (Haaken, 2010).

Like PWCL, on their website and in printed materials Bradley Angle has a commitment to both individual and structural change, with an emphasis on the larger community. They focus on community collaboration and state in their mission statement, “...mission is to offer survivors of domestic and sexual violence options for safety, 
empowerment, healing and hope, while collaborating with our communities to create social change" (Bradley Angle website).

This emphasis on collaboration appears in their work with African American and African immigrant survivors. They offer services specifically for these populations and work closely with African-American community organizations, as well as African refugee organizations. The agency offers a drop-in service center in a neighborhood with a long history of African-American residents.

In other culturally specific services the organization describes themselves as the only provider in the state offering lesbian, gay, bisexual, transgender, and queer (LGBTQ) domestic violence services. These services are also available in Spanish and the current primary advocate is a bicultural/bilingual Spanish speaker. The organization runs a shelter, crisis line, a transitional housing program, and community-based advocacy, which includes out-reach and education services in which bilingual/bicultural advocates are available. They also offer a program addressing economic empowerment; however, currently the seminars are currently available only in English.

Bradley Angle's website articulates a mainstream perspective around domestic violence when it describes the way DV affects all people, suggesting a universal effect. However, their programming belies this homogenization, indicating the application of an intersectional framework to much of their work. In addition to the work they do with marginalized communities, this is underlined in their section about awareness training. They state, "Bradley Angle is at its core, a social justice agency. We believe all types of oppression are connected, and that liberation from violence takes a concerted community 
effort toward a just society" (Bradley Angle website). This emphasis on integrating antiviolence work with larger issues around injustice suggests awareness of the varied kinds of violence people experience depending upon their social location (Sokoloff \& Dupont, 2005). This is also evident in their staff and volunteer training manual, which, like PWCL, prioritizes anti-oppression and anti-racism training along with cultural competency theory and practice.

Summary of the Agencies' orientations to DV work. The early battered women's movement was predicated on a feminist orientation that understood violence against women as a deliberate course of action used to maintain dominant systems and practices around gender, race, class and sexual orientation (Bograd, 1988; Schechter, 1982). Each of the participating organization's ways of doing domestic violence work reflects this perspective, through their common focus on alleviating oppression as a means of addressing DV. However, PWCL reflects a more radical orientation through its overtly feminist stance. Bradley Angle may be placed at the center of this political continuum in its emphasis on social change, followed by Project UNICA on the other end with its commitment to equal access to services for Latinas. PWCL and Bradley Angle further demonstrate a shared orientation in their practices around volunteer training. In each of their advocacy training manuals, the prospective volunteer is given the choice to take the training with the specific agency in which they will work, or at any of the tri-county DV organizations that might be offering a training at that time. This willingness to have volunteers trained at other agencies reflects a common belief system around how to do DV work. I was unable to procure Project UNICA's volunteer manual, 
so I do not know whether they also offer this choice.

Another example of the three groups' shared orientation is in their use of the Power and Control Wheel, a ubiquitous model for describing DV that came out of the Duluth curriculum for batterers (Pence \& Paymar, 1993). The Power and Control Wheel is present in both PWCL's and Bradley Angle's volunteer/staff training manuals, and is referenced on Project UNICA’s website.

The use of the Power and Control Wheel indicates that the groups carry certain assumptions in common about how to respond to both survivors and perpetrators of domestic violence. The notion that domestic violence is the result of one person trying to gain and maintain control over another person in an intimate relationship emphasizes the choice present on the part of the abuser. Rather than constructing DV as an individual pathology resulting from an inherent, possibly treatable illness with an external component (you get it, rather than do it), an emphasis on power and control maintains an abuser's agency. As described earlier in this document, this way of thinking shifted domestic violence out of the therapeutic realm and into the scope of the criminal justice system. Out of this emerged the common practice of grassroots DV organization's collaboration with the State and the criminal justice system (Haaken, 2010).

In addition to these common notions about DV, each of the agencies places safety at the center of their work. This is especially evident in the websites of PWCL and Bradley Angle. PWCL requires that each person entering their website read a warning describing the way that abusers can potentially stalk a person via the Internet. It then advises, "If you are in immediate danger, call 9-1-1, or call (PWCL at their number)" 
(PWCL website). This evocation of 911 links the police as the first avenue for alleviating danger. Everyone accessing the website is given this connection because in order to proceed to the website, the person reading must click a button indicating that they understand the advice about calling 911. This recommendation to enlist 911 comes up multiple times during a visit to the website. Each time a link is accessed, the message comes up again and the reader must click yes or no to proceed.

Safety plays a prominent role in Bradley Angle's website, as well. When clicking on the home page, the viewer is immediately presented with a banner with the word "Safety" in large font and it becomes the first thing the viewer sees. This is extended by their mission statement, which is just above the banner and lists safety as the first priority. Unlike PWCL, however, there is no connection made between safety and the criminal justice system on the website. Bradley Angle does not offer any indiscriminate recommendation to call 911 , nor is there any mention of law enforcement or the criminal justice system. Instead, the reader is directed to call the agency crisis line should they be in immediate danger.

Project UNICA, in contrast, does not have any description of danger or safety on their website, nor any mention of the criminal justice system. Their website is far less substantial than the other two agencies, however. They have a single page on the website of the larger organization within which they are embedded. This page includes a broad overview of their program, with no specific partnership listed. Their only link is to a program brochure. They list their direct crisis line number and have no directive to call 911 on the website. However, Project UNICA has a DVERT advocate as part of a 
coordinated community response team with an emphasis on a CJS response to domestic violence.

The three participating organizations share a similar philosophical orientation to doing DV work - as feminist, social change organizations. Additionally, as the chart below indicates, the three organizations offer similar services to survivors.

Table 1- Summary of Agency Services

\begin{tabular}{|l|l|l|l|}
\hline & PWCL & Project UNICA & Bradley Angle \\
\hline Crisis line & Yes & Yes & Yes \\
\hline Support Groups & Yes & Yes & Yes \\
\hline Emergency Shelter & No & No & Yes \\
\hline Housing & Yo & Yes (larger agency) & Yes \\
\hline $\begin{array}{l}\text { Outreach and } \\
\text { Education }\end{array}$ & Yes & Yes \\
\hline $\begin{array}{l}\text { Restraining order } \\
\text { assistance }\end{array}$ & No & Yes & No \\
\hline $\begin{array}{l}\text { Coordinated } \\
\text { Community } \\
\text { Response Team }\end{array}$ & No & Yes & No \\
\hline $\begin{array}{l}\text { Mandatory } \\
\text { Reporters }\end{array}$ & Some & All & None \\
\hline $\begin{array}{l}\text { 911 } \\
\text { recommendation }\end{array}$ & $\begin{array}{l}\text { Yes } \\
\text { message }\end{array}$ & $\begin{array}{l}\text { Yes } \\
\text { Recorded message }\end{array}$ & $\begin{array}{l}\text { Yes } \\
\text { Recorded message }\end{array}$ \\
\hline
\end{tabular}

In the following section I describe the proximity of each organization to undocumented survivors, particularly in working with Latinas. Law enforcement/ICE collaborations have targeted Latino/a people. Despite Latinos/as comprising $77 \%$ of all undocumented people in the United States, they make up 93\% of those deported under Secure Communities (Kohli et al., 2011). Enlisting the criminal justice system as a means of providing safety for survivors of domestic violence may carry a different weight if those in the relationship are Latina/o and, particularly if they are undocumented. 


\section{Proximity to Work with Undocumented Survivors}

In this section, I explain how closely each of the participating organizations works with Latina immigrant populations. This delineation of each agency's proximity to work with Latina immigrants is necessary for a key research question that guides this dissertation: what is the relationship between each group's proximity to working with undocumented survivors and their decision-making process? This question emerged from the preliminary research I conducted with two organizations in a county that had just voluntarily entered into the Secure Communities program. As I noted earlier, agency directors held widely differing understandings of the effect of this program on Latina survivors. The issue was very salient for the director of the Latina focused agency, while the mainstream shelter director confessed ignorance about the program, itself. This disparate knowledge led me to expect that agency proximity to working with undocumented survivors would affect their decision-making process.

Understanding proximity can clarify the importance of immigrant issues to the work of an agency. The principle of working closely with immigrant communities has been central to work in this field, and also to the salience of dilemmas presented in the focus group scenario related to law enforcement/ICE collaborations.

In this study, I determined proximity in multiple ways. I examined how closely each agency works with undocumented survivors, especially Latinas. I developed a list of factors indicating proximity and asked directors via in-person and phone interviews, as well as via email correspondence. Additionally, I examined public documents and agency websites and determined that the agencies represent a range of proximity to 
undocumented survivors. PWCL is the furthest, Project UNICA the most proximal and Bradley Angle is in-between. This connection to proximity in no way implies a quantifiable scale but is, instead, a general description of each agency's focus on work with undocumented survivors. In the following I describe each agency's proximity to work with undocumented survivors. I follow the narrative description with a chart summarizing the data.

PWCL. PWCL has the least proximity to undocumented survivors. The agency does not have direct programming focused on immigrants or Latinas. Additionally, they do not have any bilingual/bicultural staff. They report having a strong connection with other agencies providing services specifically for Latinas, and work with culturally specific agencies focused on several disparate populations including Russian and African, although they work only with agencies that are domestic violence focused. PWCL works especially closely with Project UNICA, because their policy is to refer all Spanish speakers to Project UNICA, as there are currently few bilingual, Spanish speakers on PWCL staff.

PWCL does not have printed materials in Spanish, nor is the website fully translated into Spanish. Additionally, when they do work with non-English speaking survivors, they must always use translation services from outside the agency. The organization does not offer any immigration-focused programs, nor do they provide trainings focused on immigration issues within the agency. But PWCL does prioritize getting staff to attend trainings offered within the community. However, this priority was described by the director as dependent upon staff interest, which vacillates according to 
the importance placed upon it by current staff members.

During the focus group with PWCL, staff requested more trainings around law enforcement/ICE collaborations. They also indicated they felt unable to address the needs of Latinas contacting the crisis line because of their lack of knowledge and limited bilingual/bicultural staff. They highlighted their collaborations with culturally specific organizations but described ways they might increase cultural responsiveness at their agency, for example, in providing materials translated into Spanish and hosting anti-racist trainings.

Project UNICA. Project UNICA has the closest proximity to Latina survivors and provides the most direct work to undocumented Latinas. The agency was created to address the gap in services to Spanish speaking survivors in Multnomah County. All staff members are bilingual-Spanish and the majority is bicultural-Latina as well. They all have specific training around the rights of immigrant survivors of domestic and sexual violence. Project UNICA collaborates with all other local domestic violence service agencies through referrals. Additionally, they work with non-DV focused organizations in the community that work around the Know Your Rights program - a program focused on giving immigrant people information about what to do if they are detained by police, the FBI, or ICE.

The participants had just gone through training around law enforcement/ICE collaborations at the time of the focus group. They were all cognizant of the Secure Communities program as well as other legal issues aimed at undocumented people. They also had a broad awareness of legal remedies available to undocumented survivors, such 
as the U-Visa, a visa option available for undocumented victims of crime (US immigration support website). Most of the advocates in the other focus groups were not aware of this program.

Bradley Angle. Bradley Angle falls in the middle of the three participating agencies in terms of proximity. Like PWCL, they have a website that can be translated almost entirely into Spanish and materials that are available in Spanish. Additionally, however, they have five staff members that are both bicultural-Latina and bilingualSpanish. While they do not have any direct focus on Latina survivors, the issues around immigration are quite salient due to their work with African refugees. They collaborate with multiple agencies in town that center on immigrant populations, especially Immigrant Refugee Community Organization (IRCO) and Catholic Charities' El Programa Hispano or Project UNICA. Bradley Angle does not offer immigration-focused trainings within the agency, but does prioritize sending staff to trainings within the larger community. Four advocates attended an immigration-focused training in 2012.

Summary. Given the stated focus on work with Latina survivors, shown through such practices as a Spanish language crisis line, bilingual/bi-cultural staff, and internal, all-staff trainings on immigration issues, Project UNICA is most proximal to work with undocumented survivors. Bradley Angle is the next proximal and PWCL the most distal in working with Latinas. As the table below suggests, Project UNICA, the Latinafocused shelter, scores highest on all indicators. 


\begin{tabular}{|c|c|c|c|}
\hline & PWCL & Project UNICA & Bradley Angle \\
\hline Total number of staff & 10 & 22 & 21 \\
\hline Percentage of bilingual staff & $1 \%$ & $100 \%$ & $24 \%$ \\
\hline $\begin{array}{r}\text { Percentage of } \\
\text { bilingual/bicultural staff }\end{array}$ & 0 & $73 \%$ & $5 \%$ \\
\hline $\begin{array}{r}\text { Programs/Written materials } \\
\text { offered in Spanish }\end{array}$ & No & Yes & No \\
\hline $\begin{array}{r}\text { Immigration assistance } \\
\text { offered at Agency }\end{array}$ & No & $\begin{array}{l}\text { Yes, via their } \\
\text { larger } \\
\text { organization }\end{array}$ & Yes \\
\hline $\begin{array}{l}\text { Internal staff trainings } \\
\text { around immigration }\end{array}$ & No & Yes & No \\
\hline $\begin{array}{r}\text { Minority (non-Latina) focused } \\
\text { programs }\end{array}$ & $\begin{array}{c}\text { Yes } \\
\text { (sex workers, } \\
\text { disabled, } \\
\text { youth) }\end{array}$ & No & $\begin{array}{c}\text { Yes } \\
\text { (LGBTQ, } \\
\text { African } \\
\text { refugee, } \\
\text { African- } \\
\text { American) }\end{array}$ \\
\hline Latina focused programs & Yes & Yes & Yes \\
\hline $\begin{array}{r}\text { Collaborations with other } \\
\text { agencies focused on } \\
\text { immigrant populations } \\
\end{array}$ & Yes & Yes & Yes \\
\hline
\end{tabular}

Table 2- Summary of information around proximity

The orientation of each agency is necessary for understanding the relationship between each group's work with undocumented survivors and their decision-making process. As my preliminary research indicated, and Project UNICA's emphasis on trainings around Secure Communities and immigration law support, law enforcement/ICE partnerships have a greater relevancy to those working closely with undocumented and immigrant survivors. Because of this I assumed those working most closely to undocumented survivors would offer the most complex articulation of how to address the effect of law enforcement and ICE collaborations on undocumented survivors. However, as the focus group findings in the following section suggest, 
advocate responses to crisis line scenarios were shaped less by their proximity to work with undocumented survivors than by agency policies around collaborating with the criminal justice system and/or the state.

The next section introduces the focus group findings. The research questions ask:

1. How do advocates work through a key dilemma that has emerged in their practice?

2. What are the discursive strategies enlisted by advocates in addressing a dilemma at the border of domestic violence and immigration politics?

3. What is the relationship between each group's proximity to working with undocumented survivors and their decision-making process?

Based on my prior fieldwork, I carried certain expectations into this project. I assumed that those working more closely with undocumented survivors would engage in an intersectional analysis. I believed that this affinity with undocumented survivors would result in more creative ideas for managing the dilemma presented by law enforcement collaborations with ICE.

\section{Focus group findings: Overview}

In the analysis of focus group findings, I engaged in an iterative process with the data, based on the research questions. I examined how the groups take into account the undocumented survivor as they consider collaborations between law enforcement and Immigration and Customs Enforcement. I introduced scenarios in which border tensions - the negotiation of multiple, often-competing claims - arose. I found that in each of the focus groups, the relationship of the agency to the Criminal Justice System (CJS) shapes 
the way in which the group can respond to undocumented survivors. Responses are predicated on the assumption that agencies will collaborate with the CJS, which is indicated through the participants' focus on mandatory reporting of child abuse in scenario one and their responses to fears of abuser lethality in scenario two.

Research question one asks how advocates work through a key dilemma that has emerged in their practice. As advocates considered each scenario, groups responded similarly. Almost immediately, one or more members introduced a strategy of organizing the material that used an implicit decision tree format - a way of proceeding that organized the potential response by breaking it down into a series of yes/no contingencies: If this is happening, then this is the response. The use of a decision tree in this yes/no format appeared to offer the advocates a means of structuring the scenarios I presented.

This approach is particularly useful when decisions are clear and concrete. However, as more complexity, ambiguity and ambivalence are introduced, the limitations of the decision tree become more apparent. By beginning with an either/or framework, only one way of proceeding can be entertained at a time, thus limiting consideration of less orderly, but perhaps more effective ways of approaching the complex needs of undocumented survivors of domestic violence. This simplification limits the possibility of a more creative, nuanced, and strategic approach which could bring about more desired outcomes balancing personal safety and institutional liability, while keeping survivors or their families from being deported. Additionally, there is a reliance on a mainstream domestic violence discourse that places the CJS at the center of services to all 
survivors of domestic violence.

Research question two asks, what are the discursive strategies enlisted by advocates in addressing a dilemma at the border of domestic violence and immigration politics? As they seek to balance competing institutional and ideological claims are they able to engage in an intersectional approach, or do they apply a more generalizing framework? Throughout the focus groups, advocates demonstrate varying abilities in intersectional thinking in responding to the scenarios. I recognize intersectional thinking as a perspective that considers multiple, dynamic, social dimensions of survivors and the way they inform one another at particular moments in time. The decision-tree heuristic employed in response to the issues described in the scenarios appeared to result in advocates moving from an intersectional perspective to a more simplistic account.

Research question three asks, what is the relationship is between each group's proximity to working with undocumented survivors and their decision-making process? I entered this work with the assumption that advocates who worked more closely with undocumented survivors would offer the most nuanced and complex suggestions about how best to advocate for this marginalized group. As I describe in more detail below, contrary to this hypothesis, the groups' relationships with the criminal justice system, manifest in policies around mandatory reporting, seemed to be more important.

In the following section I describe the findings from the focus groups in more detail. I begin by presenting the scenarios I read to each group, and then explain the responses from that group. I present quotes from the participants, which are followed by an identifying number listing the focus group and the transcript line number. At the end 
of the section I summarize the findings in relation to each of the scenarios. An entire transcript is included in Appendix F.

The first scenario is in the form of a crisis call. I based its content on an amalgam of calls I had experienced as an advocate, case studies from academic papers, and recommendations from my community partner. When the scenario was read at the focus groups, advocates expressed familiarity with the description, confirming the ecological validity of the script. One advocate asked, "Have you been listening to our crisis line?"(1.11).

Scenario one - A crisis call. A call comes into the crisis line. A woman who speaks accented English says she is seeking advice. Referring her to a culturally specific crisis line is not an option. She tells you that her partner is abusive, both physically and emotionally. The abuse is infrequent and has happened since they came to the US ten years ago. They are married with two children. She has not sought help before but now the man is beginning to abuse the children - something he has not done in the past - and she is concerned. He occasionally strikes the oldest child and is emotionally abusive (yells) to the youngest. The children are having trouble at school (she names the school) and the teacher (she names the teacher) has recently contacted her with concerns. She does not feel she can leave him because he is the primary economic provider, because they are married and because he is the children's father. She, her partner and their oldest child (11) are undocumented. Their youngest child (8) is a US citizen.

Findings. In each of the focus groups mandatory reporting emerges as a place of border tension where advocates struggle with negotiating different responses to survivors 
according to whether or not they are a mandatory reporter of child abuse. Mandatory reporting refers to the responsibility of an individual to make a child abuse report to the Department of Human Services (DHS) if they have reasonable cause to believe that abuse to a child (or elder) is currently taking place.

The response by the system to a child abuse report varies, depending on many factors related to the story, for example, the severity of the abuse, whether the child is intervening in the violence between the adult partners, whether there is a risk of "substantial harm", or if the child is impaired by living in a state of fear (DHS, 2013). These factors often require a subjective decision on the part of the caseworker taking and reviewing the report. Advocates in the focus group described frustration because child welfare reports are handled exclusively through an anonymous hotline with rotating respondents. This means it is impossible to collaborate with specific child welfare workers with whom they might have interacted before, or whom they know to be sensitive to the dynamics of domestic violence.

Haaken (2010) describes how mandatory reporting of child abuse became the norm in DV work in the 1980s. This norm arose as part of the feminist demand that the state respond seriously to violence against women and their families. With the advancement of research on the effects of witnessing violence on children, child welfare programs across the U.S. began to define exposure to abuse in the home as a form of child abuse (Edleson, 1999). One impact of this broadening of mandatory reporting was in its expansion of abuse to include survivors that continued to live with assaultive partners. 
Oregon statute ORS 419B.015 states in part,

Any public or private official having reasonable cause to believe that any child with whom the official comes in contact has suffered abuse, or that any person with whom the official comes in contact has abused a child shall immediately report or cause a report to be made... "(ORS 419B.015)

However, under the law advocates at non-profit organizations providing domestic violence and sexual assault services are exempt from being mandatory reporters. In response to the child abuse allegations at Penn State University, the 2012 House Bill 4016 increased the list of mandatory reporters, adding many groups working with youth. At the same time, the bill made special provisions exempting organizations working with survivors of domestic and sexual violence. The law that resulted from this bill codifies this distinction, defining some as mandatory reporters and exempting others:

Employees of public or private organizations providing child-related services or activities to youth, excluding nonprofit organizations whose primary purpose is to provide confidential services to victims of domestic or sexual violence. Emphasis mine. (ibid.)

Despite this exemption, many agencies require that advocates be mandatory reporters as a matter of agency policy. Advocates in the three focus groups report different practices around mandatory reporting of child abuse. At Project UNICA all advocates are mandatory reporters, at PWCL some are mandated, and at Bradley Angle none are required to report.

Mandatory reporting has a profound influence on group responses to the first scenario. Overall the policy acts as a determinant of how advocates proceed in their response to the survivor. Not only does it limit the resources available to the survivor but it also shapes the discussion itself, effectively shutting down group consideration of the 
complexity of the undocumented survivor's needs.

In the following section, I describe how the two groups with a mandatory reporting policy consider the policy and its effect upon the survivor of the first scenario. Because my research questions are focused on how advocates respond to crisis calls as they integrate new information affecting marginalized survivors, I lay out the trajectory of the focus groups. In this way I am able to map the ways that advocates manage this place of border tension where agency regulations and commitments to survivors potentially conflict.

In the two groups with mandatory reporting requirements, the outcome is similar, despite their varying use of intersectional analyses. As I describe in more detail in the following section, in focus group one, with PWCL, an intersectional analysis emerges early in the group discourse but then disappears when a DV discourse relying upon the CJS is introduced. In focus group two, with Project UNICA, the group maintains an intersectional analysis but is still constrained by the requirements of the reporting policy. Both groups invoke a decision-tree heuristic as a means of moving the discussion away from considering possibilities for challenging the policy. I contrast this with the response from focus group three, Bradley Angle, in which no advocates are mandated to report, explaining how this group is also constrained by the policy but finds a means of maintaining an intersectional response to the scenario. This group is able to keep the needs of the undocumented survivor at the center of the analysis, while imagining alternative ways of intervening.

Analysis. I read the scenario aloud to the group and finished by asking, "In light 
of what we know about current immigration policies like Secure Communities, what shall we do?" At PWCL, some advocates are mandatory reporters and some are not. This determination is related to whether the advocate has a job description specifically focused on work with children and youth. This leads the group to begin focusing both on trying to ensure that the survivor speak with an advocate who is not mandated while also warning her of the potential repercussions should a child abuse report be made. An advocate in the group explains,

I'm not a mandatory reporter and that's easy. But some of us are around here and I would express my concerns about who she talks to, that they might be mandatory reporters and the risk there. (1.64-66)

This brief statement reveals a great deal about the advocate's regard for the policy. She describes it critically. She divides the staff into reporters and non-reporters, giving a positive account of her role as a non-reporter because it is less constrained than that of the reporters. She offers a criticism of the policy, evoking concerns and referencing the risks inherent to reporting, particularly to the undocumented survivor of the first scenario. Another advocate joins her, spelling out the specific risks present for the undocumented survivor, referencing ICE and invoking the looming potential for deportation. She comments,

I think that it would be important to talk to her about potentially what happens if a report is made... what a mandatory report is, what that might look like, what ICE is, and how they could get involved. Now knowing more information that you've given us I would want her to know that information, because there are multiple threats here...the loss of economic support, abuse to her and her children and deportation. (1.76-82)

The participant integrates the information she has learned about Secure Communities from the introduction to the focus group. By placing the experience of the 
undocumented survivor at the center of the analysis, the advocate begins to employ an intersectional analysis of the survivor's needs.

Following this initial exchange, however, the group does not continue with any articulation of the dangers specific to the undocumented survivor. And as the group continues working through the scenario, the advocates do not take up an intersectional way of considering the effect of the policy nor possibilities for mitigating it, but instead introduce the decision-tree heuristic, asking only if a child abuse report must be made or not. This way of proceeding effectively erases the particularity of the undocumented survivor. An advocate states,

If there is child abuse happening...DHS could get involved in that, as well, and what we see happening with survivors, regardless of documentation, is that if you make a report, if you don't make a report and somebody finds out, then you are often held responsible for putting the children in harm's way. (1. 169-174) (emphasis mine)

The statement begins by generalizing to all DV survivors, removing the earlier emphasis by group members on the dangers specific to undocumented survivors. In disregarding documentation status, there is no need to attend to differences around the mandatory reporting policy. All are implicated equally and mandatory reporters have no leeway in imagining alternative responses to child abuse claims. Instead, advocates must concentrate on whether a report will be made or not, in this case through identifying to whom the survivor speaks.

So in the scenario when the woman said, "he hit my child" (name) would stop her there... before she had given any more information and offered her another advocate. (1.220-223)

Additionally, the group raises the possibility of advocate liability, despite the fact 
that there are no legal grounds for such concerns after the 2012 amendment (ORS

419B.015). The focus on advocate liability has the effect of moderating the critical stance initially articulated in the focus group. The critical perspective is overridden by descriptions of how to negotiate the policy, primarily through silencing the survivor and making certain she speaks only with advocates who are not mandatory reporters. Later in the focus group, an advocate explains the ways this is carried out:

Our policy is if you are a mandatory reporter as soon as somebody discloses something that you would have to report you stop the conversation. So in the scenario when the woman said, he hit my child (the advocate) would stop her there... before she had given any more information, and offered her another advocate or talked to her about, if you give me any identifying information, what that would look like, so...(1.217-224)

Again, all survivors of domestic violence are conflated and the advocate does not reference anything particular to the undocumented survivor described in the first scenario. For instance, there is no discussion of language barriers or anything that might keep someone with limited English or from a different culture from understanding the advocate's warning. As I describe below, this is in contrast to the other two groups, in which the issue of comprehension and its effect upon whether the survivor understands to remain silent is very important.

The next group, Project UNICA, is able to maintain an intersectional analysis of the survivor throughout the discussion. This may be due to their status as a Latinafocused agency, which they describe as centered on the needs of Latina survivors. As one advocate states,

We have a whole program that's built around this community and that has, you know, every service that we've been able to gather, you know, under 
this one roof designed specifically for that community (2.337-339)

The agency's focus on serving Latina survivors may account for how their responses continually place the undocumented survivor at the center, describing her particular needs and the specific effects of enlisting the CJS on her. However, their intersectional orientation does not appear to affect their responses to the issue of mandatory reporting. The issue is particularly salient in this focus group, as their agency policy requires that all advocates are mandatory reporters of child abuse. After hearing the scenario read aloud, the first thing that is said is in reference to the policy,

Well, we're mandatory reporters here at this agency. So with everything that has been shared in this crisis line call, we would be obligated to make a report to DHS. And that's something that we would try to give as much information as we could about, and maybe even encourage the caller to make a report herself. (2. 188-192)

In this setting, there is no question of whether or not to report. Instead, the issue becomes one of determining whether the advocate will have to make the report or whether the survivor will do it herself. This point is followed by a discussion of how to mitigate the potential CJS response to the agency's child abuse report. The same advocate adds,

....and then I think we would probably launch into safety planning around - if she also shared that she's undocumented - safety planning around that, and giving...empowering her with the right vocabulary to use if she is picked up (2. 192-194)

As with the first group, the participant brings in the undocumented survivor, integrating information about Secure Communities and the likelihood that the survivor will be picked up by law enforcement if a report is made. The advocate's language is halting. She pauses after "giving" and then changes the word to "empowering", as if to 
give agency to the survivor. She then articulates the potential CJS response to the child abuse report, acknowledging that the undocumented survivor may be picked up by law enforcement in response to her agency's report.

Her response indicates an implicit recognition of the contradiction in her description of their protocol. For by making the report, the advocate herself is introducing potential deportation to a survivor who has called her for help. In this case, safety planning is done to mitigate the effect of the agency's action, rather than that of the abusive partner.

Rather than discussing the contradiction inherent to this situation where a survivor's call to a crisis line for help could result in the introduction of deportation, the group continues to describe the services available to survivors. Throughout this process, the participants are still able to maintain a complex analysis of the needs of undocumented survivors around obtaining DV services. However, this recognition of the survivor's needs does not result in any alternative propositions to making a mandatory reporting. The group never discusses whether making the report is a good or bad idea. Instead they focus on her behavior and their own limited latitude of discretion around making a report. An advocate describes trying to stop survivors from disclosing information and articulates her resignation that prevention is unlikely,

it's kind of...kind of hard to prevent [laughs], it's kind of hard to prevent, because, you know, when we tell people, you know, "Hey, we're...I'm a mandatory reporter, and this is what that means," and then they're like, "Well..." You know, usually it's hard to get to the point where they've understood where our limit is. (2. 320-324)

Although the advocate implies that there are problems inherent to the policy, there 
is still no overt critique of the policy itself. Instead she focuses on trying to change the survivor's behavior, while simultaneously recognizing that reporting is inevitable, as most survivors will inadvertently incriminate themselves. Ultimately the survivor becomes responsible for the outcome of not understanding the rules or what is at stake.

This issue is raised again at the end of this section in the focus group, when another advocate describes her frustration with the policy in her one-on-one work with survivors. In contrast to the crisis line, where there is anonymity, long-term work does not allow for the same kind of protection for the advocate. One participant describes this issue:

But especially when we're working, one-on-one...with clients. We've already got all their information...And if they blurt something out, then we can't not use it. Then it breaks trust. (2. 363-365)

This statement carries with it the clearest critique of the policy. In her choice of words she underscores her frustration with how the policy determines the course of her relationships with survivors. The use of the word "blurt" serves two purposes. It references the way in which long-term work, based on building relationships, can unravel in a moment, along with the trust they have carefully cultivated. The term also suggests the inefficacy of their explanations of the policy. Blurting out information connotes doing something without forethought, speaking out in the moment without regard for consequence. Regardless of being cognizant of the potential consequences, during the course of a conversation a survivor can say something disruptive, quickly shifting the advocate-survivor relationship.

At this juncture, the group falls silent. One advocate jumps in, offering the 
decision tree heuristic as a way of framing the available actions - either the advocate can make the call, or the survivor can make it. This brings the group back to the beginning of the discussion in which the report is inevitable and the only decision revolves around who will make the call. She explains the dilemma,

...like somebody mentioned earlier, we also do encourage them to make that phone call themselves. And we can either like meet with them and we could...by their side, um, so that they can just feel that support, or they could just give them the phone number and they could make the call then on their own. Um, that's really highly encouraged as well. (2. 367-371)

The advocate (re)frames the choices, placing the responsibility of reporting on the survivor, who can make the call either on her own or in their company. This serves to remind the group of the agency policy and the inflexibility it presents, while alleviating some of the burden of complying with the policy directly off of the advocate.

In contrast to the first two groups, there are no mandatory reporters on staff at Bradley Angle. Their agency policy handbook is very clear about this, referencing 2012 House Bill 4016 in explaining that Oregon State law does not require staff to report child or elder abuse to the state (Bradley Angle handbook). Despite this explicit guideline in the handbook, advocates in focus group three still prioritize discussing the effect of mandatory child abuse reporting policies. However, their concern is with determining which agencies have mandatory reporters in order to determine where it is safe to refer undocumented survivors.

Similar to the advocates of the other two focus groups, this group begins to address my question by employing a decision tree heuristic, working through the scenario by first determining if the survivor would leave or stay. This immediately brings up the 
issue of mandatory reporting and they present the report as unavoidable. Two advocates respond, echoing one another: "And she's going to get involved with the child welfare system. Heck, yeah!” (3. 492-493)

Contrary to the other focus groups, however, the agency itself does not pose a risk for the survivor. They will not unavoidably have to make a report and so they do not have to worry about keeping the woman from speaking to them and are able to take time making sure she understands what is at stake should a report be made. In the focus group, the participants are able to continue in their exploration of the needs of the undocumented survivor. They maintain an intersectional analysis through much of the discussion. They refer to the needs of the undocumented woman, describing specifically the way fears of deportation may shape the decisions she would make. They offer ideas about ways to avoid enlisting the police, focusing on survivors' fears of losing their children when they are deported.

However, focus on the mandatory reporting policy that is in place at other agencies permeates much of the discussion, primarily for the way it constrains the group's ability to provide services or limits their referral options. The group even returns to the topic at the end of discussing scenario two, expressing frustration with how mandatory reporting policies leave no room for the nuances of individual cases, requiring reporting regardless of the threat it potentially causes to the family.

...they're mandated reporters and it's not up to them to decide. But at the same time, it's like this puts the whole family at risk. (3. 1443-1445)

At this juncture, members of the group begin to describe a new way of approaching survivors around the issue of child abuse reporting. They do not rule out the 
possibility of making a report themselves, describing a balance between getting a survivor information about mandatory reporting and having it affect the child's ability to get help. One advocate describes this site of border tension:

I wouldn't want to discourage the children from speaking about what they're experiencing. And so it's a hard thing to manage, because you might say like Child Welfare can become involved and this is what's going to happen. At the same time, you don't want her to go tell her kid, "Don't talk about it, please," because that just, you know, keeps it in the family. (3. 743-746)

Negotiating the tension between giving a survivor options and silencing them requires a way of proceeding that begins with the establishment of trust as well as clarification of the advocate's role and ethical commitments. One advocate says,

You have to earn their trust first before you, you know, you have... because everybody's afraid when they see... when I work with women, they all think like, you know, you're maybe a Child Welfare.(3. 763-765)

This reference brings the border tension experienced by the advocate to the forefront by calling into question her alliance with the survivor. If the survivor understands her to be representing Child Welfare, the advocate implies, she will be unable to gain the woman's trust.

Throughout the remainder of the discussion conversation revolves around a different way of approaching the survivor - one that puts her needs at the center. This intersectional analysis has a different nuance than any present before in the focus groups. This not only considers the specific needs of the survivor as she navigates social services, the CJS, and other external agencies but it also takes into consideration the relationship between the survivor and the advocates.

One of the participants focuses on how she and the survivor enter into their 
relationship, beginning by trying to understand how the survivor understands domestic violence culturally, rather than applying the dominant framework onto her experience. This moves the discussion around the crisis call away from the specter of mandatory reporting and onto what the survivor needs. An advocate explains how this works in practice:

You know, you don't bring paperwork, everything. Just talk and listen, and say, "Okay, we can do it tomorrow again... and then the person will open up. (3. 798-800)

This approach to DV advocacy promotes slowing down, a possibility mitigated by the mandatory reporting rule, which requires getting the information out to the survivor as quickly as possible in order to potentially alleviate the advocates' fears around her disclosing something reportable. In contrast to the other two groups, focus group three emphasizes opening up, rather than shutting down the relationship between advocate and survivor. And in contrast to the second focus group, this group focuses on building trust, rather than bemoaning the way the mandatory reporting policy potentially breaks it down.

Discussion. Research questions one and two asked how advocates responded to law enforcement/ICE collaborations and the discursive strategies they employed. In response to scenario one, the use of a decision tree heuristic was unsurprising, as it provides a useful ordering device when managing complex information, much like the multiple needs of the survivor described in scenario one. However, this ordering strategy can result in the loss of an intersectional perspective, particularly when advocates face agency requirements around mandatory reporting of child abuse.

Mandatory reporting of child abuse permeates all three of the focus groups' 
considerations of scenario one. However, the groups with mandatory reporting requirements respond differently from those without those obligations. These groups spend much of the discussion considering ways to subvert the policy, primarily by keeping the survivor from speaking with an advocate mandated to report child abuse. They describe referring her away from their agencies to other agencies, which in the case of Project UNICA, means denying her an entire program set up to meet the specific needs of Latina survivors. Avoiding the mandatory reporting policy may also mean that advocates must stop survivors from talking during a call or have them speak to someone who is not mandated to report, but may only speak English. The time and energy spent on these machinations get in the way of advocates' abilities to imagine innovative ways of responding to the particular bind undocumented survivors face through programs like Secure Communities.

The two groups' inabilities to consider alternatives to enlisting the state are not merely the result of not engaging in an intersectional analysis. Certainly the Latinafocused agency manages to hold the particular needs of the undocumented survivor at the center of their analysis, underscoring her justifiable fears around deportation, should the State become involved. Instead, this apparent incapacity to consider creative options indicates reliance on a particular mainstream DV discourse that places the CJS at the center, manifest through agency policies around mandatory reporting.

In the agency with no reporting requirements, advocates still consider whether a mandatory child abuse report should be made. However, this consideration has a different effect upon advocacy for survivors. Primarily it influences external referral 
decisions rather than directly affecting the advocates' relationships with survivors.

The relationship of proximity to work with undocumented survivors, investigated in research question three, appears to shape the participants' responses to undocumented survivors less than the agency's relationship to the criminal justice system. This association to the CJS emerges in response to scenario one in the differing mandatory reporting requirements present at each agency.

In the following section on the results of the second scenario, findings suggest that groups continue to display a reliance on the CJS, which affects the way in which advocates respond to dilemmas created by law enforcement/ICE collaborations. In response to scenario two, advocates consider whether to change the recorded message on their agency phones as well as the larger issue of referring undocumented survivors to law enforcement at all.

Just as in the previous section, I begin by presenting the scenario I read to each group, and then explain the responses from each individual group. I present quotes from the participants and summarize the findings in relation to each of the research questions.

The scenario is a description of policies typical to many domestic violence organizations. The recording recommending survivors call 911 is in place at all of the participating agencies. The advice to call 911 is included on one of the agency websites.

Scenario Two - Recommending 911. In many shelters, particularly at the administrative offices, the phone goes first to voicemail. The recorded message is generally something like the following:

"If you are in immediate crisis, please hang up and dial 911." Additionally, on many of 
the agency websites, there is the advice to call 911 if in immediate danger or to have your neighbors do so, if they are concerned about your safety.

Findings. During my preliminary research I called multiple service providers in my local area and with very few exceptions, first reached a recording that almost immediately instructed, "If this is an emergency, hang up and dial 911." This was also the advice given on several of the agency websites, particularly on their safety planning pages. This propensity for indiscriminate referral to 911 is very common on the initial recorded answer of most human service providers, from therapists to primary care physicians and dentists. However, this undifferentiated recommendation is not typical advocate practice when responding directly to crisis calls. In each of the organizations I contacted during my preliminary research, advocates were emphatic that they would never indiscriminately recommend that a caller contact the 911 line. Every advocate I spoke with said that survivors could expect to be treated differently by police, depending upon their social location. In each of the focus groups, advocates echo this same caveat throughout their discussions.

In response to scenario two each group begins by suggesting alternative messages to the indiscriminate recommendation of 911 described by the scenario. They describe their concerns with both altering the recorded message and leaving it as it is. Similar to the first scenario, all of the groups make use of a decision tree heuristic. When faced with complexity, the group deploys this structuring device, immediately simplifying the response - in this case distilling the dilemma to the question of whether the caller risks being killed or not. This framing of the problem has the effect of shutting down the 
discussion and preventing any further consideration of alternative messages.

Additionally, the groups' ability to come up with changes to the message appears to be affected by existing agency policies around collaborating with law enforcement. These policies emerge out of a mainstream DV discourse that keeps the criminal justice system (CJS) at the center of responses to DV. This comes from a fear of lethality that is predicated on an understanding of the undifferentiated potential dangerousness of all forms of domestic violence and of all abusers.

The research questions center on how advocates negotiate collaborations between law enforcement and ICE through focusing on their discursive practices. In the following section I describe the trajectory of the focus groups, recounting how they all begin with a complex description of possible responses to the scenario and then shifting to either/or responses with the introduction of the potential for lethality. I pay close attention to how this evoking of a lethal threat shapes subsequent discussion of the dilemma. Beginning with individual group responses, I then move to a summary of the pattern of responses that emerge in the combined groups.

Analysis. After the moderator reads the scenario, the first focus group immediately responds with a number of members stating that they would like to change the message. The advocates speak over one another until one advocate speaks louder, directing the discussion toward an individual analysis that generalizes the behavior of all women in crisis. She explains,

I don't think it's the worst thing. Because what I find is people in trauma, in really crisis situations, can't really think as clearly to do that... So, I get it why it would be a concern to put it on our voicemail, but at the same time sometimes people in crisis situations aren't thinking as clearly as you 
would expect them to. (1. 264-265; 269-271)

By bringing in the idea of individual deficits, the ways people in crisis lack the clarity needed to know how to negotiate the system, the group moves away from any structural critique, offering instead a homogenous description of women in crisis. The advocate pays credence to the particular needs of undocumented survivors, recognizing the necessity for considering the potential danger for undocumented survivors who call 911, but then dismisses this concern by evoking a generalized account of the irrationality of a person in crisis. In pursuing this line of reasoning, the group conflates all survivors, pathologizing them by focusing on their perceived inability to make decisions under stress. This way of thinking implicitly draws on a form of pre-feminist discourse that positions the survivor as helpless in her traumatic state (Dutton, 1998; Hughes \& Jones, 2000). This focus on individual helplessness runs counter to the broader DV discourse, as well as PWCL's feminist orientation.

The moderator attempts to direct the group back to thinking about undocumented survivors, asking if they would recommend a woman with tenuous immigration status to call 911. In response, there is no discussion of the undocumented survivor. Instead the group brings in the decision tree heuristic, evaluating the dangerousness of the situation by assessing if the caller will be killed or not. One advocate comments, "I would, (pause) if they were going to get killed"(1.277).

By invoking the possibility of lethality the advocate registers a collective anxiety inherent in DV crisis work - that by saying the wrong thing or making the wrong assessment, someone may end up dead. This notion of advocate responsibility is 
articulated by each group and mirrors my own experience as an advocate. The advocate goes on to explain, "I mean, we are talking to people in really severe domestic violence situations with unpredictable partners" (1.280-281).

Once again, crisis work is generalized, categorized by extremes and an inability to predict the behavior of the abuser. Interestingly, this unpredictability offers a kind of structure and modicum of control in that the advocates are granted a kind of moral imperative in proceeding: all decisions must be based on the assumption that there is a looming possibility of death should the advocate make the wrong recommendation. This also presumes that giving the correct advice will potentially save the survivor. The group members emphasize their role in determining the gravity of each call. One participant expresses this dilemma:

I mean, I think the issue is how dangerous is the situation? If they will be killed tonight and they are concerned they will be murdered with their kids, absolutely call 911, I don't care if you are deported at least you aren't murdered. (1. 306-308).

This statement serves multiple purposes. One effect of this invoking of lethality is that it immediately shuts down the discussion. At that moment there are murmurs of agreement, followed by silence. The statement is predicated on an assumption that the potential lethality of an individual batterer is more salient, and more likely, than the risks inherent to deportation. It also underscores the costs of using the either/or decision tree model as a means of resolving complexity. In applying this discursive strategy, it becomes necessary to create a worse this in order to make the problematic that appear reasonable. So, in assessing dangerousness, as soon as death is brought into the equation the scales shift and all actions are justified. 
This maintains the discussion at the level of the individual through the focus on generalized accounts of survivors and perpetrators of domestic violence. Each time the discussion begins to move toward a more complex understanding of the ramifications for different survivors of calling 911, someone brings the conversation back to the individual.

For example, one advocate asserts that some survivors might be afraid when hearing the advice to call 911 on the recorded message and suggests including more information. The discussion is immediately brought back to the idea that survivors in crisis share certain impairments. An advocate responds,

But it is different with people in crisis and DV, we get that all the time regardless of your ethnicity or race. (Murmurs of agreement.) Trauma affects your brain and your ability to make certain decisions ( 1 . 339-342)

This reasoning places decision-making as the responsibility of the advocate, who must base her recommendations on the potential for the caller to be killed. Accordingly, this justifies the continuing inclusion of the police, via maintaining the undifferentiated recommendation in the message, as the stakes are too high to consider alternatives.

At this point in the focus group, the moderator offers an example of organizations that no longer recommend undocumented survivors call the police. The group responds by bringing in a more complex way of thinking about undocumented survivors and law enforcement. Rather than focusing on individual survivors, the group addresses law enforcement, with one member stating, "that's a pretty big breakdown in law enforcement if you can't think of them as an ally" (1.376)

By placing the emphasis on law enforcement, rather than focusing only on the individual survivor, the group begins to explore a structural critique. An advocate 
comments,

'cause I don't think we're thinking that way, that the person making the report gets arrested too... And it gets messy there because I feel like because of this program (Secure Communities) we've lost that kind of individualized relationship with the cops. (1. 403-404; 409-410)

This argument highlights the effect of Secure Communities on both the survivor and the traditional alliances between domestic violence advocates and law enforcement. The recognition of the dissolution of these relationships leads the group back to considering the message at their own agency. One advocate says,

I think this is really, really powerful and important information to say, "this 911 call could lead to your deportation," despite what we've heard from certain sergeants." (1.434-436)

This intersectional turn is immediately challenged by another member of the group who returns to the element of fear, linking the decision by another agency not to recommend contacting the police to the tactics of abusive partners, who also warn survivors not to access law enforcement. She offers an assessment of the dilemma.

I feel for immigrant people the number one thing that is used to abuse them is fear of the law and not reaching out, so their abuser might have told them, you can't call 911, you are going to be deported and they're getting murdered and they are not calling 911, too. So I think the blanket statement that New York used sounds really empowering and awesome, but at the same time really scary, because people might actually need that resource and they're not using it. (1.439-446)

This reminder, with its evocation of "murder" and "scary" moves the discussion away from what could be done and back to insurmountable barriers. It also returns to the decision tree, with its either/or framework, positioning the CJS as the sole resource available to immigrant survivors who are constructed as either making use of it or being killed. 
As with the prior group, Project UNICA begins with an intersectional analysis of the effect of the message on an undocumented survivor. Different participants offer ideas for changing the message focused around how accessing law enforcement might affect someone who is undocumented. They describe a range of outcomes they might explain to the survivor. When the moderator reminds them that this is a recorded message and does not offer a chance for conversation, however, the group becomes silent. At that point an advocate speaks, stressing their inability to act, "I don't...I mean, I don't know if there's another option at this point" (2.464).

This response is met with silence. When the moderator asks if they can come up with any alternatives, the advocate goes on to describe the way in which many women on the crisis line are hesitant to access 911 already because of past experiences with the police or generalized fear around law enforcement. Rather than continuing with an intersectional analysis, she enlists the decision tree heuristic, saying,

But if their life's in danger, there's not much else that...you know, if it's a life and death situation It feels a little bit okay (2. 480-418)

This, too, is met with silence until the moderator asks the rest of the group for input. At that point the group is quite hesitant to imagine a different message. When prompted they describe giving survivors information about how to present themselves to the police as the victim of domestic violence. Even as this option is suggested, however, the advocate questions its efficacy, saying

But maybe I would feel a little less scared of calling 9-1-1, if I knew that I could use that vocabulary, and it would actually be effective in making me lower priority. Which is questionable if it even does that. (2. 508-510)

This distrust of the system is a theme throughout the rest of the discussion. The 
group offers a complex critique of the system, explaining that it is not the job of the survivor to figure out how to keep herself safe, nor is it the job of the advocates to remind the system how to work properly to ensure her safety. They describe multiple problematic issues, addressing specifics like a policy prohibiting native Spanish speakers at emergency services to answer 911 calls, and, more general issues such as how survivors are expected to navigate an impossible and oppressive system. Despite this line of criticism, the group continues to be unable to generate ideas for change at the agency level. There is no discussion of alternatives outside of reliance upon the criminal justice system to provide survivor safety.

As the group offers this systemic critique, the moderator brings in the example of agencies in other cities that have responded to systemic problems by no longer recommending undocumented survivors contact police. Much like their earlier response to changing the recorded message, advocates explain why this change is impossible. An advocate says,

Well, we have...I mean, we wouldn't be able to...we have partnerships with the city of Portland Police Bureau with DVERT. And the Portland Police Department Domestic Violence Reduction Unit, and it's part of the police that, really tries to work well with us. (2. 7349-749)

The introduction of agency partnerships with law enforcement immediately halts the larger systemic critique. This shift marks a return to the mainstream DV discourse that holds the CJS at the center and focuses on an individual level analysis. For the remainder of the focus group, talk revolves around changing individual officers and the possibility of being "inside making change within the Portland police" (2. 803-804). Additionally, reversing what had just been said about the problematic tendency to 
make the survivor responsible for insuring her own safety, the group returns to the idea of teaching survivors particular things to say when getting arrested. In this case an advocate describes how she safety plans with survivors, teaching them to scream "domestic violence" in English and Spanish, despite earlier group descriptions of the inefficacy of that tactic.

The advocates from Bradley Angle begin their consideration of the second scenario differently from the other two groups. Rather than discussing how to change the message, the group starts by noting the potential confusion around the message. One advocate recounts a story about a woman who heard the message telling her to call 911 and immediately hung up, thinking 911 was being called automatically. She had to wait many days before she could physically come to the advocate's office, as she was afraid to call the agency on the phone again. This anecdote sets the tone for the way this group discusses changing the message. The group employs an intersectional way of approaching the problem, considering the effect of the message on disparate marginalized groups. An advocate begins,

I know I changed mine a while ago to not say that, because I worry specifically about the LGBTQ population which is another population that has a history of institutional violence (3. 940-942)

Rather than bringing in the decision tree heuristic and describing the threat of lethality, as was the case in the other two groups, this group takes up the issue of institutional violence. An advocate adds,

Well, also too, I think that like in some communities, it's...it's institutionalized, they don't call 9-1-1. So I mean you hear that message and you're like, you know, "Screw you guy_-" (3.959-961) 
The advocate connects the choice of advocating 911 in the message with the practice of institutional violence. The group maintains this level of analysis, focusing on structural rather than individual issues. This focus leads the group to a rich discussion of the meaning of the crisis line. One advocate brings up the question of what it is that the crisis line is supposed to do. If the crisis line is supposed to be there for survivors to call if they are in crisis, why would there be a message telling them to call 911? Are survivors supposed to call the crisis line when in crisis or should they call $911 ?$ They say,

I think there's a lot of just misinformation out there about what crisis lines are able to do, or what we......you can and cannot provide. So I think that's maybe some history on why we say..."Call 9-1-1." I don't necessarily think we have to... (2. 1328-1333)

This acknowledgement of confusion and unintended consequences is in direct contrast to responses of the earlier focus group. In that discussion the confusion was located entirely in the survivor, who was described as unable to make decisions because of her traumatic state. In Bradley Angle's discussion, however, the confusion is located in the structure itself - in the agency practice of recommending 911. This practice is recognized as unclear, specifically for survivors who don't speak English as a first language and misunderstand the disparate uses of 911 (for the hospital, fire and police) and more generally, there is a lack of clarity around the function of the crisis line itself.

This discussion is different from Project UNICA's critique. Although both groups consider institutional practices oppressing marginalized survivors, the group never makes a direct connection to their own policies. In contrast, Bradley Angle advocates spend most of the discussion talking about their responsibility for implementing larger 
movement decisions, including the crisis line itself.

As this group tries to understand the role of the crisis line, advocates continue with a structural critique that includes their own agency's policy decisions. When the discussion moves to other topics, the group continues to bring it back to the question of what they are asking of survivors by offering a crisis line.

As the discussion of the crisis line continues, the group brings up possibilities for changing the message. They take up different ideas, discussing what they are able to provide and whether it matches up with the caller's expectations. As this line of reasoning continues, an advocate suggests the possibility of not recommending 911 on the recorded message. At this suggestion, a participant brings up the issue of agency liability, telling the story of a caller being severely injured while she was on the phone with her. The advocate reminds the group that the policy directing callers to enlist 911 is in place to mitigate agency responsibility for encouraging people to call them when they are in crisis in the first place.

Although the evocation of potential harm to a survivor does not appear to have the same weight as in the other groups' consideration of lethality, it has a similar effect. The discussion of alternative messages stops and the group moves instead to the idea of training individual officers and workers at DHS. The larger systemic critique continues, but there is no concurrent analysis of their own agency's policies or any ideas for working outside the confines of the Criminal Justice System. Instead the focus is on minor reforms within the system in much the same way as the advocates of focus group two discussed trying to work to change individual officers within their DVERT and 
DVRU partnerships.

Discussion. Similar to the groups' responses to the first scenario, the arc of the focus group discussions is shaped by agency policies around collaborating with law enforcement. Enlisting the police in response to fears around abuser lethality and direct collaboration with the police, for example, in participation in a Domestic Violence Enhanced Response Team (DVERT), emerge as central motifs. PWCL is able initially to imagine a range of ideas for the recorded message recommending callers enlist 911, described in the scenario. These suggestions stop abruptly with the introduction of concerns over the risk of death for callers. With the initiation of this theme, respondents turn to a DV discourse focused on individual survivors, constructed as unable to care for themselves due to the effects of trauma. Project UNICA offers a complex analysis of larger social systems but remains unable to make any inroads into what to do at the agency level. Additionally, despite the structural critique, all ideas about making change are described at the individual level via interventions with individual officers and sensitivity trainings for DHS workers.

During the focus group, advocates from Bradley Angle pursue an intersectional analysis throughout, considering multiple lines of oppression and connecting them to their own policy decisions. They are able to work creatively until discussion abruptly stops with the introduction of the agency's potential liability for harm that might come to a survivor who calls the crisis line. At this possibility, their responses begin to mirror those of the other groups, including the focus on individual-level changes and group resignation to maintaining the existing 911 recommendation. 


\section{Overall Summary of the Findings}

The first scenario describes a crisis call in which an undocumented survivor presents numerous issues, including potential child abuse by her abusive partner. In response to this scenario the two groups with requirements that some or all advocates report suspected child abuse focus primarily on mandatory reporting, framing all responses within the limitations imposed by that policy. Despite conversation revolving around how to subvert the policy through controlling the individual survivor's behavior, through keeping her from speaking with specific advocates or contacting certain organizations, the policy itself is never explicitly questioned. However, there are clear indications that the groups understand the problems inherent to indiscriminately making a mandatory child abuse report, particularly if the person reported is undocumented.

In the group with no agency reporting requirement there is a more overt critique of mandatory reporting and the risks it carries for undocumented survivors. However, even in this group, there is no discussion of alternatives. The discussion remains at the individual level, focused on keeping the individual survivor from incriminating herself via limiting access to services in which there are no mandatory reporters. The groups' inabilities to consider policy changes seem to reflect the centrality of the mainstream domestic violence discourse with its emphasis on the criminal justice system.

In the second scenario, the three groups are initially able to consider potential changes to current agency practices around both indiscriminately and intentionally recommending undocumented survivors call 911 and enlist law enforcement. Once the issue of potential lethality is raised, however, discussion shuts down in each of the 
groups. At that point, two of the three groups revert to a decision tree heuristic, simplifying the discussion. They subsequently abandon any consideration of alternatives to the criminal justice system for providing safety to callers on the crisis line. While the third group does not employ the heuristic immediately, and is able to engage in a discussion about both movement and agency policy decisions, the focus of their discussion ultimately ends up back on the individual level describing, for example, how an individual survivor's behavior can be modified within the existing system.

Throughout all of the focus groups, participants make use of particular understandings of domestic violence work that are framed by a larger domestic violence discourse - one based on assumptions about the relationship between domestic violence crisis work and the criminal justice system. This discourse centralizes the role of the CJS, prioritizing criminal responses to DV over more complex systemic possibilities outside the legal realm (Harvie \& Manzi, 2011).

In each of the groups the use of this discourse varies, depending on their partnerships with the CJS. The agencies with mandatory reporting requirements primarily enlist a mainstream DV discourse that focuses on criminality and the criminal justice system. The third agency is better able to engage in an alternative, intersectional analysis that does not reject using the CJS, but focuses primarily on building relationships and providing services to survivors.

Finally, contrary to my assumptions entering the project, proximity appears to have less effect on shaping group consideration of work with undocumented survivors than do agency policies around collaborating with the criminal justice system, regardless 
of the use of an intersectional analysis of survivor needs. Throughout discussion of both scenarios, the group most proximal is able to maintain an intersectional analysis, keeping undocumented survivors as the central focus. They also are the only group to have prior knowledge of Secure Communities and its effect on undocumented survivors. Despite this awareness, they are the least able to consider alternatives to both mandatory child abuse reporting and agency policies around recommending 911. This group is made up entirely of mandatory reporters and is the only agency to partner directly with the Portland Police Department.

In response to both scenarios, the group from the agency with no mandatory reporting requirement and no partnership with Portland Police Bureau is more able to sustain a consistent intersectional analysis and explore the most complex consideration of alternatives to both their own agency and larger DV movement practices around working with undocumented survivors and the Criminal Justice System. 


\section{Chapter Five: Conclusions}

This dissertation began with a problem that emerged out of my practice as both an advocate in the field of domestic violence and an immigrant and workers' rights activist. As an advocate on a coordinated community response (CCR) team I worked for two years in direct collaboration with law enforcement and the district attorney's office. I was struck by how the voice of the grassroots organization was subsumed under the national politics of adjudication, prosecution and incarceration. At times, advocating for marginalized women (generally women of color who experienced the system oppressively) to work outside of the CJS was considered a transgression and in opposition to the long-term goals of the group. The tendency to adopt this stance was not because members of the team were "bad" or overtly engaged in some kind of concerted effort to harm the DV survivor. To the contrary, I found that the representatives of the CJS were committed to providing safety to survivors and were generally sensitive to their needs, within the parameters of the criminal justice system. Any position outside this framework was constructed dangerous - for survivors, their families, members of the CCR team, and for the larger community.

This pairing of the criminal justice system and safety is not limited to DV work but occurs in many national policies, especially after the U.S. bombings of September 11, 2001. Across the United States, there has been an increase in criminalization, justified in the name of safety (Andreas \& Nadelmann, 2006). In addition to increased forms of social control through legislation such as the US PATRIOT Act, the criminalization of immigration has led to increased detention, incarceration and deportation of 
undocumented people as well as the massive militarization of the southern U.S. border.

As an activist, I followed this shift on border politics closely. Prior to living in Oregon I spent much of my life in the Southwest desert, and lived in Tucson, Arizona for many years. Border issues there are particularly salient and I felt an acute border tension between my work around domestic violence and my activism around worker rights and border politics. I carried this interest into my life and work in Oregon. During the late 1990s and early 2000s, I witnessed raids and deportations and heard stories of people dying in desert crossings. In both Arizona and Oregon, Latina survivors of domestic violence told me their own stories of difficult border crossings, both in leaving their home countries and in escaping domestic abuse. They described a growing distrust of the State and an unwillingness to access help on many levels. In addition to eschewing the use of 911, survivors gave accounts of families refusing the public health system and opting not to send their children to school, for fear they would be separated from their families by detention and potential deportation.

At the same time this pressure on Latino families was escalating, I witnessed no concurrent policy changes at the domestic violence agency where I worked. Despite discussion among advocates of the increasing limitations to existing services for Latina survivors, there appeared to be no sense of how to respond to this challenge among mainstream DV providers. As I left my advocacy work to return to school, however, culturally specific programs began to become more common with the promise of more relevant and effective services.

I continued to consider these problems as I began my study of community 
psychology. I was drawn to this field in part for its emphasis on an ecological perspective, which looks at whole systems, considering multiple levels of analysis (Levine, et al., 2005). Rather than beginning with a focus on the individual, inquiry centers on understanding the social context and the dialectical relationship between the forces and pressures of the context and individual dynamics within that setting (Perilla, 2006).

I brought insights to this project formed out of the integration of my practical experience and my theoretical understandings of group process derived from community psychology. These areas of praxis shaped the way I created and implemented the study, as well as in how I interpreted the results. In this dissertation I examine how advocates navigate dilemmas presented in their work with undocumented survivors. DV advocates face multiple and often conflicting pressures as they negotiate the complex dilemmas that arise in responding to crisis calls. This complexity is especially evident in work with undocumented people in situations where enlisting the criminal justice system presents risks that are difficult to assess. It is difficult to evaluate a low probability but unchangeable risk, such as lethality, with deportation, which has a higher probability. While devastating, the risk of deportation includes some possibility for mitigation, through legal processes.

In this dissertation project the research questions focus on understanding how advocates respond to law enforcement/Immigration and Customs Enforcement collaborations, the discursive strategies advocates employ in managing the difficulty inherent to work within this context, and whether the group's location affects the 
complexity of their response. Lewin (1997) suggests that by understanding the barriers and forces compelling groups confront as they work through a set of problems it is possible to comprehend why it is that individuals and groups behave the way they do. By introducing scenarios that foreground acute border tensions, the places of conflict that arise when contradictory claims must be negotiated, we can identify the forces compelling DV advocates in this work and better comprehend how decisions are made at crisis moments, which could offer a direction for making change.

In each focus group, advocates were presented with information about collaborations between law enforcement and immigration and customs enforcement. They were subsequently asked to incorporate this information into their response to a crisis call involving an undocumented survivor. In addition they were asked to consider agency and movement policies about the recommendation survivors contact law enforcement through the 911 emergency number.

Each effort at integrating the new information about law enforcement-ICE collaborations into their practices produced acute border tensions, requiring advocates to manage multiple sites of alliances, including the survivor, the agency, the larger system and themselves. Advocates grappled with the question of how to assist a survivor without causing additional harm to her and staying within the parameters of agency policies. In both the scenarios, the introduction of ICE mandates complicated standard practices involving the State for providing safety for both the survivor and her children.

Throughout all three focus groups, advocates made use of an intersectional perspective in considering multiple axes of oppression potentially experienced by 
undocumented survivors. In creating this study, I asked about the relationship between agency proximity to working with undocumented survivors and the group's decisionmaking process. Based on my preliminary research, I reasoned that advocates in groups more proximal to the phenomenon would use a more intersectional perspective in working with undocumented survivors. Further, I assumed that an intersectional perspective would be a catalyst for imagining new ways of confronting the dilemma presented by law enforcement collaborations with ICE. However, despite advocate's continual consideration of race, class, gender and other dimensions of social location, advocates in two of the three focus groups were unable to imagine alternatives to enlisting the State when working with undocumented survivors. In enlisting the concept of border tensions, I sought to work through the forces that shaped advocates' decisionmaking processes.

Responses to the two scenarios indicate that advocates bring with them a complicated relationship to the criminal justice system that affects their decision-making. In response to the first scenario, groups from agencies with mandatory reporting requirements end up focusing on compliance with the State, despite their intersectional and analysis of domestic violence (right?) Advocates express a profound reluctance to indiscriminately refer survivors to law enforcement, yet appear to see no alternative to engaging the State in response to perceived violations of mandatory reporting policies. This compliance, while understandable in the context of agency policies, contradicts repeated assertions by advocates that vulnerable populations seeking services could be disproportionately harmed through enlisting the police. 
In negotiating the paradox inherent to recommending survivors seek help from an institution they recognize to be potentially harmful, advocates in the focus groups move from a complex analysis to a simple one by employing a discursive strategy that reduces ambiguity. The decision-tree practice is quite effective in distilling complex information into a simplified, forced choice series of yes/no questions. This practice may impede intersectional analysis and creative thinking, however, in response to the dilemmas that arise around crisis intervention.

In addition to enlisting a decision-tree process for managing border tensions, advocates in the focus groups make use of a range of domestic violence discourses to negotiate the contradictions around safety in crisis work. In response to the scenario on the use of the 911 emergency number, discussion of safety in all three groups focused on lethality. Participants note that most of the calls coming into the crisis line are made when a survivor is not in actual danger of being assaulted. Unprompted, participants tell similar stories of calls in which the survivor was in immediate danger. In each account the abuser is beating on the door, threatening the caller, even though discussion in all groups included clarification that such calls are exceedingly rare. In one group, after telling this prototypical story, the advocate explains that this even happened four years ago at another agency. In another group, the advocate offers this same story, first explaining that it took place somewhere else and that she had never experienced it at her current agency. Despite this admission, the advocate uses this example to explain why the agency would be liable should they remove the 911 call message. She ends her story by saying, "That said, we don't really get any crisis calls (laughs). Like ever." (3. 1369) 
This apparent disconnect between DV dangerousness and the advocate's experience on the crisis line suggests that anxiety and group defenses operate in the field in ways not fully recognized. By examining the larger DV discourse it is possible to understand better the contradiction between the expectation of dangerousness and the reality of crisis work.

Advocate responses to both scenarios emerge out of a discourse of domestic violence that places the criminal justice system at the center. This orientation is, in turn, dependent upon a discourse of fear. In all the focus groups, the advocates are able to work through the scenarios, offering ideas that consider the particular needs of an undocumented survivor until they are stopped by agency policies and fear of lethality both of which are embedded within an uncritical acceptance of a relationship between the movement and the CJS. This, in turn, is part of a larger discourse of fear, which is reflected in indiscriminate reliance upon the criminal justice system.

In his work around mass media representations of terrorism, Althiede (2003) describes a discourse of fear, an orientation toward the world which is manifest in anxiety that carries with it inevitability that we are almost-already victims of crime. An effect of the discourse of fear is that rare events begin to be assumed as common and unavoidable. It is not a matter of if we will become victimized but when, despite the rate of violent crimes continuing to drop all over the United States (BJS, 2012; Pinker, 2011).

Domestic violence work brings another dynamic to this discourse of fear. The work sensitizes advocates to the risk of violence. Stories of violence permeate the literature, the agency handouts, and the direct work advocates do with individual 
survivors - both in-person and on crisis line calls. And this anxiety related to potential lethal violence carries real validity. Domestic violence homicides account for one third of all the murders of women in the United States. However, like all violent crime in the U.S., rates of intimate partner violence have decreased substantially, dropping $64 \%$ since 1994 (BJS, 2012). However, it is important to note that this reduction has not occurred in the same way for domestic violence homicide. While DV homicides are down $60 \%$ since 1994, this is largely due to a decrease in the rate of abused women killing abusive men. The decrease in the rate of DV homicides for women has only dropped 7\%. However, this change, though small, represents a decrease in what was already an exceedingly rare event (Wells, et al., 2010). It is more likely for a person to die from illnesses, car accidents, or suicide than from homicide.

While domestic violence homicide is a real and present danger, it remains a relatively infrequent occurrence. And yet the expectation that domestic violence will be deadly influences both policy and practice, some of which may have the unintended consequence of putting survivors in additional danger. For example, the common practice of hiding DV shelters is defended as necessary for resident safety. This policy means that survivors must separate from supportive family and friends, isolating themselves, thus becoming especially vulnerable just after leaving their partner. This is standard practice for a majority of the shelters in the U.S. despite there being no data linking the policy to decreased violence or lethality (Haaken \& Yragui, 2005; Rempe, 2000). In a similar way, mandatory arrest laws and the policy of indiscriminately recommending survivors call 911 are assumed to provide increased safety for survivors, 
though their efficacy remains equivocal. For example, Iyengar (2009) finds that in states with mandatory arrest laws, DV homicide has increased.

There are strategies with proven efficacy. For example, danger assessment tools can be an important first step in determining an increased likelihood for DV homicide (Campbell, et al., 2009) but do not appear to be commonly used in the agencies I queried. The practices of separating partners that come out of exposure theory can lead to decreases in homicide, in, specific populations (Dugan, et al., 2003). However, the way separation is implemented, via orders of protection for example, can have the opposite effect, creating fewer, but more highly charged and potentially dangerous interactions between intimate partners (Reckdenwald \& Parker, 2010).

Considering these institutional contradictions, it is not surprising that advocates express ambivalence around enlisting law enforcement and communicate a contradictory relationship to the CJS. This ambivalence can be seen in the way advocates describe subverting the system in the first scenario and using it in the second. Advocates in all three focus groups reach an impasse when considering mandatory reports of child abuse and abusers' potential lethality. In the first instance, the question centers on whether a report must be made, and in the second on whether or not the caller is likely to be killed. Each of these sites of concern marks a moment in which the larger CJS is enlisted. In one case the focus is on subverting the system, while in the other the system is employed.

In regard to both scenarios advocates articulate suspicion of the system, describing its inherent flaws, especially for marginalized populations. When discussing making a mandatory child abuse report, however, the advocate response revolves almost 
entirely around ways to get around the requirements of the system, through keeping survivors from relating things that might be reportable, to referring them to other agencies where there are not mandatory reporters.

Conversely, the fear of lethality manifests itself in turning to the police as a defensive response. In this case, the criminal justice system becomes the ally and protector, despite advocate recognition of its inherent flaws and potential dangerousness to different populations. The participants seem able to hold two contrary positions simultaneously, much like the advocate in my preliminary research that said when I asked if they referred callers to the police, "I would not necessarily recommend someone call 911. Definitely the police are our strong allies." 


\section{Advocate's relationship with the \\ Criminal Justice System (CJS) plays out in two ways:}

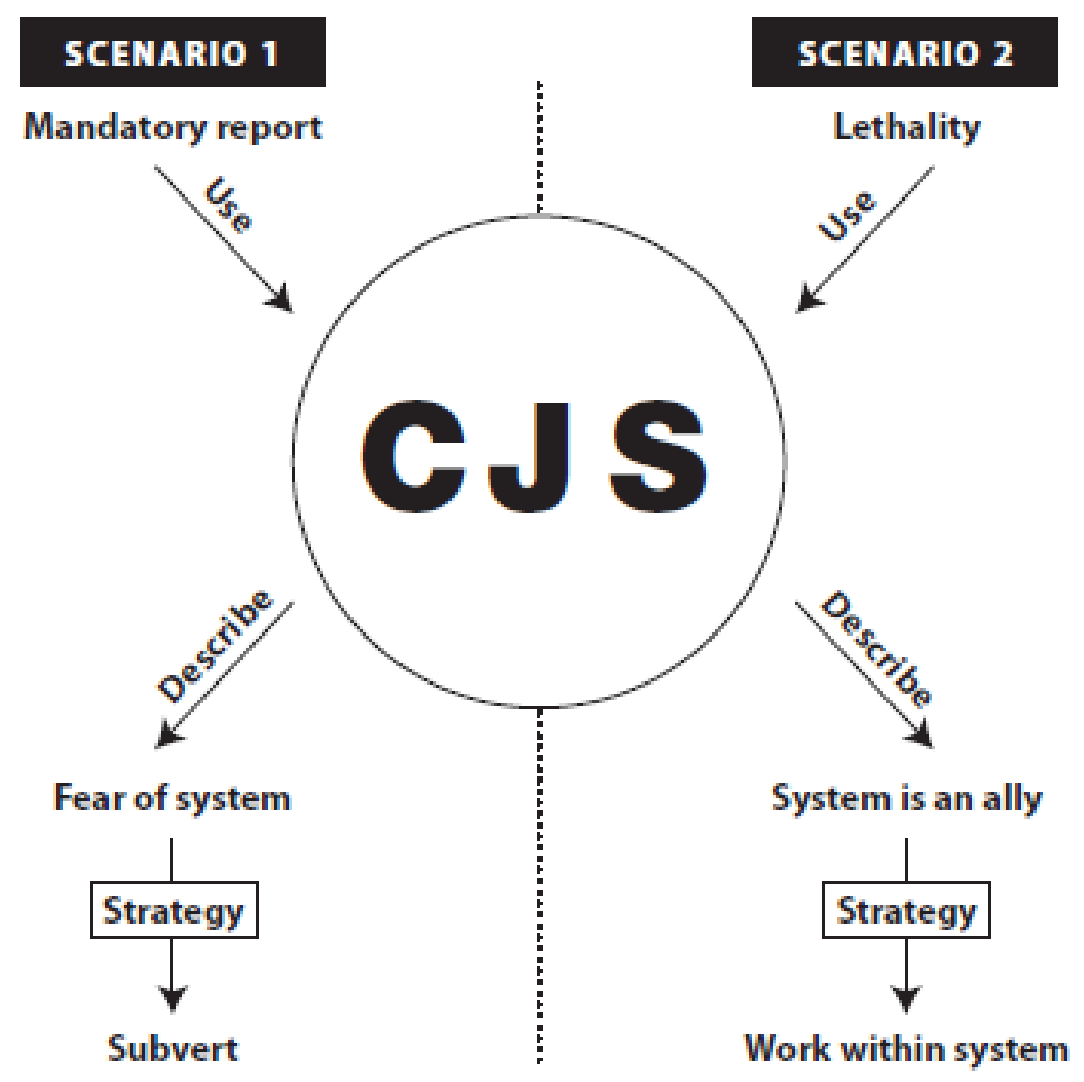

\section{Figure 1}

Advocates' ambivalence around working with law enforcement is reflected in all three focus groups. This conflict emerges in the discussion of the first scenario. In the two focus groups with mandatory reporting requirements, advocates attempt to resolve this conflict by describing how they would work with particular officers they knew (group one) or work from within the system via DVERT partnerships to train officers to be more sensitive to DV issues (group two). In the third group, with no agency reporting requirements, participants explain how they are affected by the policy, specifically how it 
limits referral possibilities for survivors. They describe an increased burden on their own agency, within a context of diminishing services for survivors.

Additionally, my expectation that agency proximity to undocumented survivors would lead to more complex decision-making was not supported by the findings of the study. Findings suggest that agency collaboration with the CJS are more determinant of responses to border tensions in the field. Advocates in the Latina-focused agency describe being bound by their agency's connection to the CJS, unable to imagine ways of making change that do not rely on the CJS as the primary response to survivors seeking services, despite the advocates' recognition of the potential dangers raised by enlisting law enforcement. Perhaps this can be explained in part because the group is one that experiences threats and insecurities from the dominant system, which can serve as a barrier to feeling able to make systemic change or even address the system at all. The consequences of questioning the dominant paradigm are greater for marginalized groups who already are cast as outsiders and subject to racist beliefs about cultural acceptance of abuse (Sokoloff \& Dupont, 2005).

Another way of explaining the responses at the Latina-focused agency is that advocates confront a larger struggle for legitimacy. The group's alliance with the CJS might be carry with it a promise of conformity to the rule of law and greater security for the Latino population. Much like the early battered women's movement's strategic alliances with the criminal justice system, coordination with the State might be seen as offering more powerful sources of help than that offered by grassroots organizations.

The findings in this dissertation suggest that reliance on the criminal justice 
system diminishes advocate's abilities to consider creative responses for service provision to undocumented survivors, regardless of their use of an intersectional perspective.

Participants adopt an intersectional perspective throughout the focus groups, considering the multiple constitutive factors that come together in undocumented survivor's lives. However the findings indicate that an intersectional analysis of survivor needs is a necessary but not a sufficient condition for progressive crisis work. The findings are part of a larger body of literature calling for reconsideration of the role the CJS plays in DV service provision (Richie, 2008; Smith, 2008; Sokoloff \& Dupont, 2005).

Parker (1992) describes the difficulty people face in trying to work outside the dominant discourse. Creating an alternative DV discourse requires (re)framing the CJS as only one of myriad tools available to the survivor seeking services. Rather than uncritical recommendation that a survivor call 911, for example, strategies for educating callers on the possibilities inherent to engaging the State must be developed. This could be as simple as saying something like "If you are in danger, call 911. As a reminder, current laws require that in the case of arrest, immigration will be notified, as well".

The findings reported here suggest that domestic violence agencies committed to structural change benefit from partnering with agencies outside traditional DV services. Advocates in all groups describe partnerships outside traditional DV services, but explain that they feel unable to develop alternative collaborative relationships because they are so over-extended by their agency work. Agencies are under-staffed and many DV agencies are closing, often due to lack of funding. This attrition places a greater burden on the remaining agencies. At the same time the needs of survivors increase. In 2011, local DV 
agencies reported a $4 \%$ increase in calls for help from survivors of domestic and sexual violence (OCADSV, 2013).

One way of achieving the aim of structural change would be through creating coordinated community response (CCR) teams that are reflections of the larger community, rather than replications of the criminal justice system. Instead of forming CCRs that revolve around law enforcement, DHS, and the DA's office, a truly effectual CCR would enlist multiple community partners, including faith communities, neighborhood associations, Rotary-like clubs, immigrant rights groups, healthcare providers - including mental health, and others. By partnering with the community DV agencies would move from their liminal positions, hiding on the margins of community (Wallpe, 2010).

In the final section I explain some of the challenges to this study, including generalizability. I follow this with suggestions for additional research and practice.

\section{Limitations to the Study and Possibilities for Future Research}

One limitation of the study centers on the follow-up responses with agency directors. In the case study section I was able to ask two of the three groups follow-up questions about their practices around advocacy and training. Two of the groups provided volunteer and staff training manuals and spoke with me about their agency's political orientation and history. The remaining group did not respond to repeated phone calls and emails. This problem with follow-up limited my ability to gather the same level of detail about this agency's orientation to DV work as I was able to achieve with the other two agencies. In addition, this group did not fill out the demographic information 
following the focus group so I was unable to include more extensive information about the participants.

Another limitation relates to sample size and generalizability. This study is based on a sample of three focus groups made up of twenty six participants, held with advocates from three agencies in a large urban area in the Pacific Northwest. It is therefore difficult to generalize my findings to other populations or settings. In this study, I sought to provide readers with an opportunity to assess the possibility for inferential generalization - how findings of studies can be applied to other settings or contexts (Lewis \& Ritchie, 2003). This concept suggests that findings much be reported in enough detail and with sufficient description of the context of the study for readers to decide if the findings can be transferred to other contexts. In this study, I have included extensive description of the participating agencies as well as the larger framework around domestic violence and immigration. In addition to providing quotes from the focus groups within the findings, I have appended an entire transcript of one of the focus group transcript (see appendix F). Potential readers include academics, advocates and activists engaged in work with survivors of domestic violence and/or immigrants. These might include those doing policy work or creating multidisciplinary teams and working in direct service.

Additionally, in this study I consider the concept of provocative generalizability as described by Michelle Fine (2006). Provocative generalizability refers to the way in which a piece of research can provoke readers to make change and to imagine what could be, rather than remaining in the current paradigm - to "rethink and reimagine current arrangements (Fine, 200p. 98). Provocative generalizability also evokes Lewin's (1997) 
question, "What shall we do?" (p. 143) by challenging researchers to create projects that compel the readers to imagine transformative responses to empirical findings.

As I wrote this report I kept a quotation attached to my computer from a conversation I had with the executive director of one of the participating agencies. She had just returned to DV work after taking a fifteen-year break. When I asked her what it felt like to be doing this work again, she said that she was struck by the way that we (the DV movement) are still engaged in the same discussions we were having when she left many years ago. She asked, "Why are we still having the same conversations?" (personal communication).

The findings around proximity speak to the way in which DV activists continue to struggle with the same problems faced by those in the earlier movement. In my study, I expected the group with the closest proximity to undocumented survivors to bring the most complex analysis to the conundrum created by law enforcement/ICE collaborations. However, these advocates were least able to imagine alternatives to engaging the CJS. This group also had the closest proximity to the CJS. Perhaps it is this relationship that is more important in determining the propensity for advocates to come up with creative solutions to challenging problems faced by marginalized survivors. This insight leads to imagining a restructuring of the relationship between the DV movement and the CJS through challenging current assumptions. These include the belief that the relationship between the CJS and the DV is benign and that the CJS is the only way of providing safety to survivors and their families.

This dissertation was conceived as an action research project. As such, it fulfills 
an aspect of Lewin's articulation of action research through providing a description of the forces acting upon groups - in this case the way alliances with the criminal justice system shape the decision-making processes of the groups as they consider new collaborations between law enforcement and ICE. A next phase in this action research project might enlist Lewin's change model in focusing on alternatives to CJS alliances. A research project could be developed in collaboration with the creation of a community focused coordinated response. One element of the research would be to test the groups' efficacy in creating more safety for survivors, which could be done both qualitatively and quantitatively. Another direction might be to measure the use of an intersectional orientation systematically, looking at whether other community members employed this perspective as well as the relationship of an intersectional perspective to the trajectory of the team.

Another research direction might focus on agencies that do caution undocumented survivors on collaborations between police and ICE. Interviews with members of these agencies could help elucidate what is different about these agencies and why they established these policies, as well as what alternatives they recommend to undocumented survivors. Information could also be gathered as to any cases of intimate partner homicides with their clients and the rate of deportations, an understudied phenomenon particularly in relation to DV (Reina, Lohman \& Maldonado, 2013).

Finally, this work is part of a larger body of research looking into the effects of fear of crime. Even as crime is dropping all over the U.S., people describe increased 
levels of fear. These are associated with multiple public health issues, including both mental and physical health (Jackson \& Stafford, 2009). DV crisis workers hear daily accounts of dangerous situations, as survivors recount stories of their experiences. This can lead to a perception of dangerousness within advocates' daily work. However, the reality is considerably more mundane, as much of what advocates do involves assisting survivors in accessing services, such as housing and financial assistance. The findings of this study suggest that perceptions of dangerousness provide a stumbling block to more complex problem solving. It would be interesting to see if something as simple as providing advocates with detailed information about actual dangerousness would be sufficient to bring about change in their decision-making process.

The findings from this research could also be used to create a workshop for DV advocates from multiple agencies where they explore more deeply the costs and benefits of engaging with the CJS. Starting from the insights gained from this study, advocates could imagine ways for responding to DV that take place outside the CJS. This could also offer a space for collaboration with other advocates engaged in similar practices to think strategically about ways of responding to DV that make use of alternative models, including such things as restorative justice and community accountability strategies for increasing safety for survivors (Arnold \& Ake, 2013; Smith, 2006).

Fine et al. (2004) describe the responsibility of the researcher engaged in a participatory project to consider both the potential and actual effects of her work in all aspects of the process. Although this is more of a researcher-centric than participatory project (Hamberger \& Ambuel, 2000), this insight remains true given the context of this 
dissertation project. Domestic violence advocacy creates a small community of people engaged in work that is loaded, both symbolically and practically, with tension and urgency. It is not surprising that metaphors of war and battle resonate strongly with advocates (Haaken, 2010). The images of conflict and battle fatigue embraced by advocates creates a strong alliance among people doing that day-to-day work, who become comrades in the struggle to support individual survivors and address larger structural violence against women. This alliance can manifest itself in a long-term commitment to domestic violence advocacy work.

Many advocates in this study have been in the domestic violence field for a long time, in multiple positions and in different agencies. Many advocates involved in this research know each other well, despite working in different settings. When the data was gathered I removed any names and overtly identifying statements from any public data. However, I recognize that it is impossible in such small groups to truly separate the person from the utterance. Because of this restriction, it is impossible to offer any real confidentiality. Consequently I have chosen to make this process as transparent as possible. In my conversations with the executive directors of all the agencies, I explained the research trajectory and described the agencies chosen to participate and the reasons for this decision. Additionally, I worked closely with an advisor who has many years doing domestic violence research and has worked directly with several of the agencies. She has worked diligently with me as throughout the research process.

Stein \& Mankowski (2004) describe the need for researchers to consider the effect of their research findings on the participants, both now and in the future. As I performed 
my analysis and wrote my discussion I tried to maintain consideration of what was at stake in this project. Hidden within these theoretical constructions are the lives of real people. The discursive object is an undocumented survivor of domestic violence $-\mathrm{a}$ woman who left her home, most likely crossed a desert, enduring unimaginable hardship to come to a country that wanted only her labor, if that. Simultaneously she is the victim of domestic violence who has experienced violence from the hands of her partner. As a researcher I did not want to lose her subjectivity in the jargon of theory or the objectivity of analysis. Similarly, I wanted the same for the advocates. Each day these women perform complicated jobs, involving endless frustration and requiring boundless compassion for very little compensation. I wanted to honor their struggles, not simply critique them.

This work is important on multiple levels. First, it offers a means of examining how groups with a shared identity navigate a common social problem. Second, it foregrounds the difficulties for groups in working through complex decisions based on competing mandates. One of the key concepts in this study relates to the decision-tree heuristic as a strategy for simplifying decisions, especially in cases involving potential child abuse or lethality. The balance between benefit and harm which make decision processes like this so challenging can be seen in other instances, ranging from large scale policy decisions to one-on-one interactions.

In analyzing how advocates talk about the intersection of immigration, domestic violence and the State it is possible to understand the processes through which groups manage highly charged issues, such as safety and lethality. Findings from this study 
indicate that when presented with complicated questions, groups rely on a heuristic that effectively simplifies complex and emotionally evocative information. In losing complexity, however, they potentially limit consideration of less manageable, but perhaps more effective strategies for approaching the complex needs of undocumented survivors.

This work is significant for the way it calls attention to a current social problem affecting a historically oppressed minority in the United States. This project potentially creates space for advocates to come together as an epistemic community (Assiter, 2000), linked through a common commitment to advocacy for people experiencing domestic violence and dedicated to systemic social change. The DV movement continues to rely heavily on the CJS, despite its disparate effects on communities. This reliance on law enforcement continues to be accepted, at least in part because of concern that questioning the trade-offs would mark a return to an earlier time when women experiencing violence were, at best, ignored by the CJS. I believe that the ceaseless work of the DV movement has created space for critically assessing dependence on the State and the costs to minority communities.

In his work on group process, Kurt Lewin describes the interdependences of human life. A group exists when those within its fold recognize that their fate depends upon the fate of the group as a whole (Lewin, 1997). By (re)imagining who it is that makes up the DV "group" it will be possible to recognize and access our constitutive power, setting in motion the possibility for progressive change for all women. 


\section{References}

Allen, N., Bybee, D., \& Sullivan, C. (2004). Battered women's multitude of needs: Evidence supporting the need for comprehensive advocacy. Violence Against Women, 10, 1015-1035.

Andreas, P., \& Nadelmann, E. A. (2006). Policing the globe: Criminalization and crime control in international relations. Oxford: Oxford University Press.

Arnold, G., \& Ake, J. (2013). Reframing the narrative of the battered women's movement. Violence against Women, 19, 5, 557-78.

Assiter, A. (2000). Feminist epistemology and value. Feminist Theory 1(3), 329-45.

Bacon, D. (2008). Illegal people: How globalization creates migration and criminalizes immigrants. Boston: Beacon Press.

Bennett, L., Riger, S., Schewe, P., Howard, A., \& Wasco, S. (2004). Effectiveness of Hotline, Advocacy, Counseling, and Shelter Services for Victims of Domestic Violence: A Statewide Evaluation. Journal of Interpersonal Violence, 19, 7, 815829.

Bhuyan, R., \& Senturia, K. (2005). Understanding domestic violence: Resource utilization and survivor solutions among immigrants and refugee women: Introduction to special issue. Journal of Interpersonal Violence, 20, 895-901.

Bilge, S. (January 01, 2010). Recent Feminist Outlooks on Intersectionality. Diogenes English Language Edition-, 225, 58-72.

Bilge, S., \& Denis, A. (2010). Introduction: Women, Intersectionality and Diasporas. Journal Of Intercultural Studies, 31(1), 1-8.

Boog, B.(2003). The emancipatory character of action research, its history and the present state of the art. Journal of Community \& Applied Social Psychology, 13, 6.)

Bograd, M. (1999). Strengthening domestic violence theories: Intersections of race, class, sexual orientation, and gender. Journal of Marital and Family Therapy, 25(3), 275-289.

Braun, V., \& Clarke, V. (2006). Using thematic analysis in psychology. Qualitative Research in Psychology, 3(2), 77-101.

Brown, L. M., O'Brien, K. M, and Salahuddin, N. M. (2007). Are shelter workers 
burned out? An examination of stress, social support, and coping. Journal of Family Violence, 22, 465-474

Buzawa, E. S., \& Buzawa, C. G. (2003). Domestic violence: The criminal justice response. Newbury Park, Calif: Sage Publications.

Bybee, D. L, \& Sullivan, C. M. (2005). Predicting re-victimization of battered women 3 years after exiting a shelter program. American Journal of Community Psychology, 36(1/2), 85-96

Campbell, J.C, Webster, D.W, \& Glass, N. (2009). The danger assessment: validation of a lethality risk assessment instrument for intimate partner femicide. Journal of Interpersonal Violence, 24(4):653-74.

Coker, D. (2005). Shifting power for battered women: Law, material resources, and poor women of color. In N. J. Sokoloff (Ed.), Domestic violence at the margins (pp. 369-388). New Brunswick, NJ: Rutgers University Press.

Cole, E. (2009). Intersectionality and research in psychology. American Psychologist, 6, 170-180.

Collins, P. (1991). Black feminist thought: Knowledge, consciousness, and the politics of empowerment. Routledge, New York.

Cottone, R. E. (2000). Ethical Decision-Making Models: A Review of the Literature. Journal Of Counseling \& Development, 78(3), 275.

Crenshaw, K. (1991). Mapping the margins: Intersectionality, identity politics, and violence against women of color. In Crenshaw, K., Gotanda, N. Peller, G. \&Thomas, K. (eds.) Critical race theory: The key writings that formed the movement. New York: NY, 357-383.

Daniels, C., \& Brooks, R. (1997). Feminists negotiate the state: The politics of domestic violence. Lanham: University Press of America.

Dasgupta, S. (1998). Women's realities: Defining violence against women by immigration, race and class. In R. K. Bergen (Ed.). Issues in intimate violence (pp. 209-219). Thousand Oaks, CA: Sage.

Davies, J. (2008). When battered women stay. . Advocacy beyond leaving. Harrisburg, PA:National Resource Center on Domestic Violence. Retrieved from http://new.vawnet.org/Assoc_Files_VAWnet/BCS20_Staying.pdf

Davis, A. (2000). The color of violence against women. Colorlines: Race, Culture, 
Action, 3(3), 4-8.

Davis, K. (2008) Intersectionality as buzzword. Feminist Theory, 9, 67-85.

Davis, R. C., Smith, B. E., \& Davies, H. J. (2002). Effects of no-drop prosecution of domestic violence upon conviction rates. Justice Research and Policy, 3(2), 1-13.

Denzin, N. \& Lincoln, Y. (2003). Introduction: The discipline and practice of qualitative research. In N. K. Denzin \&Y. S. Lincoln (Eds.), Strategies of qualitative inquiry (2nd Ed.) Thousand Oaks, CA: Sage.

DHS. (n.d.). Abuse and Neglect Information. In Oregon.gov. Retrieved February 3, 2013, from http://www.oregon.gov/dhs/abuse/pages/mandatory_report.aspx.

Dobash, R. \& Dobash, R. (1979). Violence against wives. New York: Free Press.

Dobash, R. \& Dobash, R. (1992). Women, violence, and social change. London: Routledge.

Dutton, D. G. (1998). The abusive personality: Violence and control in intimate relationships. New York: Guilford Press.

Erez, E.,\& Hartley, C. (2003). Battered immigrant women and the legal system: A therapeutic jurisprudence perspective. Western Criminology Review, 4, 155-169.

Fagan, J. (1996). The Criminalization of DomesticViolence: Promises and Limits

Family Violence and Prevention Fund (2009). Intimate Partner Violence in Immigrant and Refugee Communities: Challenges, Promising Practices and Recommendations. Retrieved from http://www.endabuse.org/userfiles/file/ImmigrantWomen/IPV_Report_March_20 09.pdf on February 3, 2010

Family Violence Prevention Fund. (2010). The facts on immigrant women and domestic violence. Retrieved Jan 7, 2011, from http://www.endabuse.org/resources/facts/Immigrant.pdf

Ferraro, K. (1996). The dance of dependency: A genealogy of domestic violence discourse. Hypatia, 11(4), 77.

Fine, M. (2006). Bearing witness: Methods for researching oppression and resistanceA textbook for critical research. Social Justice Research, 19(1), 83-108.

Fine, M., \& Gordon, S. M. (1989). Feminist transformations of/despite 
psychology. In M. Crawford \& M. Gentry (Eds.), Gender and thought: Psychological perspectives (pp. 146-174). New York, NY: SpringerVerlag.

Fine, M., \& Vanderslice, V. (1992). Qualitative activist research: Reflections on methods and politics. In E B. Bryant, J. Edwards, R. S. Tindale, E. J. Posavac, L. Heath, E. Henderson, \& Y. Suarez-Balcazar (Eds.), Methodological issues in applied social psychology (pp. 199- 218). New York: Plenum Press.

Ford, D. A. (1991). Prosecution as a victim power resource: A note on empowering women in violent conjugal relationships.25(2), 313-334.

Foucault, M. (1972). Power/Knowledge: Selected interviews and other writings $1972-$ 1977. New York: Pantheon Books.

Fox, D., Prilleltensky, I. \& Austin, S. (2009). Critical psychology: An introduction (2nd ed.). Thousand Oaks, CA: Sage.

Gladwin, C. H. (1989). Ethnographic decision tree modeling. Newbury Park: Sage.

Goldsmith, T. (2006). The Physical and Emotional Injuries of Domestic Violence.Psych Central. Retrieved on October 29, 2013, from http://psychcentral.com/lib/thephysical-and-emotional-injuries-of-domestic-violence/000348

Gondolf, E. (1997). Batterer Programs: What We Know and Need to Know. Journal of interpersonal violence(0886-2605), 12 (1), p. 83.

Goodley, D. \& Parker, I. (2000). Critical psychology and action research. Annual Review of Critical Psychology 2: 3-16.

Goodmark, L.(2004). Law is the answer? Do we know that for sure?: Questioning the efficacy of legal interventions for battered women. St. Louis University Law Review. 7(15).

Haaken J. \& Yragui, N. (2003). Going underground: Conflicting perspectives on domestic violence shelter practices. Feminism and Psychology, 13(1), 49-71.

Haaken, J. \& Fussell, H..(2007). Bringing the church to its knees: evangelical Christianity, feminism, and domestic violence discourse. Psychotherapy and politics international (1476-9263), 5 (2), 103.

Haaken, J. (2010). Hard knocks: Domestic violence and the psychology of storytelling. London: Routledge. 
Hagan, J., Levy, R. \& Dinovitzer, R. (2008). The symbolic violence of the crimeimmigration nexus:Migrant mythologies in the americas. Criminology \& Public Policy, 7, 1, 95-112.

Harding, S. (2004). The feminist standpoint theory reader: Intellectual and political controversies. New York, NY: Routledge.

Hardy, D. \& Smith, B. (2008). Decision making in clinical practice. British Journal of Anaesthetic \& Recovery Nursing, 9 (1):19-21.

Harvie, P. \& Manzi, T. (2011). Interpreting multi-agency partnerships: Ideology, discourse and domestic violence. Social \& Legal Studies, 20, 1, 79-95.

hooks, b. (1984). Feminist theory from margin to center. Boston, MA: South End Press.

Hughes, M.J., \& Jones, L. (2000). Women, domestic violence, and posttraumatic stress disorder. FamilyTherapy, 27, 125- 139

Incite! Women of Color Against Violence. (2006). Color of violence: The Incite! anthology. Cambridge, Mass: South End Press.

International Labor Rights Forum (2011). International Labor Rights Forum 2010 Annual Report. Washington D.C. Gearhart et al.

Iyengar, R. (2009). Does the certainty of arrest reduce domestic violence? Evidence from mandatory and recommended arrest laws. Journal of Public

Economics,93, 85-98.

Kelly, J. (1971). Qualities for the community psychologist. American Psychologist. 26(10):897-903.

Kendrick, K. (1998). Producing the battered woman: Shelter politics and the power of the feminist voice. In N. Naples (Ed.), Community activism and feminist politics: Organizing across race, class and gender (pp. 151-174). New York: Routledge.

Kohli A., Markowitz P., and Chavez L. (2011) Secure Communities by the Numbers: An Analysis of Demographics and Due Process, the Chief Justice Earl Warren Institute on Law and Social Policy, Berkeley.

Koss, M. \& American Psychological Association. (1994). No safe haven: Male violence against women at home, at work, and in the community. Washington, D.C: American Psychological Association.

Krueger, R.. (n.d.). Richard Kreuger. In Systematic Analysis Process. Retrieved January 
18, 2013, from http://www.tc.umn.edu/ rkrueger/focus_analysis.html.

Levine, M., \& Perkins, D. V. (1987). Principles of community psychology: Perspectives and applications. New York: Oxford University Press.

Lewis, J. (2003) Design issues. In Ritchie \& Lewis, Qualitative practice: A guide for social science students and researchers London: Sage.

Lewin, K. (1946). Action research and minority problems. Journal of Social Issues, 2, 3446.

Lewin, K., \& Gold, M. (1999). The complete social scientist: A Kurt Lewin reader. Washington, DC: American Psychological Association.

Lindsey, M. (2006). DELLUMS Report: The Impact of Waivers to Adult Court, Alternative Sentencing, and Alternatives to Incarceration on Young Men of Color. Retrieved from

Loseke, D.(1992). The battered woman and shelters: The social construction of wife abuse. Albany: State University of New York Press.

Maguire, P. (2001). Uneven ground: Feminisms and action research. In P. Reason \& H. Bradbury (Eds.), Handbook of action research: Participative inquiry and practice (pp. 59-69). London: SAGE.

Mankowski, E., Haaken, J., \& Silvergleid, C. (2002). Collateral Damage: An Analysis of the Achievements and Unintended Consequences of Batterer Intervention Programs and Discourse. Journal of Family Violence, 17, 2, 167-184.

Marrow, A. J. (1977). The practical theorist: The life and work of Kurt Lewin. New York: Teachers College Press.

Mehrotra, G. (2010). Toward a continuum of intersectionality theorizing for feminist social work scholarship. Affilia 25, 417.

Morgan, D. (1995). Why things (sometimes) go wrong in focus groups. Qualitative Health Research 5 (4), 516.

Morrison, A. (2006). Changing the Domestic Violence (Dis) Course: Moving from White Victim to Multi-Cultural Survivor. UC Davis Law Review, 39.

Nash, J.(2008). Rethinking intersectionality. Feminist Review, 89, 1-15.

Nelson, G. and Prilleltensky, I. (2005) Community psychology : in pursuit of liberation 
and well-being. Palgrave Macmillan, New York.

Orloff, L. \& Little, R. (1999) Somewhere to turn: Making domestic violence services accessible to battered immigrant women. A 'how to' manual for battered women's advocates and service providers. Washington, DC: AYUDA, Inc.

Parker, I. (1992). Discourse dynamics: Critical analysis for social and individual psychology. New York: Routledge.

Pasmore, W. (2001). Action research in the workplace: The socio-technical perspective.In P. Reason \& H. Bradbury (Eds.), Handbook of action research. Sage, London. pp 38-47.

Pence, E., Paymar, M., Ritmeester, T., \& Shepard, M. (1993). Education groups for men who batter: The Duluth model. New York: Springer Pub. Co.

Pence, E. L., \& McDonnell, C. (1999). Developing Policies and Protocols. From Coordinating Community Responses to Domestic Violence: Lessons From Duluth and Beyond, P 41-64, 1999, Melanie F. Shepard and Ellen L. Pence, eds. United States.

Peters, M. and Robinson, V. (1984) The origins and status of action research. Journal of Applied Behavioral Science 20(2): 113-24.

Pinker, S. (2011). The better angels of our nature: Why violence has declined. New York: Viking.

Piran, N. (2001). V. Reinhabiting the Body. Feminism and Psychology, 11,172-176.

Portes, A. \& Rumbaut, R. G. (2006). Immigrant America: A portrait (3rd ed.). Berkeley, CA: University of California Press.

Prilleltensky, I. \& Nelson, G. (1997). Community psychology: Re- claiming social justice. In D. Fox \& I. Prilleltensky (Eds.), Critical psychology: An introduction (pp. 166-184). London: Sage.

Ptacek, J. (2010). Restorative justice and violence against women. Oxford: Oxford University Press.

Rabinowitz, V. C., \& Weseen, S. (1997). Elu(ci)d(at)ing epistemological impasses: Reviewing the qualitative/quantitative debates in psychology. Journal of Social Issues, 53(4), 605-630.

Raj, A. \& Silverman, J. (2002). Violence against immigrant women:The roles of culture, 
context, and legal immigrant status on intimate partner violence. Violence Against Women, 8(3), 367-398.

Reckdenwald, A., \& Parker, K. F. (2010). Understanding gender-specific intimate partner homicide: A theoretical and domestic service-oriented approach. Journal of Criminal Justice, 38(5), 951-958.

Rieser-Murphy, E. M., \& DeMarco, K. D. (2012). The Unintended Consequences of Alabama's Immigration Law on Domestic Violence Victims. U. Miami L. Rev., 66, 1059-1183.

Reina, A., Lohman. B., \& Maldonado, M. (2013). "'He Said They'd Deport Me": Factors Influencing Domestic Violence Help-Seeking Practices Among Latina Immigrants". Journal of interpersonal violence (0886-2605).

Rempe (2001). Hidden in plain sight: Secrecy and safety in battered women's shelters. Unpublished Master's thesis in Women's Studies. University of Arizona.

Richie, B. (2005). Introduction. In Sokoloff, N. Domestic Violence at the Margins" Readings on Race, Class, Gender and Culture. New Brunswick: Rutgers University Press.

Ritchie, J., \& Lewis, J. (2003). Qualitative practice: A guide for social science students and researchers London: Sage.

Ritchie, A. \& Mogul (2007). In the shadow of the war on terror: Persistent police brutality and abuse of people of color in the united states. A report prepared for the United Nations Committee on the Elimination of Racial Discrimination.

Romero, M., \& Serag, M. (2005). Violation of Latino Civil Rights Resulting From INS and Local Police's Use of Race, Culture and Class Profiling: The Case of the Chandler Roundup in Arizona. Cleveland State Law Review, 52, 75-96.

Rothenberg, B. (2002). Movement advocates as battered women's storytellers: From varied experiences, one message. In J. Davis (Ed.), Stories of change: Narrative and social movements (pp. 203-225). Albany: State University of New York Press.

Salter, M. (2012). Managing recidivism amongst high risk violent men. Australian Domestic and Family Violence Clearinghouse. Retrieved from: http://www.adfvc.unsw.edu.au/PDF\%20files/IssuesPaper_23.pdf

Sanders, J. (2004). The Bradley Angle House. The Portland Mercury. Retrieved from: http://www.portlandmercury.com/portland/the-bradley-anglehouse/Content?oid $=32657$ 
Schechter, S. (1982). Women and male violence: The visions and struggles of the battered women's movement. Boston: South End Press.

Shepard, M., \& Pence, E. (1999). Coordinating community response to domestic violence: Lessons from Duluth and beyond. Thousand Oaks, Calif: Sage Publications.

Sherman, L., \& Berk, R. (1984). The specific deterrent effects of arrest for domestic assault. American Sociological Review, 49, 261-272.

Sherman, L., Schmidt, J. \& Rogan, D. (1992). Policing domestic violence: Experiments and dilemmas. New York: Free Press.

Sirin, S. \& Fine, M. (2008). Muslim american youth: Understanding hyphenated identities through multiple methods. New York University Press.

Smith A.(2000). It's My Decision, isn't it? : A Research Note on Battered Women's Perceptions of Mandatory Intervention Laws. Violence Against Women 6:1384.

Sokoloff, N. \& Pratt, C. (2005). Domestic violence at the margins: Readings on race, class, gender, and culture. New Brunswick, N.J: Rutgers University Press.

Sokoloff, N. \& Dupont, I. (2005). Domestic violence at the intersections of race, class, and gender. Violence Against Women 11: 38-64.

Spencer, Ritchie, \& O’Connor (2003). Analysis: Practices, Principles and Processes. In, J. Ritchie, (ed.) Qualitative practice: A guide for social science students and researchers pp 199-217. London: Sage.

Stein, C. \& Mankowski, E. (2004). Asking, witnessing, interpreting, knowing: Conducting qualitative research in community psychology. American Journal of Community Psychology 33 (1-2) p. 21-35.

Steinman, M. (1991). The Public Policy Process and Woman Battering: Problems and Potentials, from Woman Battering: Policy Responses Lincoln: Anderson Publishing Co.

Stinson, P. M., \& Liederbach, J. (2013). Fox in the Henhouse: A Study of Police Officers Arrested for Crimes Associated With Domestic and/or Family Violence.Criminal Justice Policy Review, 24, 5, 601-625.

Sudbury, J. (2003). Toward a holistic anti-violence agenda: Women of color as radical bridge-builders. An introduction to the "Critical resistance-Incite! statement". 
Social Justice : a Journal of Crime, Conflict \& World Order, 30, 3, 134.

Sullivan, C. \& Bybee, D. (1999). Reducing violence using community-based advocacy for women with abusive partners. Journal of Consulting and Clinical Psychology, 67, 43-53.

Thelen, R. (2000). Advocacy in a coordinated community response: Overview and highlights of three programs. Gender Violence Institute. Retrieved April 26, 2012, from http://www.vaw.umn.edu.

Teo, T. (2005). The critique of psychology: From Kant to postcolonial theory. New York: Springer.

Trickett, E., Watts, R., \& Birman, D. (Eds.). (1994). Human diversity: Perspectives on people in context. San Francisco: Jossey-Bass.

United States Library of Congress: http://memory.loc.gov/cgibin/ampage?collId=1lsl\&fileName $=001 / 11$ s1001.db\&recNum $=226$

Vidales, G. (2010). Arrested justice: The multifaceted plight of immigrant Latinas who faced domestic violence. Journal of Family Violence, 25, 533-544.

Walpe, C. (2010). Engaging a systems approach to evaluate domestic violence intervention with abusive men: Reassessing the role of community

Walton, C. (2007). Doing Discourse Analysis. In E. Lyons, \& A. Coyle (Eds.), Analysing Qualitative Data in Psychology. (pp. 117-131). SAGE Publications, Ltd.

Wells, W., Ren, L., \& DeLeon-Granados, W. (2010). Reducing intimate partner homicides: The effects of federally-funded shelter service availability in California.Journal of Criminal Justice, 38, 4, 512-519.

Willig, C. (2008). Introducing qualitative research in psychology: Adventures in theory and method. Maidenhead, England: McGraw Hill/Open University Press.

Yin, R. K. (2009). Case study research: Design and methods. SAGE Publications: Thousand Oaks, CA.

Yuval-Davis, N. (2006) Intersectionality and feminist politics. European Journal of Women's Studies, 13(3), 193-209. 


\section{Appendix A - Group Scenarios}

\section{Scenario 1: A crisis call}

A call comes into the crisis line. A woman who speaks accented English says she is seeking advice. Referring her to a culturally specific crisis line is not an option. She tells you that her partner is abusive, both physically and emotionally. The abuse is infrequent and has happened since they came to the US ten years ago. They are married with two children. She has not sought help before but now the man is beginning to abuse the children — something he has not done in the past — and she is concerned. He occasionally strikes the oldest child and is emotionally abusive (yells) to the youngest. The children are having trouble at school (she names the school) and the teacher (she names the teacher) has recently contacted her with concerns. She does not feel she can leave him because he is the primary economic provider, because they are married and because he is the children's father. She, her partner and their oldest child (11) are undocumented. Their youngest child (8) is a US citizen. 


\section{Scenario 2: The recorded message}

In many shelters, particularly at the administrative offices, the phone goes first to voicemail. The recorded message is generally something like the following: "If you are in immediate crisis, please hang up and dial 911. " Additionally, on many of the agency websites, there is the advice to call 911 if in immediate danger or to have your neighbors do so, if they are concerned about your safety. 


\title{
Appendix B - Focus Group Letter for Consent
}

\author{
Dear NAME OF PARTICIPANT,
}

Thank you for agreeing to participate in a research study conducted by Diana Rempe from

Portland State University, Department of Psychology, in partial fulfillment of the requirements for a doctoral degree, under the supervision of Dr. Jan Haaken.

The purpose of this study is to assess how advocates within the domestic violence movement are responding to law enforcement-Immigration and Customs enforcement partnerships within the tri-county area of Portland, Oregon. The focus group will be audio recorded and will take about 90 minutes. The study will be held during a regularly scheduled staff meeting and will be composed entirely of staff members from the organization.

Your participation in this study is completely voluntary, and you may withdraw from it at any time with no penalty. There is minimal risk to participants. Risks include being identified with a quote or statement that may cause concern or in some way affect your position in the field. Although participants will not be named in any published reports or documents unless the participant requests to be identified, there is some risk that you could be identified by your quote. Quotes from the interview may be used in future publications, for example, in journals, and in papers for conferences. You may not receive any direct benefit from taking part in this study, but the study may help to increase knowledge, which may help others in the future.

A code will be created for your name so that your name does not appear on the transcript. This code key will be kept in a separate password protected file and only the principal investigator and her advisor will have access to this key. All additional records and transcripts will be kept confidential and in a locked file.

This study is important because it may support on-going dialogue and creative brainstorming among advocates who work with particularly vulnerable members of the community. Participation in the focus group may also lead to improvement in domestic violence service practices for women experiencing violence from an intimate partner, especially those who may lack legal citizenship status in the U.S.

Please sign a copy of the consent form and keep one copy for your personal records. Thank you again for taking part in the interview. If you have any concerns or problems about your participation in this study, please contact Diana Rempe at (503) 819-9845 at Portland State University, or the Human Subjects Review Committee, Office of Research and Sponsored Projects, 111 Cramer Hall, Portland State University, (503) 725-4288.

Name of Participant

Date

I understand that the interview will be audio recorded and agree to be audio recorded as part of my participation in the interview.

Name of Participant

Date 


\section{Appendix C - Focus Group Script}

\section{Introduction and information about Secure Communities (20 m)}

- Welcome participants and provide introduction of self and co-moderator.

- Explain the consent form and ask each person to sign and date. Give a copy to each to keep.

- Explain the general purpose of the discussion and why the participants were chosen.

- Explain recording equipment and talk about pausing recorder at any time.

- Outline general ground rules and discussion guidelines such as the importance of everyone speaking up, talking one at a time, and being prepared for the moderator to interrupt to assure that all the topics can be covered.

- Address the issue of confidentiality.

- Inform the group that information discussed is going to be analyzed as a whole and that participants' names will not be used in any aspect of the project.

\section{Example script}

Hello, I am Diana Rempe and I am doctoral student at PSU's department of community psychology. I am also a former advocate. I worked most recently at Clackamas Women's Services and as relief staff at Bradley Angle. I also worked for many years in Arizona prior to moving here. I am meeting with you all today as part of my research around the intersection of domestic violence advocacy and recent collaborations between law enforcement and immigration and customs enforcement or ICE.

Before beginning I want to explain the process a little more and lay out some basic ground rules for the conversation. To begin with, this is my co-moderator, Amy. (Amy does introduction). Amy will be leading the discussion today and I will be taking notes. We will be audio taping the meeting. If at any time you would like to say something that you don't want to be taped - something "off the record" just let me know and I will turn off the tape. Following this meeting, the audio will be transcribed. In the transcription of the meeting, numbers will be substituted for your names, in order to offer some confidentiality in the written documents.

As for confidentiality, I will do my best to keep what you all say today 
confidential. However, I have no control over what happens once you all leave the room. I ask each of you to keep the connection between what we talk about today and those participating in the conversation, here in the room. Not to say that you are expected to refrain from talking about our discussion, but rather that you not connect what is said to those who said it. In other words, if you want to tell you roommate or partner that you learned about a new law enforcement/ICE collaboration today, that is great. Just don't then say that your co-worker had this to say about it. Also, I will do everything I can to keep your identities disconnected from the quotes I use in my dissertation. However, the local DV advocacy community is a small one, so there is a chance that you will be recognizable in print, but I will do all I can to avoid that, including returning the full transcript to you all so that you have an opportunity to read over the quotes and ask that any be stricken that you feel are too identifying.

In the group today, you will be given two scenarios to work through as a group it is a situation that you might encounter during your work as an advocate. You all will read through them and be asked some questions. Prior to this, however, I would like to share some information with you about a current program that is operating here in Oregon.

Secure Communities is a federal program that links local law enforcement and ICE. What it is means, practically, is that when a person is arrested their fingerprints are sent to both the FBI database and the ICE database. If there is a match in the ICE database, a hold is placed on them and even if the other charges are dropped, they can be held by immigration. This program is supposed to be focused on high level offenders people who have outstanding warrants for things like rape, felony assault, etc... What it has meant in practice has been much more indiscriminate: people pulled in for traffic violations, or an outstanding check, or a misdemeanor DV charge are being deported, even if the criminal charges are dropped. Janet Napolitano who heads the Dept. of Homeland Security announced that in 2010 we had the highest number of deportations on record.

Do you have any questions? Great, let's move on. 


\section{Focus group discussion begins: $(50 \mathrm{~m})$}

\section{First Scenario.}

- Each person is given a copy of the first scenario

- The first scenario is read aloud by the moderator who then asks the group to read over it and consider it for a minute or two.

Q: In light of what we know about current immigration policies like Secure

Communities, what shall we do?

- Prompt: Safety planning: "there is a range of ways of thinking about safety planning. In light of Secure Communities, how might you go about creating a safety plan?

Q: In this scenario the school is already aware of the children's abuse by the father, how might you help her determine how to respond to the school?

- Prompt:

What might be at stake in enlisting the neighbors or the schools? Are there ways of working with others that might be more effective? What strategies have you used in your practice as advocates that have worked well?

Q: What is your role as a mandatory reporter? how might this new information affect the way you respond to her report of her child's abuse?

- Prompt:

Even if you are not a mandatory reporter how do you handle the ethical issue of having child abuse reported to you?

\section{Second Scenario.}

- Each person receives a copy of the second scenario

- The second scenario is read aloud by the moderator who then asks the group to read over it and consider it for a minute or two.

Q: Given our discussion, what do you think about this message?

- Prompt: How might you modify the message? What might be gained in changing it? What might be lost in changing it?

- Prompt: Recently the largest DV agency in New York City announced that because of Secure Communities, they would no longer be recommending undocumented people contact the police. What do you think about that decision? What other ways might there be to address this issue? Are there other agencies you might work with in the Portland area? 
Thank you, that was great.

\section{Reflection $15 \mathrm{~m}$}

Q: How might this discussion affect your work?

Q: Let's go around and each say what stands out in your mind about what we have talked about today. Say what comes to mind in about 30 seconds.

Thank you all very much. Please fill out this brief demographic sheet.

- Hand out compensation

Moderator Notes:

- Treat this like a clinical interview, do not intervene if possible.

- After some discussion or if one or two answer somewhat comprehensively and there is silence, say something like: "a number of you have responded, is there anything else you would like to add" (wait 30 seconds)

- If one or more people answer definitively or are held up as the experts in the room, say something like "In this room there are people with differing degrees of knowledge and experience who are able to bring different perspectives to the issues. It can be helpful to hear the thoughts of those who are closer and farther away from the issue." 


\title{
Appendix D - Resources
}

\author{
Diana Rempe: dianarempe@,gmail.com
}

503-819-9845

\section{Local organizations:}

ACT for Safety and Justice: http://actforjusticeanddignity.org/ Activists Coming Together for Justice and Dignity (ACT) advocates for the social, political, and economic inclusion of immigrants and disenfranchised communities, regardless of their immigration status.

American Friends Service Committee: http://afsc.org/office/portland-or A Quaker organization that includes people of various faiths who are committed to social justice, peace, and humanitarian service.

Causa: causaoregon.org Oregon's statewide Latino immigrant rights organization. Causa works to defend and advance immigrant rights by coordinating with local, state, and national coalitions and allies. We are the largest Latino civil and human rights organization in the Pacific Northwest.

Center for Intercultural Organizing: http:/www.interculturalorganizing.org/ A statewide organization of locally-based groups that work to create communities accountable to a standard of human dignity: the belief in the equal worth of all people, the need for equal access to justice and the right to self-determination.

Jobs with Justice(JwJ): jwjpdx.org A national campaign for workers' rights. Working through coalitions of labor, community, religious and constituency organizations, Jobs with Justice is fighting for workers ' rights and economic justice.

The National Lawyers Guild: http://portlandnlg.org A group of lawyers, legal workers and students dedicated to the need for basic and progressive change in the structure of our political and economic system.

Oregon ACLU: http://aclu-or.org/ A non-partisan organization dedicated to the preservation and enhancement of civil liberties and civil rights.

Oregon New Sanctuary Movement: http://www.oregonsanctuary.org/ An interfaith coalition of individuals, faith leaders and congregations, called by our faith and conscience to respond actively and publicly to the suffering of our immigrant 
brothers and sisters residing in the United States

Pineros y Campesinos Unidos del Noroeste (PCUN): http://www.pcun.org/ Oregon's union of farmworkers, nursery, and reforestation workers, and Oregon's largest Latino organization.

Portland Central American Solidarity Committee (PCASC): http://www.pcasc.net/ Educates and mobilizes the community, workers, and students in the fight for human rights and social justice in the Americas

Rural Organizing Project (ROP): http://www.rop.org/ A statewide organization of locally-based groups that work to create communities accountable to a standard of human dignity: the belief in the equal worth of all people, the need for equal access to justice and the right to self-determination.

VOZ workers' rights education project: http://portlandvoz.org/ A worker-led organization that empowers immigrants and day laborers to gain control over their working conditions through leadership development, organizing, and community education.

\section{National:}

Turning the Tide: http://altopolimigra.com/

Turning the Tide seeks to create a coordinated network of community organizations to build power in our communities in order to turn the tide against criminalization.

Women's Law:

http://www.womenslaw.org/laws_state type.php?statelaw_name=Immigration\&state_cod $\underline{\mathrm{e}=\mathrm{US}}$ A project of the National Network to End Domestic Violence (NNEDV), providing legal information and support to victims of domestic violence and sexual assault. 


\section{Appendix E - Demographic Information}

Age:

Race/Ethnicity:

Gender:

How long have you worked at ?

How long have you been in this position?

Have you had other jobs at this agency? Yes No

If so, please describe them and indicate the months and/or years you were in those positions:

Have you done DV work prior to coming to this agency? Yes No If so, for how long?

What sort of things did you do? 


\section{Appendix F - Transcript of a focus group}

2
I: Well, if you consider it in light of what I've told you about Secure Communities and the possibilities that occur there, what shall we do?

F1: Legal protection. Legal protection, like documents to stay until they finish with our case. One of those I think that I say, ah, they got in Italy, like deportations, so involved with...I mean...In this cases, he...even if he is legal, or especially when they are legal, the man is legal, he can ask for the custody of the kids. And of course the mother's going to be freaking about leave the...the house because he is legal for sure, or he speaks better English than her, or maybe she doesn't know.

I2: And in this case, where we've got both parents are undocumented...

F1: And in your...

F2: So she doesn't qualify for (common law 26:51), she doesn't qualify (? 26:52). (?).

F1: So I heard years ago that even if they are not legal in here, but they...they are marry, and... and if they're...I mean, the abuser and the victim, they are married. And even if either one is legal, it's something that come up. But I never hear again about it. Like the view...the...the victim can say that to what...like, "I'm married with this person who is my abuser," and blah-blah-blah, and then they protect the family. So that's what we're looking for. Like even if not both parties are legal...

I: As far as I'm...

F2: The only one who's legal is the kid. You can't...I mean, they have to wait till he's 18 and then he can petition for the family. Or she.

I: What do other folks think? What would you guys do?

F1: (? 27:44).

I: Okay.

F1: And then from...there might be...you can connect the legal system.

F2: Encourage her to buy a fake social security number [laughter]. 
60

61

62

63

64

65

66

F3: I would ask her what she wants to do.

F2: And obviously she doesn't want to leave. She doesn't feel like she could move. So...exploring options she thinks she has in front of her first, for what she would ideally like to have happen, and then also by exploring options, things that I know about.

F3: And she's going to get involved with child welfare system.

F2: Heck, yeah.

F1: And maybe...maybe (? 28:38). Like maybe has something to...issue going on that he needs help.

F2: So when you what we can do or what you are asking us to do, it's you as the parties of immigration law or you as a party...

I: No, just...

F2: ...oh, okay.

I: $\quad$...thinking of the safety planning and what we could give advice to this woman, what... what we think that she could do, what steps she might take. Like what would you say?

F1: You know, that's fine. But I was confused, I...

I: Yeah.

F1: I'm so excited about immigration, talking about immigration [laughter]. This is what you should do, because this is...

\section{I: Yeah.}

F1: ...what we need. But, no.

I: But if she comes to you here, if you're her case manager?

F1: I would look for (? 29:14), first of all, and see what her options are. If...because she has a one child born in the United State, I will see her resources that she qualify. It's not very much. I mean, working with, participating with childrens that only one of the childrens has documents, and her hope is really low. 
I2: She's like what? 424 in Taniff?

89

90

91

92

93

94

95

96

97

98

99

100

101

102

103

104

105

106

107

108

109

110

111

112

113

114

115

116

117

118

119

120

121

122

123

124

125

126

127

128

129

130

F1: Yeah, it's nothing. So...

I2: Uh-huh.

F1: ...encourage the family to see their resources, like what kind of experience of what they have, what they can do, how do they can get some support. I mean, I will be given what I can. Like a food, yes, we have food once a week, we can provide for the family. If we can find some resource of housing, like in my kids, if I have an opening, I will put it in the housing. I mean, I interview and do all the (? 30:01) for sure. And then if we have any other resources, for rental assistance, of course - encourage her. If she has a rental history, she can, she cannot, how do we can advocate for her for that. And so we get housing for her. If she has family, friends, where she can be supported, or go to the shelter or all that stuff. So the thing is put her in a safety place, and make...And this has been happen to us. I been working with so many immigrants, and then it's not only Latinas. But we have that...we've been working with escaping women. Like they still with abuser, and they need to leave.

\section{I: Right.}

F1: So fortunately, we...we can help them at the time. But sometimes maybe we don't have the money, maybe we don't have the space. But always is looking for all the resources.

F2: We can find resources, maybe calling Catholic Charities, (? 30:40) immigration (for down there), or Legal Aid.

I: Right.

F2: Sometimes even call 2-1-1 and get some information.

I: What about safety planning? You mentioned safety planning. So how do you safety plan in this... in this context? In other words, part of safety planning has often been, talk with your neighbor about, you know, having them call 9-1-1 if...if they hear something going on.

F1: But you're afraid then, (that's true 31:19).

131

I: Right. So what do you do? 
F2: You don't want to be deported, and you...

133

\section{I: Right.}

F2: ...if you're deported, your child will be staying here...

I: Right.

F2: ... and then he can be put into foster home.

I: Yeah.

F2: So...that's the main... One of the main concerns that women have, Latin - or...Latina women that they're undocuments, like "Who's going to take care of my child?"

\section{I: Right.}

I2: Um-hum. You look like you have something to say.

F3: Yeah, um, okay. So the scenario sounds like she's not really ready to leave him, doesn't feel like she wants to leave him, being that he's the primary economic provider. So I think safety planning around, um, other options that she may have other than like calling the police. Like are there other family members that she can maybe contact that would maybe show up and be able to get her out of the house, or somewhere that she can go. Um, and then just giving her information, or offering her information about, um, like other options for her when she is ready to leave. And, you know, somewhere along talking about like documentation about the abuse, that she can, um, have other forms of documenting the abuse that might be able to help her later on if she does chooses to proceed in a legal manner against, um, her abuser, um or child custody issues that she might have in the future. So even if the police is not involved just being able to help her document that abuse. Um, having other family members involved, maybe, um, if she does have other family members that can maybe help her with like, you know, code words, or something, or someone checking in with her. Or, you know, if he shows up at home and, you know, it's going to escalate or something, how can you evacuate your house with the kids, and do you have somewhere to go? Um, just other ways of... of just, you know, safety planning with her that doesn't involve the police, because it doesn't sound like she wants to get the police involved, and it doesn't seem like she wants to leave him yet. So...that's kind of what I would explore. And then I would also, um, maybe talk to her about, um, like (? 
176

177

178

179

180

181

182

183

184

185

186

187

188

189

190

191

192

193

194

195

196

197

198

199

200

201

202

203

204

205

206

207

208

209

210

211

212

213

214

215

216

217

218

219
33:44) said, like, you know, now that you have the teachers involved and they're being concerned, what does that mean?, and maybe explaining to her that this also means that DHS could be involved and maybe talking to her a little bit about that scenario and how that happens, you know. They can show up at your... at your kid's school without your permission, they can question your kids...

I: Um-hum.

F3: Like just preparing this participant to what might happen and just informing her and having her have that information so she knows what to do when she's presented in that situation. Um, and...

I: Are you a mandatory reporter? Are you all..?

Voices: No.

I: Nobody is.

F1: Officially, no, (we said 34:25)...

I: Officially, no. What about your crisis line people?

Voices: No.

F2: And it's all anonymous.

I2: Yeah. Because the issue's when you start bringing structures in, like the school and DHS and Child Services, then things start getting much trickier. I'm sorry, you were going to say...

F1: No, I was saying that maybe she can qualify for a DV grant...

I: Um-hum.

F1: ...And if she knows somebody in another state, she can relocate...

I: Right.

F1: ...you know, with the kids and get the benefit when she has kids.

I: Does she have to go the Gateway to get the grant, or can she get through (? 34:57)...? 
F2: She can go to any DHS station. I think the other thing too is kind of like if he's the main economic provider and that's one of the hindrances, and just letting her know that there are resources available, that she doesn't have to have a social security number, that she doesn't have to be documented to leave, like to access the DV grants or that even like a shelter is available, or transitional housing for grants - that there are other options that can give her some time and some space so she can figure out what she wants to do.

I: Um-hum.

F2: And like for (? 35:22), maybe he just needs help, or maybe they can get somebody involved in the community who can help facilitate that, as opposed to bringing in law enforcement, or traditional structures.

I2: Yeah.

F1: I have an issue with one...it says "Refer her to cultural... specific crisis line is not an option"?

I: Oh, that...only for this scenario.

F1: Oh.

I: Just to...I want to hear how you all work through the problem. And one of the things that I think I would do is say, you know what...Project Unica...Unica knows a lot of stuff and can provide a Spanish speaking if this a Spanish speaker. Or finding a different culturally specific...depending on...

F3: And sometimes that's a problem (? 35:59)...

I: $\quad .$. where the person's from.

F3: ...because a small community...

F2: Um-hum.

I2: Yep. Um-hum.

F3: ... and then like the second they call that crisis line, then they say, oh, to that interpreter, then like, hey, back to let the family in...

I: Right. 
F3: ... "Did you know that your sister's calling, and she's saying...

I2: Um-hum.

F3: ...that's not..." you know...

I2: Right.

F3: But that (? 36:08), "Is there nay problems?"

F4: And I think it's also important to know that whoever you're referring them to, or what agency you're referring them to, that they're not mandatory reporters, or if they are, they're sort of informing the part...

F2: Just have (? 36:19).

F4: It just depends if they are mandatory reporters, that what you do share with them, you know, you're saying that he's abusing the kids, then that could result in a report being made.

I: Yeah, because Clackamas Women's Services was when I worked there.

F1: Well, the...the options are more...the options are more (? 36:35) when the families are already out of the house. In this case, it's the first they will be like asking her what she wants to do and tell her the options. She can stay, and we're going to start talking and supporting her, and what she can do, how do she can manage this, and how long she...Until she decided to leave. So that's one of those...the first thing she plans. If she really wants to go, she wants to move out and leave this person, so see what is her options are. So, ah, once she's out, it's more foc(used) because, yeah, we can refer her to more resources, because they are mandatories and all that. But if we'll report her... if we refer this family to someone who report, they must be reported to DHS and Child Welfare become involved, because she is living in the house with abuser, where she is exposing the kids, and then teacher move the kids, and all that stuff. It's kind of two different safety plans, depends what she wants to do - she want to stay, she want to go.

I: Sounds like for this case, what information gets handed out is going to be really crucial... 
308

309

310

311

312

313

314

315

316

317

318

319

320

321

322

323

324

325

326

327

328

329

330

331

332

333

334

335

336

337

338

339

340

341

342

343

344

345

346

347

348

349

350

351
I: ...who gets to hear what, what agencies are involved, what you tell the neighbors or the school or which... which agencies you refer to. So information management for this one seems to be pretty crucial.

F2: And at the same time, I wouldn't want to discourage the children from speaking about what they're experiencing. And so it's a hard thing to manage, because you might say like Child Welfare can become involved and this is what's going to happen. At the same time, you don't want her to go tell her kid, "Don't talk about it, please," because that just, you know, keeps it in the family ends.

I: Do you all have that connection...

F1: That...

I: ...that Child Welfare...go ahead.

F1: And so it's okay, can I explain. No, I want to say the first thing is trust, and also women who English is their second language or cultural specific, I think the first thing normally you ask is, "How do you do domestic violence in your own country, where you came from?" And, you know, in forcing them into, let's say, you know, American culture, how do you deal with that, if for them it being kind of (? 38:27), "We are going to help you." But I think trust...

I: Um-hum.

F1: ... You have to earn their trust first before you, you know, you have...because everybody's afraid when they see... when I work with women, they all think like, you know, maybe a Child Welfare.

I2: Um-hum.

I: Right.

F1: So they don't know the difference. So you have to start with the trust, and then...

F2: Trust in the culture, you say?

F1: Yeah. And they'll find out, you know, how do you do domestic violence in your culture. Their culture, you know, that both parents will meet and talk, and try to solve the problem and give the guy a warming and tell the guy, "Well, if you're not going to be with this woman, just divorce 
here," and others so like, "We don't do this." Others believe in abuse.

I: Um-hum.

F1: You know, it's maybe the culture they came from. So I think...

F2: And then like in a lot of cultures, it's super taboo to even discuss what was happening in your family.

F1: Exactly, yeah. Exactly, yeah.

F2: So I mean like a lot of it too is just saying like, "I'm so grateful that you called today," like just offering like a practical level of appreciation that...something like that.

F1: And... and letting... You don't rush. Just take time...

I2: Um-hum.

F1:...like, you know, you don't bring paperwork, everything. Just talk and listen, and say, "Okay, we can do it tomorrow again, it's not (? 39:29)," and then the person will open up.

I2: Um-hum.

F1: And that's how you can earn their trust.

I2: Um-hum.

I: Yeah, that's great. Anybody that hasn't spoken? Everybody has different levels of expertise, and I'd love to hear from everybody.

I2: You have some pretty great ideas.

I: So do you want to go on to the second one?

I2: Yeah.

I: And this is not one we're passing out. We're just going to read it. So the second scenario is really brief, and I just want you all to kind of grapple with what you would do in this situation.

F2: Hm... 
I: And you don't have that.

F2: Don't think I do.

I: Okay. Ah...tsh-tsh-tsh-tsh...I might have left it at home. Um, I think I can remember it [laughter]. It ends on the end, on...

F1: Ah, yep.

I: ...what I did last...

F1: Because you...

I: ...yeah. Because you're the one that does homes. Sorry, everybody.

I2: Um, so, um...thinking about the...

I: I did (? 40:36) leave it at home.

I2: Oh, look at you...they're perfect [laughs]. In many shelters particularly at the administrative offices, the phone goes first to voicemail. The recorded message is generally something like, "If you're in immediate crisis, please hang up and call 9-1-1. Additionally, on many of the agency websites, there's the advice to call 9-1-1 if in immediate danger, or to have your neighbors do so if they're concerned about your safety." So we want to kind of think about this message that's being put out there, and what... what are some of the problems with it, how you would change it, what you might do about it, thinking about the Secure Communities issue.

I: What's good about it? Why should it stay? You know, negatives and positives. So any thoughts? And we can read that again if you want.

F1: I had somebody [laughs]...I'm just laughing because this somebody, they call in, they got to 9-1-1, so they thought if they call 9-1-1, police will come straight. That's where...

\section{I: Ah...}

F1: ...because they don't have documents.

I: Um-hum.

F1: So it's...it's...it's a good in a way. In a way it's people who are 
$440 \quad$ culturally specific, they don't understand.

441

442

443

444

445

446

447

448

449

450

451

452

453

454

455

456

457

458

459

460

461

462

463

464

465

466

467

468

469

470

471

472

473

474

475

476

477

478

479

480

481

482

483

I: Um-hum.

F1: So it's 50-50.

I: So in this case somebody thought that by calling $9-1-1 \ldots$

F1: Um-hum.

I: $\quad .$. immediately the police will come.

F1: The police will come.

I: So then they didn't call?

F1: Um-hum.

I: Yeah. So...I think that they...

F1: So they had to take two days...

I: Uh-huh.

F1: ...to all go back to the Gateway and talk to me.

I: Yeah.

F1: Yeah.

I: So, yeah. This is somebody who avoided calling and said, "Not to call" because they wouldn't take the risk of having the police come. And they thought that was the way to talk to you also?

F1: Yeah.

I: Yeah.

F1: They were trying to get hold of me and I wasn't there. It was a Friday... I: Right.

F1: ...evening, and it went and, you know, it goes all... So they couldn't leave a message, even though I have a voicemail. 
484

4852: Uh-huh.

48фtogether]

487: Right.

488

48F1: So when it says $9-1-1$, she got afraid...

490

49I: Um-hum.

492

4932: And just... Yeah. Gotcha. Yeah.

494

495 F2: I think...I think ours doesn't say that anymore, does it? Or was...I

496 know my voicemail is...

497

498 F3: I think ours does.

499

$500 \quad$ I: $\quad$ It does.

501

502 F2: Oh, really? Mine is (? 42:27). [voices together]

503

504 F1: I think all of them says, all DV.

505

506

507

508

509

510

511

512

513

514

515

516

517

518

519

520

521

522

523

524

I2: Um-hum.

F2: I think it's...yeah, even the crisis line.

I2: Could we change and say, "If 9-1-1 is a safe option for you."

F4: Yeah.

F3: I know I changed mine a while ago to not say that, because I worry specifically the LGBTQ population which is another population that has a history of sexual violence...

I2: Um-hum.

I: Um-hum.

F3: ...on (? 42:51). I didn't realize the crisis line (? 42:56).

I: So what do you think? Should it stay that way on your messages here?

F1: I think what Adam said is valuable, like "Call 9-1-1 if it feels like a safe option for you." 
528

529

530

531

532

533

534

535

536

537

538

539

540

541

542

543

544

545

546

547

548

549

550

551

552

553

554

555

556

557

558

559

560

561

562

563

564

565

566

567

568

569

570

571
I: Um-hum.

I2: And I'm not sure what to think [light laughter].

F2: Well, also too, I think that like in some communities, it's...it's institutionalized, they don't call 9-1-1. So I mean you hear that message and you're like, you know, "Screw you guy_-" like...

I: Right. Yeah.

F2: ...yeah. So, um, my option is talking to a recording or calling 9-1-1 and I'm just going to stick I it out.

F3: So what example (? 43:27).

F4: Well, they're in crisis so that's why they call them. So it's not generally (? 43:31).

I: Say the last part again. You said they're in crisis...

F4: You don't call them because they're in crisis...

I: Right.

I2: Um-hum.

F4: ...so you send...they...or they're immediate danger, so they're calling. And if you tell them that if they're in immediate danger, call 9-1-1, then I don't know.

I: That's a really good point.

F4: Well, if they're calling, they get that recording. So that's all right.

F5: Right.

F1: And I think it's...when you say people, if they (? 43:51), when you say $9-1-1 \ldots$

I: Yeah.

F1: People assume 9-1-1 is going to go straight to the police. 
572

573

574

575

576

577

578

579

580

581

582

583

584

585

586

587

588

589

590

591

592

593

594

595

596

597

598

599

600

601

602

603

604

605

606

607

608

609

610

611

612

613

614

615
I2: Um-hum.

I: Right.

F1: And then police will come and get you. People, especially people who English is a second language.

I: Um-hum.

F1: So I think that's...the language is the main...I know what you say...

F4: I don't get that, what you're saying.

F1: No, I'm saying like people who English is their second language, when they hear 9-1-1 and they don't have documents, they know it's the police, because even their own kids are told, if anything happen at home, make sure you call 9-1-1. So they involved everything with the police.

Voices: Um-hum.

F4: So they don't think like paramedic might come out.

F1: Might come, yeah.

F4: Or, you know, a fire or apartment? Yeah, might come or...They don't understand that their...their phone calls can be screened, (you guys? 44:31).

F1: Exactly, yeah...

I: Um-hum.

F1: ...they have option of the men will only do these option, right?

I: And I think that you're saying is - tell me if this is right - is that people who are calling this number are in crisis. And so you're giving them a direction to call 9-1-1.

F2: Well, they're supposed to be in crisis. I mean, we get a lot of phone calls every...

I: Yeah. 
$616 \quad$ F2: ...who are really not in crisis, just need housing. But they're supposed

\section{I: Right.}

I2; Um-hum.

F2: And then they're in crisis or in immediate danger, and now you're telling them, if you're in immediate danger, call $9-1-1 \ldots$

\section{I: Exactly.}

F2: ...Are they supposed to call the crisis line if you're in danger, or are you supposed to call 9-1-1 if you're danger.

I2: Yeah. So why am I calling you, if I'm supposed to called 9-1-1?

I2: Right.

I: Yeah.

I2: I think you make a really good point. We talked...there was an option somebody said, um, what if it said, ah, "If it's a safe option for you, call 9-1-1." What about folks whose English is very basic, or whose cultural background, they don't really understand how the 9-1-1 process works here. Does that make...does saying if it's a safe option for you, does that cover these folks?

F2: Also, if they're in crisis, are they able to determine what the safe option would be these days?

I: Yeah.

F2: Because nothing feels safe...

I: Yeah.

F2 ...you know. 9-1-1 doesn't feel safe. We're supposed to be a warm person on the other line.

I: Yeah.

F3: So are there trained 9-1-1, about the (response 45:40), do they have someone, like if they get a call from...? 


\begin{abstract}
660
661

662

663

664

665

666

667

668

669

670

671

672

673

I: No.

?: Not...

I: There is, as part of the Secure Communities initiative or whatever program, they have... States tried to opt out of being part of Secure Communities. So, um, New York, Illinois, a lot of places said, "We are not participating in this." Because in addition to advocates not want to be part of Safe Communi-Secure Communities, and activists in the communities, saying this problematic, police departments find it very problematic too, for some of the same and some different reasons. For one...some of the same, because how do you do community policing if your community is scared to call you?
\end{abstract}

674

675

676

677

678

679

680

681

682

683

684

685

686

687

688

689

690

691

692

693

694

695

696

697

698

699

700

701

702

703

F1: Um-hum.

I: That's not very effective. So it's really expensive for...for the county jails to become the housing places for detained immigrants. So there was a lot pushback from law enforcement also. I mention this because, um, then the Obama Administration came forward and said, "Sorry, you can't opt out. We said you could opt out, and not be part of this, but... but you can't opt out. And in fact, by 2013, every single state will have implemented this. But - and this is why I bring this up now we're going to put in some more protections and we're going to put a thing for, um, for domestic violence victims that goes under what is called prosecutorial discretion. So when the prosecutor...prosecutor gets your case, if there's domestic violence involved, they have the right to be... to act discretionary and to let you out of the system.

The problem is, is that you don't always get to the prosecutor at that point. You get set...if you get detained in Tacoma, you may never see anybody. And so that's...So, yes, there are provisions for people experiencing domestic violence. Are they effective? We don't really know yet. They've just put them into place, they're called prosecutorial discretion. We don't know. That's the thing. There's so much unknown about this. The only thing that's known are the numbers I gave you, which is rates of deportation and...up to now. So, yes, hopefully, there will be things for people who are experiencing domestic violence. It sounds like in a case that you had, you know, they let that woman out because she had experienced domestic violence, they closed her case. But I don't know how broadly you can say that.

I2: So this is an issue that a lot of people are trying to figure out in talking about it, because it kind of...it's very, very complicated and there's no 
704

705

706

707

708

709

710

711

712

713

714

715

716

717

718

719

720

721

722

723

724

725

726

727

728

729

730

731

732

733

734

735

736

737

738

739

740

741

742

743

744

745

746

747 good solution for it. Um, there is a...the biggest agency in New York recently decided to not DV agency...DV agency, sorry. Decided to not keep sending women who are experiencing DV, asking them to call the police. So their new policy became to not do that. This was back last...in 2011. They may...issued a statement saying they would not recommend that undocumented people contact the police. And they got a lot of pushback from that.

F1: Um-hum.

I2: And I'm not sure that person that I'm supposed to talk to today is from that agency. And so I'm not sure of what happens after that because since then they... New York tried to opt out of the program, and then all the stuff I just said happened. So I don't know where they stand with it. But I would love to hear what you all think about telling undocumented people not to call the police. I mean, we have police... We have all these partnerships in place, right? So they...this was a blanket statement. It wasn't...it wasn't... it wasn't...it was "Don't call the cops." And, um, I wondered if... what you guys thought about that too.

I: Is that the way to go? Is that a good option?

F1: Well, the first thing is, you...if you're people of color, are they going to treat you...?

I2: Um-hum. Anybody who's not documented, do we tell them to not call?

I: So they can't use the police anymore. You know what I mean? They...

F2: Understand, I'm not going to tell anybody not to call the police...

I: Um-hum.

F1: Yeah.

F2: I'm not. That's...that's my only kind of (interest 49:45).

I2: Um-hum.

F3: I think as an organization, we operate under the assumption that the survivor knows what's safest for them. So it feels like I would be depriving them of an option that they had. So it seems unfair for me to say you cannot call the police, when it might be what they want to do, and what's safest for them. 
I2: Um-hum.

F3: So giving them the option makes more sense to me, rather than saying, "Do not call the police."

\section{I: Right.}

I2: Um-hum.

F4: But you let them know what the potential ramifications are...

F3: Yeah, definitely.

F2: Yeah, probably be...and...

F3: Like if you get...

F5: And it could be about making informed choices...

F3: Yeah.

F5: ...about your own situation.

I: How would you let them know about it? Like what would you do?

F3: Well, (? 50:17) crisis line...

F2: Straight up.

F3: Just call, just kind of let, you know, the police is an option if they're like at the heightened level of danger. Um, if they happen to be the one that's arrested, these will be the following resources to contact, you know - try to (? 50:31) immigration lawyer, like he's going to do a pro bono or something. But like that that's...that's the potentiality.

F1: So what is the differen' with crisis and emergency? I mean, crisis and (? 50:42).

F3: Emergency is like when you're actually getting bed is broken or, you know, you're physically...

F1: What about dangers in crisis, what is the difference? 
792

793

794

795

796

797

798

799

800

801

802

803

804

805

806

807

808

809

810

811

812

813

814

815

816

817

818

819

820

821

822

823

824

825

826

827

828

829

830

831

832

833

834

835
F2: It's all the same thing.

F1: Dangers in crisis?

F3: I was in crisis this morning, but I wasn't in any (? 50:55).

F1: Of course. You didn't was in dangers, right?

F3: I wasn't in danger now.

F1: You and I might call 9-1-1.

F3: No. I might call 9-1-1.

I2: Okay [laughs]

F3: But that's just a personal thing [laughing].

F1: So that's one of...one of those things that I really say, cri-immediately crisis. Maybe just change that? Like if you feel like safe or that are you are immedial dangers, call 9-1-1.

F2: I think that...

F1: I mean, the education of the 9-1-1, it's different. It's a...the big issue. But we don't have a time to educate everybody, like, yeah, call 9-1-1. It's really safe, look. But we cannot promise that it's going to be safe, because it depends of the police. Sometimes police guys come, officers came, and they're very kind and very nice. They understand the situation, and they don't do anything. Some of them, they are very rude and really bad, and they just arrest you. And they are just because you are immigrant.

F4: Well, and the other thing too though is...

F1: But anyway...

F4: ...if their partner too is deported, and that's...you know, and that's their financial person, or that's their father of their children, I mean, like there's so many reasons that calling $9-1-1$, just immediately involving the police, isn't maybe what they want to do.

I: So how do you get that across in the message? 
$836 \quad$ F4: Um-hum [laughter].

837

838 F3: I...[more laughter].

839

840

841

842

843

844

845

846

847

848

849

850

851

852

853

854

855

856

857

858

859

860

861

862

863

864

865

866

867

868

869

870

871

872

873

874

875

876

877

878

879

I2: And in easy-to-understand language where somebody's calling over the phone, have very basic English...

I: They're in crisis [laughing], they're in danger.

F1: Some, the kids are screaming...

I: How do you...?

F1: So one of the... sorry...

F2: I think everybody's definition of crisis and danger is going to be different.

I: Um-hum.

F2: Because to me, I say crisis should be she really is in danger. I mean...

I: Um-hum.

F2: ...you know, but that's my opinion and that's how I feel, you know.

I: Um-hum.

F2: So I think...

F1: That pretty much...

F2: ...I think it's going to be different with... with each situation.

F3: Is there a message could be like, "If you are physically getting hurt or assaulted...

\section{I: [laughs]}

F3: ...right now, AND you're legal," or "have documentations on you, we would recommend...

[laughter] 
880

881

882

883

884

885

886

887

888

889

890

891

892

893

894

895

896

897

898

899

900

901

902

903

904

905

906

907

908

909

910

911

912

913

914

915

916

917

918

919

920

921

922

923
F3: ...that you maybe call 9-1-1 if you feel like that's a safe option for you." Yeah.

I: If you had a job, is that what you said? [laughter]

F4: I think not to defend why we say "Call 9-1-1", but I think there was some level of liability, agency...

I: Um-hum.

F4: ...liability, um, tied in with why we said "Call 9-1-1."

I: Yeah.

F4: Because I think there is...there is some level of, um, responsibility that we take on if we're encouraging folks to call us in their...in the midst of their danger.

I: Um-hum.

F4: We are...we are not immediate responders, we are not focused, I can navigate you through maybe an immediate crisis...

I: Um-hum.

F4: ...We're not someone that can provide for your physical safety.

I: Um-hum.

F4: We are so...And... and maybe that's just being clear on... on the things that we can do for someone, um, if they're expecting to call a crisis line and for someone to come out and help them.

I: Um-hum.

F4: I think there's a lot of just misinformation out there about what crisis lines are able to do, or what we...

I: Um-hum.

F4: ...you can and cannot provide. So I think that's maybe some history on why we say...

I: Um-hum. 
924

925

926

927

928

929

930

931

932

933

934

935

936

937

938

939

940

941

942

943

944

945

946

947

948

949

950

951

952

953

954

955

956

957

958

959

960

961

962

963

964

965

966

967
F4: “Call 9-1-1.” I don't necessarily think we have to.

I2: And I think that's the situation that a lot of agencies find themselves in, is how do we handle our responsibility, how do we keep people safe, and also make sure that we're covered.

F4: Because I think, I mean, I've been on crisis line calls - not here but the woman was literally being attacked in the midst of the crisis line call, and she's like, "I'm not ready to call...I don't want to call any...like I just want you to talk me through this.. I just want you..." And like, "Dude's in the other room, like pounding down the door. Now he's got a gun. I...like I helped her to get into the tub, like "Go in here, do these things," da, da, da, da, da, right? Like, she could have been injured, and if...if she was injured because she was on the phone with me, or because I was the service provider that was helping her in that situation, that's our agency on the line.

\section{I: Um-hum.}

F4: That us either not protecting her, not...not that we have any sort of claim that we wouldn't do those sorts of things. But I do think that's something that we need to like be thoughtful of, and... and what our responsibility is legally and in providing services over the phone.

F5: I mean, I think back in the day, like I had... we had several calls like that. And we used to have a policy where it's like we always had (? 55:03) one staff...

\section{I: Um-hum.}

F5: ...if you got a phone call with somebody who is in the middle of getting injured, somebody else would call the line, they'd trace and run back to - this is back when we had landlines, and the police would come. Because honestly, like when somebody's getting hit and you're talking to them on the phone, it's like the shittiest feeling in the world.

\section{I: Um-hum. Um-hum.}

F5: That said, we don't really get any crisis calls [laughs]. Like ever.

I2: I think... and what's important I think also there is that...

F3: Other than (? 55:31). 
968

969

970

971

972

973

974

975

976

977

978

979

980

981

982

983

984

985

986

987

988

989

990

991

992

993

994

995

996

997

998

999

1000

1001

1002

1003

1004

1005

1006

1007

1008

1009

1010

1011
I2: ...is you're talking about your individual response to a woman, and you were talking... or a man or a survivor. Argh! And I really wish I'd get myself to be more mindful and thoughtful about this. But, um, but I think that...that maybe...So are there other intervention points that you as an agency can...other places for intervention that you as an agency can do? Because you're right, the change...from what you've said, changing that call, especially the way you described it, to this lengthy message that explains everything and might not work for somebody who doesn't... who has limited English, or a woman...or a different cultural understanding, it doesn't seem like it might be the most practical and effective thing to do. So where could you, as an agency, as a group, intervene and try to work on this problem also? I mean, are there...Do you see other places?

I2: We've talked about how hard it is to handle this much information, this complicated, in the middle of a crisis. You could think about rape education (coverage 56:46).

F4: I think too, when I...I can totally (? 56:49) if I'm wrong, but I think that we're trying...

I: Um-hum.

F4: ...to kind of more work with systems and more with systems. So, but other agencies, or partner agencies, are working with like DHS, or working with like theoretically the law enforcement - that they would understand that, you know, this is what's occurring, or these are signs of, or this is what the person is experiencing when they make that phone call when that referral's made, or when they have contact. So if systems were better informed, ideally, they would know...I don't know, because then we have the mandatory arrest law, which I think is really great. At the same time, I think it's amazing it gets reported.

I: Um-hum.

F4: I mean, sometimes it's really great. But sometimes it really isn't.

I: Um-hum. What about working with non-domestic violence systems? In other words, there's a lot of people in the community doing work around Secure Communities, but they're not related to domestic violence at all. I mean, they're related, because I think everything's related, and structurally, I think everything's really related. But at least my experience has been, and I would love to hear what you all's is, 
1012

1013

1014

1015

1016

1017

1018

1019

1020

1021

1022

1023

1024

1025

1026

1027

1028

1029

1030

1031

1032

1033

1034

1035

1036

1037

1038

1039

1040

1041

1042

1043

1044

1045

1046

1047

1048

1049

1050

1051

1052

1053

1054

1055 that...that domestic violence work is kind of done over here, and then there's...And we don't traditionally align with labor organizations, with, um, immigrant rights organizations, with different community groups that might traditionally be more patriarchal, more traditional in U.S. culture. I don't know. I mean, whatever words you'd want to call it, but that...that there's... That...but these people are doing this work right now, so...I don't, I don't know what, as an agency you all feel like you do or are interested in doing. I don't know. I'm curious. Is that beyond the scope, or is that...is there just not enough time for it? What's... what's up?

F3: I think time and funding, and...I mean, I think that we all...I mean, and we're all out against (? 59:03), we all are kind of maxed out. And so at the end of the day, like I don't want to go home and talk about domestic violence.

I: Um-hum.

F3: I don't want to go to my local grocery store and talk about domestic violence. I saw this woman who like had this bruised up face the other day at (Fred 59:14) Meier's, and I was like, "Hey!...so..." And she was like, "I fell." And I was like, do I give her my card, like I don't really know. But, you know, it's like I think at the end of the day like maybe that's going to be a priority, or maybe that's something that not in the advocate realm to like make those connections with community organizations. I mean, I think that like...like just even working with like the schools, like and educating them and trying to help them decide when they're going to make a child abuse report and when they're not. Like their mandated reporters and it's not up to them to decide. But at the same time, it's like this puts the whole family at risk.

I: Um-hum. And do you think the teachers know about or DHS knows about Secure Communities and the affect on immigrant people?

F2 (? 59:56) they don't care.

F3: I doubt it.

I: Because we're...we were talking about informed choice before, and the person making the informed choice of whether they want to call 9-11 and get the police involved. But even reporters, the ones that are not mandated, should have the ability to make an informed choice. They should know that when they call, it's likely that they're buying somebody a deportation. So like Diana was saying, the option of just 
1056

1057

1058

1059

1060

1061

1062

1063

1064

1065

1066

1067

1068

1069

1070

1071

1072

1073

1074

1075

1076

1077

1078

1079

1080

1081

1082

1083

1084

1085

1086

1087

1088

1089

1090

1091

1092

1093

1094

1095

1096

1097

1098

1099 saying, "Well, let them sort of it, I'm taking both, and then we'll let the court sort it out," isn't really an option. So if DHS doesn't know that they might be getting somebody into deportation, they're not making an informed choice.

F4: And I think that, I mean, um, I work with...this... we basically work with Title X, the homeless kids. Um, and I don't think that they have the awareness. I struggle a lot with like, do we make a referral or not, because this family's homeless. And teachers come to them. And so like that's the weird point is the lay teachers are coming in and saying, "Like I don't know." And then their response is like, "Well, the hotline makes the decision." "Which hotline are you talk-?" Like it's always like somebody else makes that decision...

I: Um-hum.

F4: ...so we just do our job.

I: Um-hum. Do you feel like that happens here because of resources and time? And I don't mean to slam Bradley Angle I mean just in terms of all...all crisis work is so...you've got...you all are doing such amazing things every day, and they're exhausting and you're not paid well, and you.... and you're constantly trying to find like the last four dollars to offer somebody, you know, for a bus ticket or something like that. So I feel like, it seems to me that it would make a lot of sense to be like, oh, that goes to that - so to compartmentalize, to be like that work goes over there to those people, because it's a way of...of managing an unmanageable load.

F4: Um-hum.

I: I mean, I don't know if that's your experience, and I'm bringing my own stuff into it, but that's it felt to me a lot of the time. Like I did a lot of saying "Sorry, there's nothing I...we can do." Or, "These are the...these are the options." And the idea of going out and doing like some political organizing if you don't exactly like something I wanted to get involved in.

F4: Yeah. What...because of the econ - economy, agencies are competing for funds. So, you know, we don't have the resources.

I2: Um-hum.

F4: We... whatever resources we have, that's how we're going to help our 
participants.

I2: Um-hum.

F4: And, if, you know, you're taking re-funds from my agency to help yours, it's like it'll prevent me, or...

I2: That seems like a good place to...to stop. Do you guys have any questions, anything to add about this? Um, anything, any feedback at all, anything like that?

F1: Thank you so much for your ideas.

I2: Yeah.

F1: This is really, really valuable.

I: It's really helpful. And I want to offer to you all some resources. Because I think what... what you said is really, really important, that...that nowadays there's a struggle for the tiny pot of money that...And it's...it's unethical and it's...not the struggle but the fact that we're having to do this struggling and that distribution is the... of money and resources is the way it is. But it is right now this way. So I want to offer you some resources in the community that you can turn to perhaps for work on this...this issue specifically. And I know many of you don't...don't run into this issue in your daily work.

F2: Um-hum.

I: But you may know somebody that does. Or you may talk to the crisis line person and....and say, "Hey, here's something I learned," or something like that. But, um, so I'll...so I put together a little resources sheet of, um, places in the local organizations, um, that are working on... on secure communities and specifically. And then the Oregon New Sanctuary Program, which is on here, actually has a program that works specifically with people that are in deportation hearing right now, and they give you sort of like an advocate to walk through it who knows a whole lot about the deportation process. And so I would urge you to, um - I'm speaking directly to you, because you brought up that question - but I would urge you to contact them, um, and I'm writing on your sheet the name of the main person about that program. Because, um, I think...I think that one thing that happen...

F2: And this is for, um... 


$$
\text { F2: ...DV situations or just immigrant... }
$$

I: This is immigration issues in general. This is...

F2: Oh.

I: ...these are organizations that are not generally connected with domestic violence. Because a lot of...like I said, there are tons of people doing things in the community right now about this issue. There are not a lot of domestic violence service providers that are connected with all of the people that are doing some pretty great work right now. There was an immigration forum last Friday at the Unitarian Church that was really interesting. But I don't think there was anybody there from the DV community.

F2: $\mathrm{Hm}$.

I: And the voice is missing, because it's really an issue that affects survivors in a way that, you know, is...is very, very profound, and so it's a shame to have that voice not at the table. Um, I went to...the county commissioners have just decided to...they just made a statement requiring the county to...the county prosecutors to engage in prosecutorial discretion. So they don't want...they want the county out of doing immigration work. They can't do it because of Secure Communities, so they're looking for ways to do that. And the organization - some of them are listed here - have some great ideas how they can do that. There, of course, it's a government agency. They're not there yet. But their first step was to make a statement about prosecutorial discretion. So the...the (? 1:05:47) County district attorneys will not... will not be enforcing Secure Communities if they can...

F2: Um-hum.

I2: If they can, yeah.

I: It's mostly a...it's mostly just a - what's a word? - a symbolic gesture, but it's a...

I2: Yeah. 
1188 I: $\quad$...a nice first step. But I testified there about domestic violence. And there was.... and it was a packed room. And one other person mentioned DV, but that was it. And everything else was more about, um, about undocumented students, about day laborers, about really, really marginalized populations. But DV was missing. So I think your voice would be welcomed there. And if there's anybody, any survivors that you work with who want to testify, who are in that place, they would love that too, because there's a lot of stuff going on at the county level, that's going to, I think make a difference hopefully ultimately around this. So there are places to get involved. And that's my last spiel to you all.

And then I have a demographic sheet, if you don't mind filling it out anonymously, don't put your name on it. And fill out what you want to of it, and you can leave blank what you want to. And thank you. So do you guys have any questions? Anything that I can do? Anything you want to know about immigration that I can put together and email to you? Anything like that, that didn't get touched on today?

F2: I just would like to know how it works in general. And I don't mean saying it slow, but I really am...this is not something that I know a great deal about.

\section{I: Yeah.}

F2: But I hear you, so...

I: Right.

F2: Just...

I: So let me see if I can put a basic fact sheet together for you about immigration, or send you...there's a website on the back page...

I2: Resource list.

I: ...resource list that says "National Women's Law Center" that has a lot of basic information.

F2: Okay.

I: There's also, um...there's also a really great national study about, um... about Secure Communities, and I can send you...Are you a....are you an internet person? 
1232

1233

1234

1235

1236

1237

1238

1239

1240

1241

1242

1243

1244

1245

1246

1247

1248

1249

1250

1251

1252

1253

1254

1255

1256

1257

1258

1259

1260

1261

1262

1263

1264

1265

1266

1267

1268

1269

1270

1271

1272

1273

1274

1275

F2: Um-hum.

I: So you want to...you want to give me your email? And I'll send you just a few, um... a few links for you to look at on your own time, and then I'll try to sort of write out the process for you in the next week or so. Anybody else questions?

F1: I got...I got a really (stop 1:08:03) on the phone call type of thing. Because I want to... things that have come through my mind. I think it's a...it's...it would be a good idea, like I say, and maybe I'm wrong, and you can say it better than I...but, um, when someone calls to the crisis line, they can say like, "If this is a dangerous situation or in the middle of dangers or something, like it means physical," because...

I: Um-hum.

[together]

I2: Um-hum.

F1: We can maybe help somebody by phone like a supporting them talking with them, planning with them, tell them where to go, what... who to go something. But if they are in dangers, like physical, they can call 9-1-1.

I: Right.

F1: And... and it will be nice to have like a...options, like a...if you need a support or agencies or other kind of resources, you can dial 1 for support, 2 for agency. So you leave different numbers of agencies that it can help peoples with different planning thing or something.

I: Um-hum.

F1: So that would be a good idea.

I: So to really...really piece...parse out what... what danger means in this situation, like really make it specific.

F1: And...and... and clarify. Like if you feel safe calling 9-1-1, they...they have (? 1:09:10).

I: Um-hum. That's great thank you. Thanks. And my email's on the top of the resource list so you'll see...

F2: Oh, okay. 
I: ...you'll see that's what it'll come form, my gmail account.

F2: Okay.

I: Thanks.

F2: Thank you.

[long pause / paper shuffling]

I: Okay, then...thank God it works. Oh, it was two...two...we're still...take your time.

I2: Was he okay?

F? Yeah, I think she's the participant.

F?: Did you guys hear there was like... something on NPR. It might have been "This American Life" where they interviewed this like police chief maybe, in I want to say Alabama, somewhere where they like really heavily started enforcing this, and he was talking about how he'd been one of the people who really pushed for it, and then was realizing that, oh, this is terrible. Like it makes my job way harder and it's also really terrible for the people that we're doing this to. And the interview was like, "So, you know, what (do you expect 1:11:07), do you think Jesus would have voted to pass this?"

F?: Oh, wow.

F?: And I was like, well, to be honest, no [laughs].

I: That was...yeah, that was "This American Life."

F? I mean, that was like I totally pushed her in like (? 1:11:17) were like..

I: Yeah. I think...I think that's...that's...that was really inten-Alabama is a mess, and I don't know if you all know that, that Alabama's like Arizona on steroids. And they actually...And the police officers are...they talk about this in that....in that also, that they're doing their job. And like there was a guy from Daimler...whoever makes Mercedes and also freight line - things for big trucks and stuff like that, they moved a plant to Alabama. And he was a German man who was there visiting a plant executive, and they pulled him over and he didn't have his...his... 
1320

1321

1322

1323

1324

1325

1326

1327

1328

1329

1330

1331

1332

1333

1334

1335

1336

1337

1338

1339

1340

1341

1342

1343

1344

1345

1346

1347

1348

1349

1350

1351

1352

1353

1354

1355

1356

1357

1358

1359

1360

1361

1362

1363
I2: Oh, yeah, his...

F1: Yeah.

I2: Yeah, yeah, yeah.

I: $\quad$...proper identity with him and they took him to jail. And so they're...you know, they're really doing the...the ident - you have to have your proof of identity with you. At all times, you have to carry your papers.

I2: Even if you're...in that one case, right.

I: And in one...in some way, you're like, okay, at least they're doing it indiscriminately. At least it's not just all brown people, you know. But...but it's crazy. My mom...

F2: (? 1:12:13) Did that just happen?

I: Yeah, just happened. And it happened twice.

F2: Did they report her missing or something?

I: $\quad \mathrm{Hm} .$.

F2: It was a guy recently that they just...I think his dad or somebody reported...reported her missing that I guess deported him on accident.

I: Yeah. There was a young...

F2: It was on the news.

I2: A young girl.

I: ...there was a...in Texas...

F1: Yeah.

I: $\quad$...there was a wom - a girl, a teenager, 15 years old. She ran away from home.

F2: Oh. 
1364 I: $\quad$ She got arrested...

1365

1366 F2: I heard about that.

1367

1368

1369

1370

1371

1372

1373

1374

1375

1376

1377

1378

1379

1380

1381

1382

1383

1384

1385

1386

1387

1388

1389

1390

1391

1392

1393

1394

1395

1396

1397

1398

1399

1400

1401

1402

1403

1404

1405

1406

1407

I: $\quad .$. They, um, they...her name matched in the Secure Communities database. Her name came up with an immigration hold on it. They deported her. I'm laughing not at her.

F2: But that was for a minute, though.

I: They deported her to Colombia.

Voices: Wow.

F2: She was working and everything.

I: She didn't speak any Spanish. She was African American and she was 15.

F2: Um-hum.

I: And she came back pregnant. So who knows...

F3: Whoa!

I: I mean, it's a big mess.

F1: They're being sued though.

I: Yeah. Are they?

F1: Yeah.

I: Yeah. It's good. So I wanted to thank you all and I knew you were close to New Seasons, and I thought, well, you could always get coffee or something to eat or something, so I got you a little gift card that you see.

Voices: Oh!! Wow.

I: And just like in your situation, I was buying all these gift cards and the woman behind the counter who I kind of know from shopping there at Interstate, I...I...this is still...There's enough people there, I'm not going to add anybody. But she said, "What are you doing?" And I said, 
1408

1409

1410

1411

1412

1413

1414

1415

1416

1417

1418

1419

1420

1421

1422

1423

1424

1425
"Oh, I'm buying these for going and talking to a group of advocates at Bradley Angle," and she's like, "Oh! I just had to go to the Gateway Center," and she just like told me this whole DV story. And she's like, "And I...this was the first time. I never have had anything like this happen. I..." you know, and I was just like...it was crazy. It was though...it was the same thing. Like it just...the minute you open up anything, it's there. Yeah. Thank you again.

F1: Thank you so much this was wonderful.

I: Yeah, it was really, really helpful for...for me, and I hope you all learned something and hope it was decent use of your time to think about these things and talk about them, because it really was for me. So thanks. Okay.

I2: We have just a little bit of time if anybody wants to make...

The End 